Universidade de São Paulo

FFCLRP - DEPARTAMENTO DE FísICA

Pós-GraduaÇão em Física Aplicada À Medicina e Biologia

\title{
Avaliação das Doses Efetivas e Efetivas Coletivas da Radiação Natural na Região de Ribeirão Preto (SP)
}

Fernanda Cavalcante

Dissertação apresentada à Faculdade de Filosofia, Ciências e Letras de Ribeirão Preto da Universidade de São Paulo, como parte das exigências para a obtenção do título de Mestre em Ciências. Área: Física aplicada à Medicina e Biologia.

Ribeirão Preto - SP

2012 


\section{FERNANDA CAVALCANTE}

\section{Avaliação das Doses Efetivas e Efetivas Coletivas da Radiação Natural na Região de Ribeirão Preto (SP)}

Dissertação apresentada à Faculdade de Filosofia, Ciências e Letras de Ribeirão Preto da Universidade de São Paulo, como parte das exigências para a obtenção do título de Mestre em Ciências.

Área de Concentração:

Física aplicada à Medicina e Biologia.

Orientador:

Adelaide de Almeida.

Versão corrigida

Versão original disponível na FFCLRP-

Ribeirão Preto - SP

2012 
Autorizo a reprodução e divulgação total ou parcial deste trabalho, por qualquer meio convencional ou eletrônico, para fins de estudo e pesquisa, desde que citada a fonte.

\section{FICHA CATALOGRÁFICA}

Cavalcante, Fernanda.

Avaliação das Doses Efetivas e Efetivas Coletivas da Radiação Natural na Região de Ribeirão Preto (SP)/ Fernanda Cavalcante; orientador Adelaide de Almeida. Ribeirão Preto, 2012. 84 p.

Dissertação (Mestrado - Programa de Pós-Graduação em Física aplicada à Medicina e Biologia) - Faculdade de Filosofia, Ciências e Letras de Ribeirão Preto da Universidade de São Paulo.

1. Radiação Natural Terrestrial. 2. Dose Efetiva ao Ar Livre. 3. Cintilador Orgânico Plástico FHT 1376. 4. Sistema de Informação Geográfica. 
Nome: Cavalcante, Fernanda

Título: Avaliação das Doses Efetivas e Efetivas Coletivas da Radiação Natural na Região de Ribeirão Preto (SP)

Dissertação apresentada à Faculdade de Filosofia,

Ciências e Letras de Ribeirão Preto da Universidade de São Paulo, como parte das exigências para a obtenção do título de Mestre em Ciências.

Aprovado em:

\section{Banca Examinadora}

Prof. Dr. :

Instituição:

Julgamento:

Assinatura:

Prof. Dr. :

Instituição:

Julgamento:

Assinatura:

Prof. Dr. :

Instituição:

Julgamento:

Assinatura: 
Aos meus pais, Nemésio e Marystella, e irmãos, Carla e Fábio, pelo amor incondicional e por acreditarem nas minhas decisões. 


\section{AGRADECIMENTOS}

À Profa. Dra. Adelaide de Almeida, pela preciosa confiança e constante estímulo científico, que se estende da iniciação científica ao mestrado. Pela orientação que me forneceu ferramentas para a conclusão deste trabalho. Pelos ensinamentos que foram muito além da física, passando pela filosofia e pelo exemplo de competência, simplicidade e elegância. Agradeço por todas as sugestões, discussões, correções e pela paciência.

Ao Prof. Dr. Nivaldo Carlos da Silva pela oportunidade de realizar este trabalho, despendendo de seu tempo para me ensinar tantas coisas sobre a dosimetria ambiental, pela paciência em me mostrar a metodologia necessária, pelo empenho para a realização das medidas em Ribeirão Preto e no IRD, pelas valiosas discussões e pela confiança em mim depositada.

Ao Heber L. C. Alberti (O Homem do Geoprocessamento), por tamanha dedicação em me ensinar os passos básicos para a construção dos mapas; pelas discussões e sugestões sobre o trabalho e pelas muitas caronas até o LAPOC.

Ao Eder T. Z. Guerrero, que com muita paciência, me ensinou a fazer a coleta radiométrica e a trabalhar com os dados no programa do detector, além das diversas discussões compartilhando não apenas seu conhecimento na área como também nas grandes pescarias!

Ao Prof. Dr. Cláudio C. Conti e Prof. Elder M. de Souza pela chance de realizar as medidas no IRD, pelos ensinamentos, discussões e sugestões indispensáveis na realização deste trabalho.

Ao Prof. Dr. Martin E. Poletti, pela oportunidade de realizar um estágio na Física Médica, ampliando minha visão sobre esta ciência, pelo exemplo de dedicação e destreza.

Aos grandes amigos e companheiros do Laboratório RADIARE, Francisco Sampaio, Lucas Del Lama, David Oliveira, Caroline Czelusniak, Rosângela Costa, Rodrigo Sato por diretamente me ajudarem para a realização desse trabalho com discussões/críticas/sugestões que foram essenciais ; aos amigos Marcos Moreira, Paulo Petchevist, Roberto Pitorri, Gabriel Arruda, Hystters Kovalski, Michey 
Silveira pelo apoio e incentivo. A convivência com vocês foi um presente, vocês são incríveis jovens!

Ao Marcos Nakandakari por estar ao meu lado em todos os momentos; das conversas sobre o trabalho até as palavras de carinho e conforto.

Aos amigos Tiago Arruda (Turco), Hermes Kamimura (Josis), Marina Berardi, Stela Nardi, Déborah Gonçalves, Ana Paula Vollet, Letícia Sicchieri (Teka), Renato Caron, Gislaine Marini, Éder Guidelli, pela amizade de tempos remotos, pelo apoio e conversas produtivas em mesa de bar!

À amiga Alessandra Tomal, que transformou discussões em física radiológica em conversas agradáveis!

Ao LAPOC, seus funcionários e alunos, que de alguma forma me ajudaram com sugestões e discussões. Ao motorista Celso, pela paciência durante as monitorações.

Aos Professores do Departamento do Física, pela minha formação na Física Médica; aos técnicos e funcionários que contribuíram de alguma forma neste trabalho.

À Nilza M. L. Marino, Sérgio O. B. da Silva (Serginho) e ao Eldereis de Paula, que me ajudaram de tantas maneiras durante o mestrado.

À Karla, Pedro e Caio da Silva, por me receberem em casa nas viagens à Poços de Caldas.

À Universidade de São Paulo e ao Departamento de Física da Faculdade de Filosofia, Ciências e Letras.

À CNEN pela disponibilidade de instrumentação.

À CAPES, pelo apoio financeiro.

Finalmente, às minhas famílias Cavalcante, Petroucic, Fogaça e ao Rodrigo Souza, que permaneceram incansavelmente ao meu lado no desenvolvimento deste trabalho, torcendo para meu sucesso, apoiando minhas decisões e confortando meus momentos difíceis.

Muito obrigada! 
"É preciso que eu suporte duas ou três lagartas se quiser conhecer as borboletas.

Dizem que são tão belas!" Saint-Exupéry 


\section{RESUMO}

\section{CAVAlCANTE, F. Avaliação das Doses Efetivas e Efetivas Coletivas da}

Radiação Natural na Região de Ribeirão Preto (SP). 2012. 84 p. Dissertação (Mestrado - Programa de Pós-Graduação em Física aplicada à Medicina e Biologia) - Faculdade de Filosofia, Ciências e Letras de Ribeirão Preto da Universidade de São Paulo. 2012.

Medidas da radiação gama ambiental foram feitas em algumas regiões da cidade de Ribeirão Preto-SP, de forma a contribuir para o conhecimento acerca dos níveis desse tipo de radiação no estado de São Paulo e no território brasileiro. Escolheu-se determinar as médias anuais de dose efetiva e dose efetiva coletiva, uma vez que estas grandezas levam em conta o risco de possíveis efeitos biológicos associados a exposição à radiação ionizante. Para determinar os valores dessas grandezas, os diversos setores censitários das regiões selecionadas foram mapeados e avaliados individualmente, de acordo com a taxa de dose média absorvida no ar e número de habitantes de cada setor. Utilizou-se um sistema de detecção da radiação gama baseado em cintilador plástico e GPS, que possibilitaram a medida da taxa de dose absorvida no ar a cada segundo, para as coordenadas geográficas selecionadas. Embora este sistema tenha sido desenvolvido para a detecção de fontes artificiais perdidas, ou seja, não tem o objetivo principal de fazer medidas dosimétricas da radiação gama natural, teve seus modos de leitura calibrados e comparados com resultados da literatura (com uma incerteza média de 8,7\%). Dos resultados obtidos, dos mapeamentos realizados nas regiões consideradas, as médias anuais da dose efetiva e dose efetiva coletiva para ambientes ao ar livre foram encontradas com os valores $0,034 \pm 0,004 \mathrm{mSv} /$ ano e 25,62 \pm 9, 25 homem.mSv/ano respectivamente, sendo a primeira cerca da metade da média mundial da dose efetiva recomendada pela UNSCEAR. As médias obtidas são baixas quando comparadas às encontradas em outros estudos sobre dose de radiação gama ao ar livre no estado de São Paulo e em outras regiões do território brasileiro (sendo, de 1, 7 até 5, 6 vezes menor).

Palavras-chave: 1. Radiação Natural Terrestrial. 2. Dose Efetiva ao Ar Livre. 3. Cintilador Orgânico Plástico FHT 1376. 4. Sistema de Informação Geográfica. 


\section{ABSTRACT}

CAVALCANTE, F. Effective Dose and Collective Effective Dose Evaluation from Natural Radiation in the Region of Ribeirão Preto (SP). 2012. 84 p. Dissertation (M.Sc. - Graduate program in Física aplicada à Medicina e Biologia) - Universidade de São Paulo Faculdade de Filosofia, Ciências e Letras de Ribeirão Preto. 2012.

Gamma environmental radiation measurements were done for some urban regions in the city of Ribeirão Preto-SP, in order to contribute with this knowledge on the annual ambiental values of this type of radiation in the São Paulo state and in the Brazilian territory. The quantities chosen were effective dose and effective collective dose, once they take into account the possible biologic damage related to the ionizing radiation energy absorbed. For the assessments of these quantities, selected census sectors were initially mapped out, regarding their average absorbed dose in air and the number of inhabitants living in each one of the sectors. The detector system used is based on an organic plastic scintillator and a GPS, that allows to obtain the absorbed dose rate for each second and their respective geographic coordinates. Even though this system was developed to detect missing artificial gamma sources, in other words, its main function is not for dosimetric measurements, both display modes were calibrated in exposure rate $(\mathrm{R} / \mathrm{h})$ and absorbed dose rate $(\mathrm{Gy} / \mathrm{h})$ and their readings were compared to results from the literature (with an average uncertainty of $8.7 \%$ ). From the mapping results of the selected regions, the annual average effective dose and effective collective dose for outdoor environments were obtained, respectively as $0.034 \pm 0.004 \mathrm{mSv} /$ year and $25.62 \pm 9.25 \mathrm{man} . \mathrm{mSv} /$ year. The value for the first average dose is lower (about half) than the worldwide average value published by the United Nations Scientific Committee on the Effects of Atomic Radiation (UNSCEAR), also lower than the values from other regions in the national territory, regarding the gamma dose rate in outdoor environments (from 1.7 up to 5.6 times lower).

Key-words: 1. Natural Terrestrial Radiation. 2. Outdoor Effective Dose. 3. Organic Plastic Scintillator FHT 1376. 4. Geografic Information System. 


\section{LISTA DE FIGURAS}

1.1 Localização do município de Ribeirão Preto dentro do estado de São Paulo. . . . . . . . . . . . . . . . . . . . .

2.1 Dependência dos efeitos fotoelétrico, compton e produção de pares, de acordo com a energia do fóton incidente e número atômico do material alvo [19]. . . . . . . . . . . . . . . . . . . . 10

3.1 Imagem dos componentes do sistema FHT 1376, com cintilador plástico (A), fotomultiplicadora (B), GPS (C), bateria interna (D) e interface serial $(\mathrm{E}) \ldots \ldots \ldots$. . . . . . . . . . . . . 18

3.2 Janela do programa MobiLog. . . . . . . . . . . . . . . . . . . . . . . 19

3.3 Janela do programa MobiView durante monitoração da região Jardim Paulista. . . . . . . . . . . . . . . . 20 20

3.4 Distribuição geométrica das fontes de concreto pertencentes ao IRD $/$ CNEN . . . . . . . . . . . . . . . . . . . . . . . . . . . 24

3.5 Regiões da cidade de Ribeirão Preto selecionadas para monitoração da taxa de dose gama ambiental. . . . . . . . . . . . . 26

3.6 Densidade Populacional, segundo IBGE 2000. . . . . . . . . . . 27

3.7 Diagrama de blocos representando a instalação do sistema, computador e detector dentro de um veículo de monitoração. . . . . . 28

4.1 Comportamentos dos modos de leitura em função da distancia fonte-detector, com diminuição da intensidade do sinal com $\mathrm{d}^{-2} \mathrm{e}$ fator $=100$ entre os dois modos. . . . . . . . . . . . 31

4.2 Correlação dos dois modos de leitura do sistema FHT 1376 em função dos valores de taxa de exposição e taxa de dose absorvida no ar, respectivamente (a) e (b).

4.3 Comparação entre os comportamentos dos dois sistemas em (a) e incerteza entre os valores medidos pelo sistema FHT 1376 e aqueles de referência descritos por Conti et al em (b). A figura também apresenta os limites inferior e superior a serem considerados pela radioproteção. 34 
4.4 Histograma de frequência dos valores de taxa de dose efetiva considerando o grupo das oito regiões monitoradas. . . . . . . . . . . 35

4.5 (a) Esquema ilustrativo das regiões avaliadas, relativas à coroas circulares referenciadas ao centro da cidade; (b) valores de $\dot{E}$ média anual de cada coroa. . . . . . . . . . . . . . . . . . . . 37

4.6 Distribuição espacial das doses efetivas anuais para a região do Centro. 39

4.7 Distribuição espacial das doses efetivas anuais para a região da Vila Tibério.

4.8 Distribuição espacial das doses efetivas anuais para a região do Jardim Paulista.

4.9 Distribuição espacial das doses efetivas anuais para a região do Jardim Irajá. . . . . . . . . . . . . . . . . . . . . . . . . . . 42

4.10 Distribuição espacial das doses efetivas anuais para a região do Parque Ribeirão Preto.

4.11 Distribuição espacial das doses efetivas anuais para a região do conjunto Quintino/Simioni. . . . . . . . . . . . . . . . 44

4.12 Distribuição espacial das doses efetivas anuais para a região de Bonfim Paulista. . . . . . . . . . . . . . . . . . 45

4.13 Distribuição espacial das doses efetivas anuais para a região do Campus da USP. . . . . . . . . . . . . . . . . . . . . 46

4.14 Dose efetiva anual média para cada setor censitário, sendo a média geral de $0,034 \pm 0,004 \mathrm{mSv} /$ ano. . . . . . . . . . . . . 47

4.15 Dose efetiva coletiva anual média para cada setor censitário, sendo a média geral de $25,62 \pm 9,26$ homem $\mathrm{mSv} /$ ano. . . . . . . . . . . 48

A.1 Série radioativa do ${ }^{238} U$, retirado de [62] . . . . . . . . . . . . . . . . 60

A.2 Série radioativa do ${ }^{232} T h$, retirado de [62]. . . . . . . . . . . . . . . . 61

A.3 Esquema de decaimento radioativo do ${ }^{40} \mathrm{~K}$, adaptado de [63] . . . . . . 62

A.4 Esquema de decaimento radioativo do ${ }^{137} C s$, adaptado de [63] . . . . . 62 
A.5 Espectros das fontes extensas padrão, K1, K2, U1 e U2, obtidos por Conti et al com um detector de HPGe a 1 metro da superfície de cada fonte. A identificação dos picos foi feita neste trabalho, baseado nas emissões das fontes considerando o decaimento dos radionuclídeos das séries utilizadas. . . . . . . . . . . . . . 68

A.6 Espectros das fontes extensas padrão, Th1, UTh1 e UTh2, obtidos por Conti et al com um detector de HPGe a 1 metro da superfície de cada fonte.A identificação dos picos foi feita neste trabalho, baseado nas emissões das fontes considerando o decaimento dos radionuclídeos das séries utilizadas. . . . . . . . . . . . 69 


\section{LISTA DE TABELAS}

2.1 Médias anuais das doses efetivas devido a radiação natural [2]. . . . . 8

3.1 Dados radiométricos do sistema FHT 1376 [47]. . . . . . . . . . . . 18

3.2 Características da fonte de teste ${ }^{137}$ Cs utilizada neste trabalho. . . . . 22

3.3 Composição e concentração dos minérios radioativos das fontes extensas padrão localizadas no IRD/CNEN [56] . . . . . . . . . . . . 25

3.4 Fatores de conversão entre dose absorvida no ar e dose efetiva para potássio, urânio e tório presentes no solo, feito por Saito et al [58]. . 29

4.1 Taxa de dose absorvida de cada fonte medida pelo sistema FHT 1376, junto com sua comparação aos os valores de referência a 1 metro do solo. . . . . . . . . . . . . . . . . . . 33

4.2 Doses efetivas e efetivas coletivas obtidas em cada área monitorada. Os valores máximos, mínimos e médios são relativos aos setores censitários. . . . . . . . . . . . . . . . . . . 36

4.3 Comparação dos valores de taxa de dose absorvida deste trabalho com outros da literatura, feitos em regiões urbanas. . . . . . . . . . 38

A.1 Grandezas radiológicas (antigas e atuais) e suas unidades . . . . . . 59

A.2 Série de Decaimento Radioativo do ${ }^{238} \mathrm{U}$, adaptado do IAEA, TECDOC $1363[19] . \ldots \ldots$. . . . . . . . . . . . . 63

A.3 Série de Decaimento Radioativo do ${ }^{235} \mathrm{U}$, adaptado do IAEA, TECDOC 1363 [19]. . . . . . . . . . . . . . . . . . 64

A.4 Série de Decaimento Radioativo do ${ }^{232} \mathrm{Th}$, adaptado do IAEA, TECDOC 1363 [19]. . . . . . . . . . . . . . . . . . 65

A.5 Fator peso da radiação ionizante $\mathrm{w}_{R}[11] \ldots$. . . . . . . . . 66

A.6 Fator peso do tecido irradiado $\mathrm{w}_{T}[11] \ldots \ldots$. . . . . . . . . 67 


\section{Lista DE ABREVIATURAS}

ABNT Associação Brasileira de Normas Técnicas.

CNEN Comissão Nacional de Energia Nuclear.

GPS Sistema de Posicionamento Global (Global Positioning System).

HPGe Germânio Hiper-Puro.

IAEA Agência Internacional e Energia Atômica (International Atomic Energy Agency).

IBGE Instituto Brasileiro de Geografia e Estatística.

ICRP Comissão Internacional de Proteção Radiológica(International Commission on Radiological Protection).

ICRU Comissão Internacional de Medidas e Unidades de Radiação (International Commission on Radiation Units and Measurements).

IDH Índice de Desenvolvimento Humano.

IPRS I Indice Paulista de Responsabilidade Social.

IRD Instituto de Radioproteção e Dosimetria/CNEN.

LAPOC Laboratório de Poços de Caldas/CNEN.

PNUD Programa das Nações Unidas para o Desenvolvimento.

SIG Sistema de Informação Geográfica.

UNSCEAR United Nations Scientific Committee on the Effects of Atomic Radiation. 


\section{SUMÁRIO}

Lista de Figuras $\quad$ x

Lista de Tabelas xiii

Lista de Abreviaturas xiv

1 Introdução 1

2 Aspectos Teóricos 5

2.1 Radioatividade . . . . . . . . . . . . . . . 5

2.2 Interação da Radiação Fotônica com a Matéria . . . . . . . . . . . . . 9

2.3 Grandezas e Unidades Dosimétricas Utilizadas neste Trabalho . . . . 13

3 Materiais e Métodos $\quad 17$

3.1 Materiais . . . . . . . . . . . . . . . . 17

3.2 Metodologia . . . . . . . . . . . . . . . . . 21

4 Resultados e Discussões $\quad 31$

4.1 Caracterização do Sistema FHT 1376 . . . . . . . . . . . . . . . . 31

4.2 Obtenção da $\dot{D}_{a r} \ldots \ldots \ldots \ldots$. . . . . . . . . . . . . . 34

4.3 Dose Efetiva Média Anual na Cidade de Ribeirão Preto . . . . . . . . 38

5 Conclusões $\quad 49$

Referências Bibliográficas $\quad 52$

$\begin{array}{ll}\text { A Apêndice } & 59\end{array}$

$\begin{array}{ll}\text { Anexos } & 66\end{array}$

A.1 Fatores de Ponderação: Fator peso da radiação ionizante $w_{R}$ e fator peso do tecido irradiado $w_{T} \ldots \ldots \ldots 6$

A.2 Espectros das Fontes Extensas Padrão . . . . . . . . . . . . . . . . . 67 


\section{CApÍtulo}

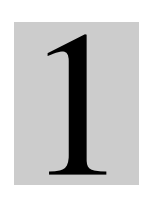

\section{INTRODUÇÃO}

A população mundial é constantemente submetida a doses de radiação ionizante por fontes naturais. Essas fontes podem ser classificadas em dois tipos; os raios cósmicos, originados no espaço, e as radiações emitidas por radionuclídeos naturalmente encontrados na Terra. O primeiro se origina quando partículas de alta energia, produzidas em explosões fora da Terra, interagem com constituintes atmosféricos, dando origem aos radionuclídeos cosmogênicos (os mais conhecidos são o ${ }^{3} \mathrm{H}$ e ${ }^{14} \mathrm{C}$ ) cuja exposição de uma pessoa a eles é função da altitude e latitude que essa pessoa se encontra [1]. O segundo tipo tem origem terrestre e é encontrado nos solos, rochas, ar e consequentemente nos materiais de construção, alimentos, água e também no corpo humano. Esses radionuclídeos possuem meias-vidas comparáveis à própria idade da formação dos elementos da Terra, cerca de $10^{9}$ anos, e são eles o ${ }^{40} \mathrm{~K}$ e os radionuclídeos das séries do ${ }^{238} \mathrm{U},{ }^{235} \mathrm{U}$ e o ${ }^{232} \mathrm{Th}$. Dessa maneira, a radiação natural terrestrial é responsável pela maior parcela da dose absorvida anual total pela população mundial [1,2], por contribuir com exposições internas e externas ao corpo de um indivíduo.

As exposições externas, dependente dos radionuclídeos terrestres, têm níveis em função do tipo da rocha que os originou [1]. Assim, os níveis de radioatividade mais altos se encontram geralmente em rochas ígneas (ou também conhecidas como magmáticas) [3], que se formaram pelo resfriamento do magma, como o granito e o basalto. No outro extremo, as rochas sedimentares, formadas a partir do acúmulo de materias sedimentares transportados pelos rios e vento, respondem pelos menores níveis de radioatividade natural. As exposições externas levam em conta tanto as 
radiações em ambientes fechados quanto ao ar livre, sendo que nos primeiros, a taxa anual de dose absorvida no ar é cerca de $40 \%$ maior do que aquela ao ar livre [1]. Este fato, deve-se principalmente ao gás radônio (filho do ${ }^{226} \mathrm{Ra}$ ) presente nos materiais de construção, cujas emanações ficam confinadas nos ambientes fechados, principalmente nos países de clima mais frio. Ao ar livre, a taxa de exposição se dá principalmente pelos radionuclídeos presentes ou originados daqueles que estão no solo e até daqueles que foram incorporados por organismos vivos (pessoas, animais, plantas), que podem contribuir com emissõess da radiação gama do ${ }^{40} \mathrm{~K}[2,4]$.

As exposições internas são devidas principalmente a ingestão e/ou inalação de radionuclídeos terrestriais, como alguns das séries do ${ }^{238} \mathrm{U},{ }^{235} \mathrm{U}$ e ${ }^{232} \mathrm{Th}$, que podem estar presentes na água, comida e no ar. Um produto do decaimento do ${ }^{238} \mathrm{U}$ é o gás radônio que juntamente com seus filhos, constituem a maior parcela da dose absorvida por inalação [1].

A UNSCEAR (United Nations Scientific Committee on the Effects of Atomic Radiation) é o comitê da ONU responsável por avaliar as doses efetivas anuais que a população mundial está submetida. Com as informações fornecidas pelos países membros, assim como com aquelas obtidas da literatura, este comitê elabora relatórios e os coloca à disposição do público. Estes servem de base científica para que os países possam avaliar os riscos da radiação ionizante em seu território e formular e/ou implementar possíveis medidas de radioproteção. Em seu último relatório de 2008 [2], a dose efetiva média anual relativa a população mundial, considerando as fontes de radiação natural, foi apresentada com valores no intervalo de 1 a $10 \mathrm{mSv} /$ ano, sendo sua média igual a 2,4 mSv/ano. Para ambientes fechados a média foi de $0,41 \mathrm{mSv} /$ ano, enquanto para as exposições ao ar livre esta foi de $0,07 \mathrm{mSv} /$ ano.

Nos três últimos relatórios publicados pela UNSCEAR, sobre os níveis de radiação natural (1993, 2000 e 2008) considerando os países da América do sul, apenas o Chile e Paraguai contribuíram com dados das médias de taxa de dose absorvida pela radiação natural externa em seus territórios. O Brasil já participa desses relatórios com dados relativos as áreas de alta radioatividade natural, que não são representativas de todo o território nacional [5-7]. Entretanto, recentemente alguns trabalhos foram publicados em revistas internacionais, sobre exposições ao 
ar livre em locais de radioatividade natural abaixo daquelas de alta radioatividade [8-11], no entanto, não existe ainda um valor médio da exposição oriunda da radiação gama natural ao ar livre, que a população brasileira como um todo está submetida, principalmente aquela das regiões urbanas.

A identificação dos níveis de radiação de um determinado local é importante para possíveis implementações de medidas de proteção. A exposição prolongada a baixas doses de radiação ionizante tem uma probabilidade maior de comportamento estocástico, isto é, não tem um limiar de dose e independe da sua intensidade; por isso, os resultados seriam observados depois de passados muitos anos [12].

A cidade de Ribeirão Preto foi escolhida para este trabalho por ser o município mais representativo de uma região com grande desenvolvimento econômico no estado de São Paulo. De acordo com o último relatório apresentado pelo Programa das Nações Unidas para o Desenvolvimento (PNUD) em 2001, o Índice de Desenvolvimento Humano (IDH) posicionou-a em sexto lugar no estado de São Paulo (dentre 645 municípios considerados) e em vigésimo primeiro no país, dentre 5506 municípios selecionados [13]. Outro índice mais atual (2008), refere-se ao Índice Paulista de Responsabilidade Social (IPRS), que leva em consideração a riqueza, a longevidade e a escolaridade em um município, que posicionou Ribeirão Preto no grupo dos 61 municípios com maior IPRS, dentre os 645 já referidos. Ainda neste índice, considerando apenas a riqueza municipal, esse município se encontra em quinto lugar [14].

A região de Ribeirão Preto se encontra no nordeste do estado de São Paulo (Figura 1.1), sobre o Planalto Centro-Ocidental e a Bacia Sedimentar do Rio Paraná, cujas altitudes variam entre 300 a 600 metros. Esta região é composta principalmente de rochas sedimentares e basaltos, apresentando o solo de terra roxa característico [15].

Este trabalho tem por principal objetivo a medida da dose efetiva média anual e dose efetiva coletiva média anual, devido exposições à radiação gama ao ar livre, em regiões da cidade de Ribeirão Preto, com radioatividade natural desconhecida, cujos resultados serviriam para compor os dados do território nacional. Os objetivos específicos são: 1) a caracterização de um sistema móvel de detecção da 
18 40'0"W 48 $40^{\circ} 0^{\prime} \mathrm{W} \quad 48^{\circ} 20^{\prime} 0^{\prime \prime} \mathrm{W} \quad 48^{\circ} 10^{\prime} 0^{\prime \prime} \mathrm{W} \quad 48^{\circ} 0^{\prime} 0^{\prime \prime} \mathrm{W} \quad 47^{\circ} 50^{\prime} \mathrm{O}^{\prime \prime} \mathrm{W} \quad 47^{\circ} 40^{\prime} 0^{\prime \prime} \mathrm{W} \quad 47^{\circ} 30^{\prime} 0^{\prime \prime} \mathrm{W} \quad 47^{\circ} 20^{\prime} 0^{\prime \prime} \mathrm{W} \quad 47^{\circ} 10^{\prime} 0^{\prime \prime} \mathrm{W}$

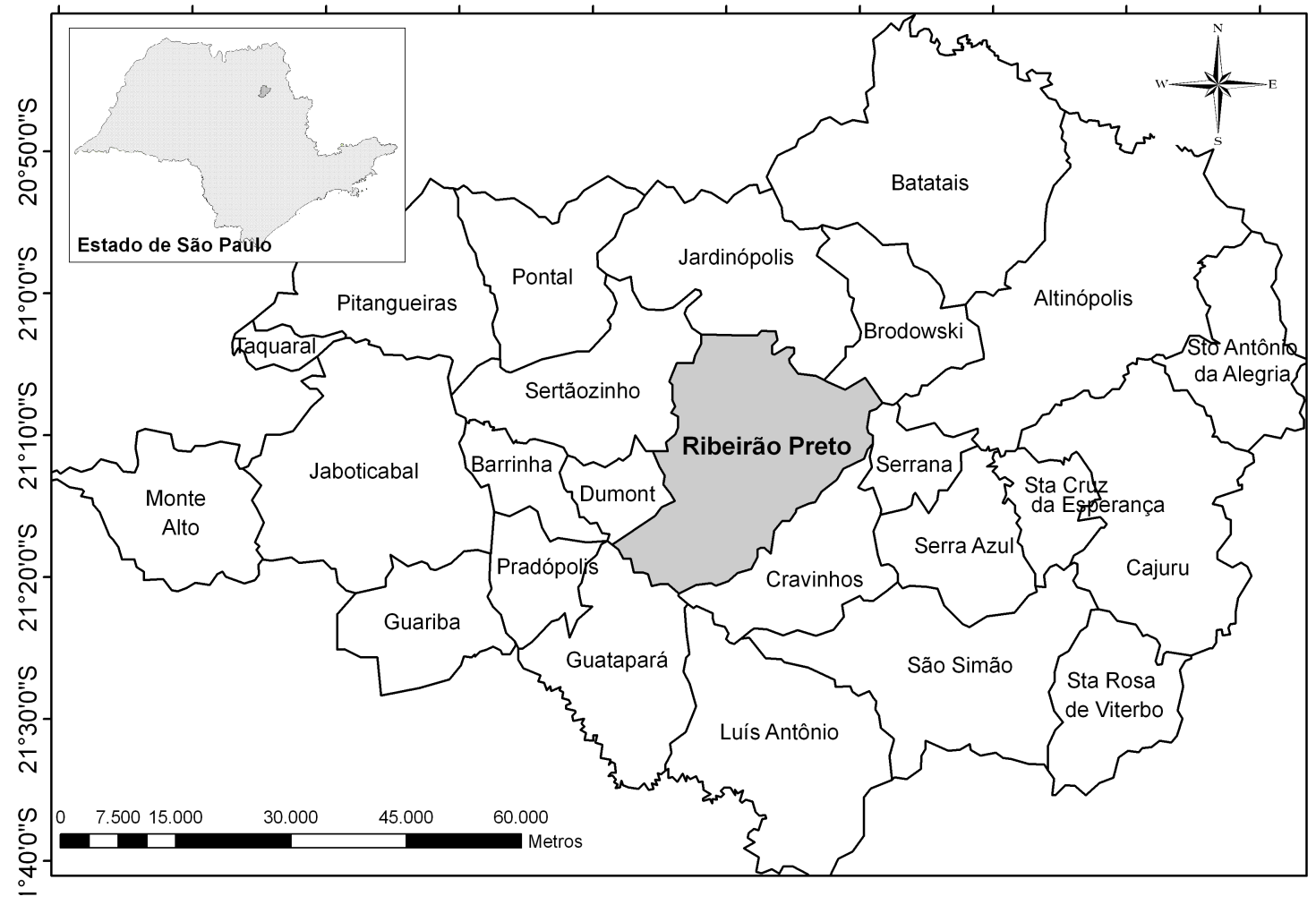

Figura 1.1. Localização do município de Ribeirão Preto dentro do estado de São Paulo.

radiação gama (Thermo Eberline/FHT 1376 MobiSys), com as etapas de calibração de seus modos de leitura e comparação de seus resultados com os de outro sistema espectrométrico (germânio hiper-puro EG\&G Ortec/GEM-20190-P) e 2) o mapeamento radiométrico das regiões selecionadas da cidade, correlacionando-os com os dados censitários do Instituto Brasileiro de Geografia e Estatística (IBGE). Pelo tipo de solo existente na região do município de Ribeirão Preto (Latossolo Roxo), não se deve esperar doses efetivas significativas para ambientes ao ar livre, entretanto com o surgimento da cidade e seu desenvolvimento esses dados podem ser alterados.

Dos resultados obtidos com esta pesquisa, os valores das dose efetiva média anual e dose efetiva coletiva média anual nas regiões selecionadas da cidade de Ribeirão Preto, SP, puderam ser determinados e avaliados, dos quais tem-se que os mesmos são inferiores ao valor médio mundial esperado. 


\section{Capítulo}

\section{Aspectos TeÓRICOS}

\subsection{Radioatividade}

O núcleo atômico é formado por nucleons fortemente ligados pela força nuclear forte que é independente da carga das partículas envolvidas e por isto não diferencia prótons de nêutrons [16].

A estabilidade do núcleo depende da razão entre o número de prótons e nêutrons do átomo, ou seja, núcleos leves são mais estáveis porque apresentam o mesmo número de prótons e nêutrons enquanto núcleos pesados, que apresentam maior número de nêutrons para compensar a repulsão eletrostática dos prótons, são mais instáveis porque não conseguem manter o equilíbrio e buscam a estabilidade emitindo partículas $(\alpha, \beta$, nêutrons) ou radiação eletromagnética $(\gamma)$, através de processos de decaimento.

O processo pelo qual um núcleo instável atinge espontaneamente o equilíbrio, gerando um ou mais núcleos filhos mais estáveis, é conhecido como decaimento radioativo ou radioatividade. Este processo foi primeiramente observado por Henri Becquerel em 1896, seguido por Pierre e Marie Curie com a separação do elemento rádio. O decaimento radioativo numa amostra de radionuclídeo, Equação 2.1, segue um comportamento exponencial baseado na variação do número de átomos com o tempo (Atividade $A$ ) e constante de decaimento $\lambda$ (específica para cada radionuclídeo).

$$
A_{t}=A_{0} e^{-\lambda t} \quad\left[B q=s^{-1} ; C i=3,7.10^{10} B q\right]
$$

Sendo $A_{t}$ a atividade da amostra depois de um tempo $t(\mathrm{~s}) ; A_{0}$ a atividade inicial 
no instante $t=0 ; \lambda$ é a constante de decaimento radioativo $\left(s^{-1}\right)$.

\section{Equilíbrio Radioativo}

O comportamento da equação citada descreve o decaimento radioativo de um núcleo predecessor instável (pai com $\lambda_{P}$ ) para um núcleo filho estável $\left(\lambda_{F}\right)$. Existem, no entanto, outras formas mais complexas de decaimento, como nos casos de núcleos cujos filhos também estão em desequilíbrio ou núcleos que sofrem mais de um tipo de decaimento. Nesses casos, o decaimento forma uma cadeia radioativa (série), onde existe além de um pai instável, várias gerações ainda em desequilíbrio para alcançar um núcleo descendente estável.

Em muitas relações entre núcleos pai-filho, depois de um determinado tempo a razão entre as atividades se torna um valor constante com o tempo; esta condição é conhecida como equilíbrio radioativo [17], e pode ser descrita através de análises feitas a partir da razão entre as atividades, equação 2.2 .

$$
\frac{A_{F}(t)}{A_{P}(t)}=\frac{\lambda_{F}}{\lambda_{F}-\lambda_{P}}\left\{1-e^{-\left(\lambda_{F}-\lambda_{P}\right) t}\right\}
$$

Dessa equação, é possível inferir alguns tipos de equilíbrio radioativo, dependendo dos valores de meias-vidas $\mathrm{T}_{1 / 2}\left(\mathrm{~T}_{1 / 2}=\ln 2 / \lambda\right)$ dos núcleos pai e filho. A primeira situação de equilíbrio acontece quando o valor de meia-vida do núcleo pai é muito maior que do núcleo filho, ou seja, $\lambda_{F} \gg \lambda_{P}$. Este caso é chamado de equilíbrio secular, e é descrito, partindo da equação 2.2 como:

$$
\frac{A_{F}(t)}{A_{P}(t)} \approx 1-e^{-\lambda_{F} t}
$$

Para um longo intervalo de tempo a razão se aproxima do valor unitário e as atividades dos núcleos pai e filho se tornam iguais, ou seja, estes núcleos decairão segundo uma mesma taxa. Embora existam outras situações de equilíbrio e não equilíbrio entre as atividades do núcleo pai e o núcleo filho [18], essas não serão citadas, pois neste trabalho só está envolvida a situação de equilíbrio secular entre os radionuclídeos pertencentes às fontes extensas utilizadas $\left({ }^{40} \mathrm{~K},{ }^{238} \mathrm{U}\right.$ e $\left.{ }^{232} \mathrm{Th}\right)$. 


\section{Tipos de Decaimento}

No decaimento radioativo, o núcleo instável procura o equilíbrio através da emissão espontânea de partículas e/ou ondas que carregam energia. Os processos de emissão podem ser por: decaimento alfa, decaimento beta (abrange $\beta^{+}, \beta^{-}$ e captura eletrônica), decaimento gama (abrange também a conversão interna), fissão espontânea, decaimento por emissão de prótons e decaimento por emissão de nêutrons [17].

Em núcleos radioativos de alto número atômico $(>82)$, geralmente se observa a emissão de uma partícula pesada, partícula alfa, que possui dois prótons e dois nêutrons (núcleo do Hélio), (decaimento alfa). Outros processos acompanham a emissão de partículas positivas ou negativas devido a núcleos com excesso de prótons ou nêutrons, que atingem a estabilidade por emissão de um elétron ou pósitron, partículas beta, através do decaimento beta. Já no processo de captura eletrônica, um núcleo, que se apresenta com excesso de prótons, pode alcançar o equilíbrio pela captura de um elétron orbital, transformando um próton em nêutron [19].

Nos processos de decaimento alfa, beta e captura eletrônica, a emissão das partículas podem geram núcleos filhos ainda instáveis, que poderão atingir o equilíbrio emitindo a energia em excesso de duas formas: pela emissão de um fóton $\gamma$ (decaimento gama) ou de um elétron orbital (conversão interna). A energia do fóton $\gamma$ liberado nesses processos será proporcional à diferença de energia, nos níveis do núcleo, de estado excitado e não excitado [19]. Os demais modos de decaimento não serão considerados neste texto porque não são passíveis de ocorrerem com os radionuclídeos considerados neste trabalho.

\section{Radionuclídeos Naturais}

Os radionuclídeos naturais podem ter sua origem no espaço (radiação cósmica) ou se encontram na crosta terrestre desde a origem do planeta. Alguns radionuclídeos terrestres formaram séries radioativas de decaimento com meias-vidas comparáveis à própria idade do planeta, a partir de núcleos bastante pesados como os das séries ${ }^{238} \mathrm{U},{ }^{235} \mathrm{U}$ e ${ }^{232} \mathrm{Th}$. Juntamente com o ${ }^{40} \mathrm{~K}$, os radionuclídeos dessas séries contribuem com a maior parcela de exposição à população mundial [2] e produzem radiação gama 
com energia suficiente para serem detectados [20].

A distribuição dos radionuclídeos naturais na crosta terrestre se apresenta de forma não homogênea, devido às transformações geológicas da Terra, sendo que em alguns lugares houve maior depósito desses elementos radioativos levando a níveis mais elevados de radiação. Tem-se por exemplo, locais de formação de areia monazítica, com alta concentração de tório (como Guarapari/ES no Brasil, Kerala e Madras na Índia, Yangjiang na China) ou então, locais de formação vulcânica, com altas concentrações de minérios de urânio e tório (como Poços de Caldas/MG no Brazil, Lázio na Itália) [2].

Assim como os radionuclídeos das séries do ${ }^{238} \mathrm{U}$ e ${ }^{232} \mathrm{Th}$, o radioisótopo do potássio $\left({ }^{40} \mathrm{~K}\right)$ é encontrado na natureza nos solos, rochas e também nos seres vivos, desde solos sedimentares como o arenito (em menor concentração) até rochas ígneas como o granito (em maior concentração) [21]. Nos seres vivos este radionuclídeo participa de processos biológicos e nos humanos é encontrado principalmente nos músculos [22] e em maior concentração nos homens do que nas mulheres [4].

Os materiais de construção, por serem provenientes de rochas e solos, têm em suas composições concentrações dos radionuclídeos naturais citados [23-25], levando à exposições internas (principalmente devido a inalação do gás ${ }^{222} \mathrm{Rn}$, da série do ${ }^{238} \mathrm{U}$ ) e externas (pela exposição à radiação gama) de seus moradores. Os valores típicos para exposições externas e internas, publicados pela UNSCEAR [2], são apresentados na Tabela 2.1.

Tabela 2.1. Médias anuais das doses efetivas devido a radiação natural [2].

\begin{tabular}{lcc}
\hline \hline Fonte de exposição & \multicolumn{2}{c}{ Dose efetiva média anual (mSv/ano) } \\
& Média mundial & Intervalo \\
\hline Radiação Cósmica & 0,39 & $0,3-1,0$ \\
Radiação terrestre externa & & \\
Ambientes ao ar livre & 0,07 & \\
Ambientes fechados & 0,41 & $0,3-1,0$ \\
TOTAL & 0,48 & $0,2-10$ \\
Inalação & 1,26 & $0,2-1,0$ \\
Ingestão & 0,29 & $1,0-13,0$ \\
\hline Total & 2,40 & \\
\hline \hline
\end{tabular}


Neste trabalho, os radionuclídeos naturais detectados e utilizados como fontes de radiação foram ${ }^{40} \mathrm{~K},{ }^{238} \mathrm{U}$ e ${ }^{232} \mathrm{Th}$ (Apêndice $\mathbf{A}$ ). Além destes, o ${ }^{137} \mathrm{Cs}$ (que não é um radionuclídeo natural, mas sim um produto de fissão) também foi utilizado para calibração do detector (Apêndice A).

\subsection{Interação da Radiação Fotônica com a Matéria}

Os diversos tipos de radiação $(\alpha, \beta, \gamma, X$, nêutrons) interagem com o meio material de forma particular, promovendo ou não a absorção de energia e/ou espalhamento da radiação. Para fótons, a probabilidade de ocorrência de um determinado efeito depende tanto de sua energia incidente como do número atômico e/ou da densidade do material alvo [17]. Neste trabalho, considerando os radionuclídeos utilizados e suas energias (de 1,460 - 2,614 MeV), os efeitos da radiação $\gamma$ ambiental passíveis de ocorrerem são:

\section{Efeito Fotoelétrico}

O efeito fotoelétrico ocorre pela interação de um fóton incidente com um elétron ligado na eletrosfera do átomo de um material alvo. Na interação, o elétron absorve toda a energia do fóton e é ejetado com uma energia cinética $\left(E_{c}\right)$, igual à diferença das energias do fóton incidente $(\mathrm{h} \nu)$ e da energia de ligação do elétron $\left(E_{l}\right)$ da eletrosfera. Para tal, a energia do fóton incidente deve ser $\geq E_{l}$. A probabilidade de ocorrência deste efeito depende de $(\mathrm{h} \nu)^{-3}$ do fóton incidente e aproximadamente $\mathrm{Z}^{3}$ do material [18].

\section{Efeito Compton}

Neste efeito, o fóton incidente interage com um elétron fracamente ligado (elétron livre) na eletrosfera de um átomo do material alvo, parte da energia é utilizada para liberação do elétron da eletrosfera e a diferença entre a energia incidente $(\mathrm{h} \nu)$ e a de ligação do elétron $\left(\mathrm{E}_{l}\right)$ é cedida para a energia cinética do elétron $\left(\mathrm{E}_{c}\right)$ mais a energia do fóton espalhado $\left(\mathrm{h} \nu^{\prime}\right)$ [18]. Este efeito depende da energia do fóton incidente e da densidade do material alvo. 
Produção de Pares

É uma interação entre o fóton incidente e o núcleo do material alvo, onde o fóton é absorvido produzindo um par elétron-pósitron que saem com energias cinéticas $E_{e}$ e $E_{p}$ (não necessariamente iguais). Essas energias são advindas da diferença entre a energia do fóton incidente $(\mathrm{h} \nu)$ e a energia limiar necessária para a ocorrência deste efeito, que tem probabilidade de ocorrência dependente de $\mathrm{Z}^{2}$. Embora o limiar de energia para a formação do par deva ser igual a 1,022 MeV, a energia do fóton incidente deve ser maior do que este valor, para que as duas entidades formadas possam adquirir energia cinética para ionizar o material alvo [18]. Na Figura 2.1 a seguir, é mostrada a dependência das interações descritas com a energia do fóton incidente e o Z do material alvo, adaptado do IAEA, TECDOC 1363 [20].

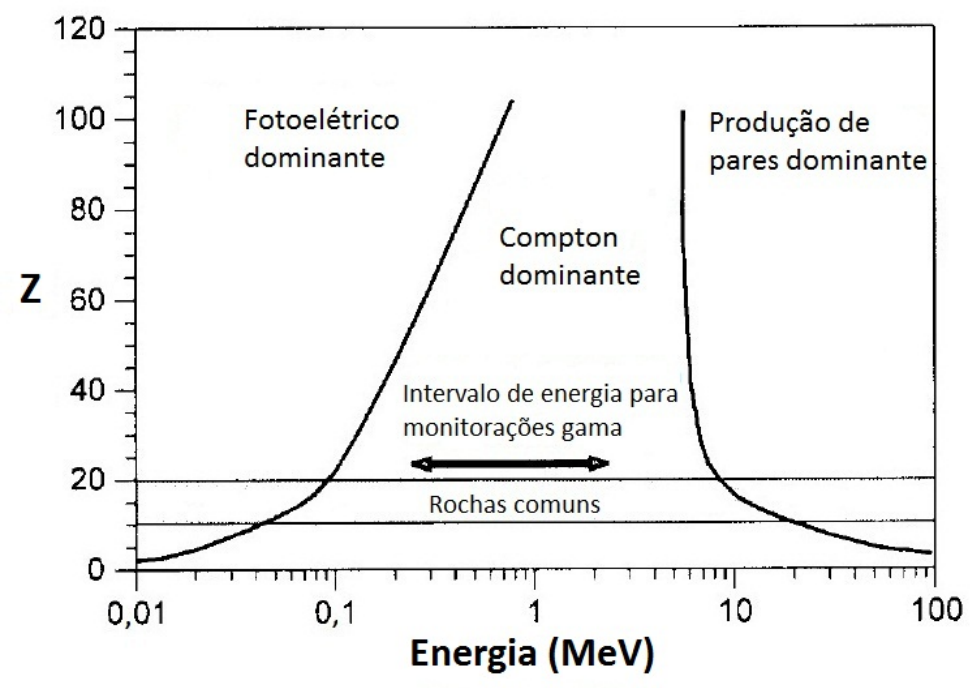

Figura 2.1. Dependência dos efeitos fotoelétrico, compton e produção de pares, de acordo com a energia do fóton incidente e número atômico do material alvo [19].

\section{Efeitos Biológicos da Radiação}

Na interação da radiação com o material biológico, parte da energia carregada pela radiação poderá ser cedida aos elétrons desse meio, que irão através de suas interações, depositá-la no material biológico em questão. Dependendo do tecido e da dose de radiação dada, as células poderão se recuperar através de mecanismos de reparo no seu ciclo celular. No entanto, o dano biológico pode não ser reparado 
durante os ciclos celulares, levando à morte funcional ou reprodutiva daquela célula. Quando este dano acontece nas células somáticas, este é conhecido como efeito somático que, dependendo da dose, pode provocar queimaduras, vômitos ou até indução de cânceres. Quando as gônadas são irradiadas (glândulas reprodutivas), os gametas podem sofrer danos que poderão ser passados para as gerações descendentes, levando a efeitos hereditários [26].

Normalmente, quanto mais diferenciada for a célula mais radioresistente ela é, uma vez que o ciclo celular é mais longo e a probabiblidade de recuperação dos danos biológicos é maior. Assim acontece, por exemplo, com as células do sistema nervoso e muscular. Em contrapartida, as células de maior atividadade (como as células do sistema hematopoiético, as células epiteliais e as do revestimento intestinal) [26] são mais radiosensíveis já que seu ciclo celular é mais curto e estão em constante divisão.

Dentre os efeitos da radiação no material biológico, a Comissão Internacional de Proteção Radiológica (ICRP) os classifica de duas formas: efeitos estocásticos e efeitos determinísticos [12]. Quando a probabilidade de ocorrer um efeito biológico e sua severidade não dependem da dose, tem-se o efeito estocástico. Este tipo de efeito é o mais provável de acontecer em exposições por baixas doses de radiação, como por exemplo, exposições rotineiras de trabalho, o que justifica os limites de dose em trabalhadores ocupacionalmente expostos.

A gravidade dos efeitos determinísticos varia com a dose absorvida e, por isto, existe um limiar de dose no qual acima dele, os efeitos serão provavelmente observados. Esse tipo de efeito será principalmente observado em exposições por altas doses de radiação em curtos intervalos de tempo, como por exemplo, situações acidentais ou planejadas para situações de guerra, espionagem e até terrorismo.

A partir da classificação dos efeitos determinísticos e estocásticos, a proteção radiológica (ICRP e CNEN) fixa limites de dose [12,27], pequenos o suficiente para que não se alcance nenhuma dose limiar de radiação (evitando os efeitos deterministicos). Além desses limites, fixa também o princípio ALARA ("A $s$ Low $\boldsymbol{A}$ s $\boldsymbol{R}$ easonably $\boldsymbol{A}$ chievable = Tão baixos quanto possam ser razoavelmente exequíveis" $[12,27])$ dentro de um processo de otimização, para práticas de irradiação justificadas (e obedecendo os limites de dose) para diminuir a probabilidade de ocorrência dos efeitos estocásticos. 


\section{Instrumentos de Medida}

Nas avaliações da radiação natural terrestrial, os detectores espectrométricos gama (geralmente cintiladores inorgânicos como o $\mathrm{NaI}(\mathrm{Tl})$ ou semicondutores como o germânio hiperpuro, HPGe) são muito utilizados para medir a atividade de uma amostra de solo [8,9,28-33], que a partir de calibração e uso de coeficientes de conversão apropriados [34,35], a dose absorvida no ar pode ser inferida. Outros sistemas dosimétricos, baseados em cintiladores, também foram caracterizados e utilizados para obtenção da dose absorvida no ar como os dosímetros termoluminescentes (de $\mathrm{CaSO}_{4}: \mathrm{Dy}$ ou $\mathrm{CaF}_{2}$ :Dy) $[10,11]$ e os detectores cintiladores orgânicos plásticos (Thermo Eberline/FHT 1376, Eberline/ESP-2) [36,37].

\section{Detectores Cintiladores}

Materiais cintiladores são aqueles que emitem luz (cintilam) quando expostos a um estímulo do tipo químico (quimioluminescência), biológico (bioluminescência) ou físico, por calor ou radiação (fotoluminescência). Quando um material cintilador é exposto à radiação, dentre os fenômenos que podem ocorrer, dois deles se destacam que são a fluorescência e a fosforescência. Na fluorescência, o material excitado pela radiação emite luz imediatamente (da ordem de $\approx 10^{-9}$ segundos) e na fosforescência a emissão de luz se dá depois de um intervalo de tempo maior (da ordem de $\approx 10^{-3}$ segundos). Para um cintilador ser considerado adequado, o seu material deve converter a maior parte da radiação incidente em luz, através da fluorescência, minimizando os efeitos de fosforescência [38].

Em cintiladores orgânicos, as moléculas ao absorverem a energia da radiação incidente o fazem ou na forma de energia vibracional ou de energia de excitação, que ao retornarem para o estado fundamental, emitem luz. A energia dessa radiação emitida é mais baixa do que a necessária para excitar outra molécula no material e por isso, os cintiladores orgânicos são transparentes à maior parte da luz produzida por eles mesmos [38]. Esses cintiladores se forem dissolvidos em um solvente e então polimerizados, podem ser fabricados em diferentes formatos (bastões, cilíndros, placas), transformando-se em cintiladores plásticos, muito utilizados nas medidas da radiação gama natural, por terem uma rápida resposta a ela [39]. 
No processo de cintilação, poucos fótons são emitidos (cerca de algumas centenas de fótons) e por isso, para que os materiais cintiladores possam ser utilizados como detectores de radiação, utilizam-se sensores de luz como as fotomultiplicadoras (PM), que convertem o sinal luminoso em sinal elétrico. Os fótons oriundos da cintilação interagem com o fotocatodo da PM, onde fotoelétrons de baixa energia são produzidos e amplificados no tubo por diversos eletrodos (dinodos), gerando um sinal elétrico passível de ser quantificado na saída da PM (cerca de $10^{7}-10^{10}$ elétrons) [38].

Embora os espectrômetros, que fazem uso de cintiladores inorgânicos, realizam medidas da radiação natural podendo discriminar os radionuclideos presentes numa amostra, os cintiladores orgânicos não apresentam esta capacidade e são eficazes nas medidas de radioproteção [40-42] porque indicam, de forma rápida, a presença da radiação dos radionuclídeos que estiverem na amostra.

O sistema de detecção utilizado neste trabalho, Eberline/FHT 1376, foi fabricado com fins de proteção radiológica para a detecção da radiação de fontes gama perdidas, principalmente aquelas com atividades significativas e meias-vidas de média a alta (como as de ${ }^{137} \mathrm{Cs},{ }^{60} \mathrm{Co},{ }^{192} \mathrm{Ir},{ }^{125} \mathrm{I}$ ) que eventualmente teriam sido utilizadas em aplicações médicas ou industriais, onde ocorreram acidentes [43] ou foram utilizadas de maneira displiscente.

\subsection{Grandezas e Unidades Dosimétricas Utilizadas neste Trabalho}

As grandezas dosimétricas e de radiometria foram estabelecidas pela Comissão Internacional de Medidas e Unidades de Radiação (ICRU) [44], que as descrevem levando em consideração os campos de radiação (por exemplo, fluência de fótons e fluência de energia) e os coeficientes de interação da radiação com a matéria (por exemplo, seção de choque, coeficiente de atenuação de massa e stopping power). Existe ainda um outro grupo de grandezas de proteção radiológica que foram estabelecidas pela Comissão Internacional de Proteção Radiológica (ICRP) [45], para avaliar o risco dos danos provocados pelas radiações ionizantes. Serão apresentadas a seguir apenas as grandezas pertinentes a este trabalho realizado, são elas: 
Exposição $(X)$

A exposição descreve a capacidade da radiação X ou $\gamma$ ionizar o ar, é definida como o valor absoluto da carga total de íons de um sinal $(d Q)$, produzidos no ar de volume $(d V)$, quando todos os elétrons e pósitrons liberados ou criados por fótons no ar (de massa $d m$ ) são totalmente freados no ar deste volume [44].

$$
X=\frac{d Q}{d m} \quad\left[C . k g^{-1}\right]
$$

Os valores de exposição $(X)$ e taxa de exposição $(\dot{X})$, podem ser medidos em feixes de radiação $(\gamma, X)$, utilizando dosímetros calibrados nessas grandezas. No entanto, esses valores também podem ser inferidos, sem o uso de dosímetros, para fontes radioativas através de uma relação que leva em conta a atividade dessa fonte $(A)$, a distância desta em relação ao ponto de interesse da medida $(d)$ e uma constante que relaciona esses parâmetros $\left(\Gamma_{X}\right)$. Esta constante, conhecida por constante taxa de exposição ou $\Gamma_{X}$ é dada para uma fonte radioativa gama em um ponto $P$ de interesse, como sendo:

$$
\dot{X}_{P}=\frac{A . \Gamma_{X}}{d^{2}} \quad\left[C . k g^{-1} \cdot h^{-1}\right]
$$

Sendo $A$ dada em bequeréis $[\mathrm{Bq}], \Gamma_{X}$ dada em $C / k g \cdot m^{2} \cdot(B q \cdot h)^{-1}$ (nas unidades antigas, $\left.R . m^{2} \cdot(C i . h)^{-1}\right)$.

$\operatorname{Kerma}(K)$

O kerma resulta da primeira interação entre as partículas não carregadas (fótons e nêutrons) com os elétrons do meio absorvedor. É definido como sendo a soma das energias cinéticas iniciais de todas as partículas carregadas liberadas pelas partículas não carregadas $d \bar{E}_{t r}$ em um material de massa $d m$ [44].

$$
K=\frac{d \bar{E}_{t r}}{d m} \quad\left[G y=J . k g^{-1}\right]
$$


Dose Absorvida (D)

Para quantificar a energia absorvida pelo material, devido a todas as classes de radiação ionizante, surge o conceito de dose absorvida. Esta é definida em um ponto como o valor esperado da energia média $d E_{c}$ depositada no material por unidade de massa $d m[44]$.

$$
D=\frac{d \bar{E}_{c}}{d m} \quad\left[G y=J . k g^{-1}\right]
$$

$\mathrm{Na}$ dosimetria, a medida de dose absorvida em um determinado meio pode ser realizada de forma direta, se o dosímetro estiver calibrado neste grandeza. No entanto, esta grandeza também pode depender de outros tipos como a exposição ou o kerma colisional, através de relações que consideram as características do meio irradiado. Como a dose por definição deve ser medida em ponto, o que leva em consideração a teoria da cavidade [18], e esta tem como requisito a Condição de Equilíbrio de Partículas Carregadas ou Equilíbrio Eletrônico, as medidas neste trabalho foram feitas com esta condição. O equilíbrio eletrônico acontece num volume de material irradiado $(V)$ se para cada partícula carregada (de um tipo de energia) saíndo desse volume existir outra partícula idêntica e de mesma energia entrando em $(V)$. Essa condição supões portanto, que todas as partículas criadas dentro do volume alvo, permanecerão nele.

Dose Equivalente $\left(H_{T}\right)$

A dose equivalente $H_{T}$ é a grandeza fundamental em proteção radiológica pois considera os possíveis efeitos biológicos dos diferentes tipos de radiação ionizante. $H_{T}$ é definida como sendo a dose absorvida média $\left(\bar{D}_{T, R}\right)$ por um determinado tecido ou órgão $T$ devido exposição à radiação $R$ de fator peso $w_{R}$ [12].

$$
H_{T}=\sum_{R} \bar{D}_{T, R} \cdot w_{R} \quad\left[S v=J \cdot k g^{-1}\right]
$$


O fator peso da radiação varia de 1 (para fótons e elétrons de qualquer energia) até 20 para partículas alfa e núcleos pesados $[12,46]$, como descrito na Tabela A.5 do Anexo 1.

Dose Efetiva (E)

Esta grandeza leva em conta o fato de que tecidos diferentes podem ter diferentes sensibilidades; dessa maneira, a possibilidade e intensidade de danos biológicos também será diferente para esses tecidos. A dose efetiva $E$ é definida como a somatória das doses equivalentes ponderadas pelos diferentes tecidos de fator peso $w_{T}$, como apresentado na equação 2.9.

$$
E=\sum_{T} w_{T} \cdot H_{T} \quad\left[S v=J . k g^{-1}\right]
$$

O fator peso $w_{T}$ é apresentado na Tabela A.6 do Anexo 1 [12] com valores que variam de 0,20 para as gônadas (tecido radiosensível) até 0,01 para superfícies ósseas (tecido radioresistente).

\section{Dose Efetiva Coletiva (S)}

Quando se estuda um grupo de pessoas, é interessante analisar a dose efetiva do grupo todo para que se identifique possíveis ações de intervenção. Define-se a dose efetiva coletiva $S$, como o produto da dose efetiva média $\bar{E}$ de um determinado grupo de indivíduos $\bar{E}_{i}$ pelo número $N$ desses indivídos expostos, ou seja:

$$
S=\sum_{i} \bar{E}_{i} . N_{i} \quad\left[\text { homem.Sv }=\text { homem.J. } \mathrm{kg}^{-1}\right]
$$

Os aspectos teóricos apresentados, relativos às grandezas dosimétricas, aos radionuclídeos naturais e os possíveis efeitos biológicos da radiação ionizante, foram apresentados com o intuito de possibilitar uma compreensão das medidas de doses efetivas e doses efetivas coletivas realizadas neste trabalho. 


\section{Capítulo}

\section{MATERIAIS E MÉTOdos}

As avaliações radiológicas ambientais podem ser feitas tanto de forma direta através de medidas feitas in situ, ou de forma indireta através de amostras ambientais retiradas do local a ser investigado. A técnica in situ é mais realista porque considera as radiações advindas das construções, pavimentação do solo e outras [34,35].

Monitorações através da técnica in situ utilizam tanto espectrômetros de cintiladores inorgânicos como sistemas baseados em cintiladores orgânicos que, uma vez adaptados em veículos aéreos ou terrestres, podem facilitar a monitoração de grandes áreas [20]. Os sistemas de cintiladores orgânicos não apresentam resolução das fontes presentes numa amostra, mas indicam a presença da radiação ionizante.

Neste trabalho foi utilizado o sistema de detecção com cintilador orgânico FHT 1376 MobiSys/Thermo Eberline, acoplado a um veículo terrestre; ambos pertencentes ao Laboratório de Poços de Caldas (LAPOC) da Comissão Nacional de Energia Nuclear (CNEN), com o qual esta pesquisa foi conjuntamente desenvolvida.

\subsection{Materiais}

FHT 1376

O sistema móvel de detecção da radiação, Thermo Eberline/FHT 1376 MobiSys é constituído de um detector cintilador orgânico plástico de 5 litros, fotomultipliadora, pré-amplificador e um Sistema de Posicionamento Global (GPS) [47]. Todos esses componentes são ligados por interface serial.

Os componentes citados são organizados em uma caixa, onde conectores externos fazem a ligação com uma fonte de tensão externa e um computador para o 
armazenamento e visualização dos dados. A fonte de alimentação para o detector pode ser de 10 - 30V, corrente contínua (DC), o que facilmente permite a utilização da própria fonte de tensão do veículo de $12 \mathrm{~V}$.

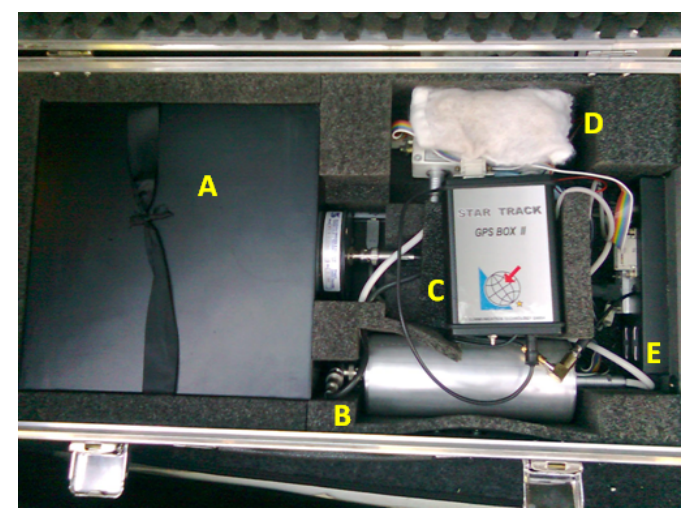

Figura 3.1. Imagem dos componentes do sistema FHT 1376, com cintilador plástico (A), fotomultiplicadora (B), GPS (C), bateria interna (D) e interface serial (E).

Na Figura 3.1, tem-se em (A) o detector cintilador plástico com uma proteção contra a luz, em (B) o gerador de alta tensão, a fotomultiplicadora (tensão de operação igual à $620 \mathrm{~V}$ ) e um pré-amplificador. O sistema ainda possui uma bateria de $9 \mathrm{~V}$ (D), que serve como buffer de dados para o sistema de GPS (C) [47] com uma antena colocada no teto do veículo, operando com sinais de três satélites diferentes. O sistema GPS fornece, além dos dados geográficos de latitude, longitude e altitude, informações que podem ser úteis nas análises que incluem velocidade e direção do veículo e tempo de medida. A saída de dados de todos os componentes (A)-(D) é organizada, através de uma interface serial (E), que através do software MobiSys, armazenana e analisa os dados.

As propriedades radiométricas do sistema FHT 1376 foram descritas no seu manual [47] e são apresentadas na tabela a seguir.

Tabela 3.1. Dados radiométricos do sistema FHT 1376 [47].

\begin{tabular}{cc}
\hline Tipo de leitura & Radiação gama $>100-\approx 1400 \mathrm{keV}$ \\
Faixa de leitura & $0,001 \mu \mathrm{Sv} / \mathrm{h}-20 \mu \mathrm{Sv} / \mathrm{h}$ \\
Sensibilidade & $20000 \mathrm{cps} / \mu \mathrm{Svh}^{-1}\left({ }^{137} \mathrm{Cs}\right)$ \\
\hline \hline
\end{tabular}




\section{MobiSys}

Este software integrado ao sistema de detecção móvel é dividido em três blocos diferentes: MobiLog, MobiView e MobiConv, para armazenamento, edição e visualização dos dados em diferentes formas.

\section{MobiLog}

O programa MobiLog foi desenvolvido para a coleta e armazenamento das medidas radiométricas, além de possibilitar a visualização geográfica dos dados. Os valores coletados são mostrados em intervalos de 1 segundo e armazenados em arquivos binários (.BIN). A janela do programa é mostrada na Figura 3.2.

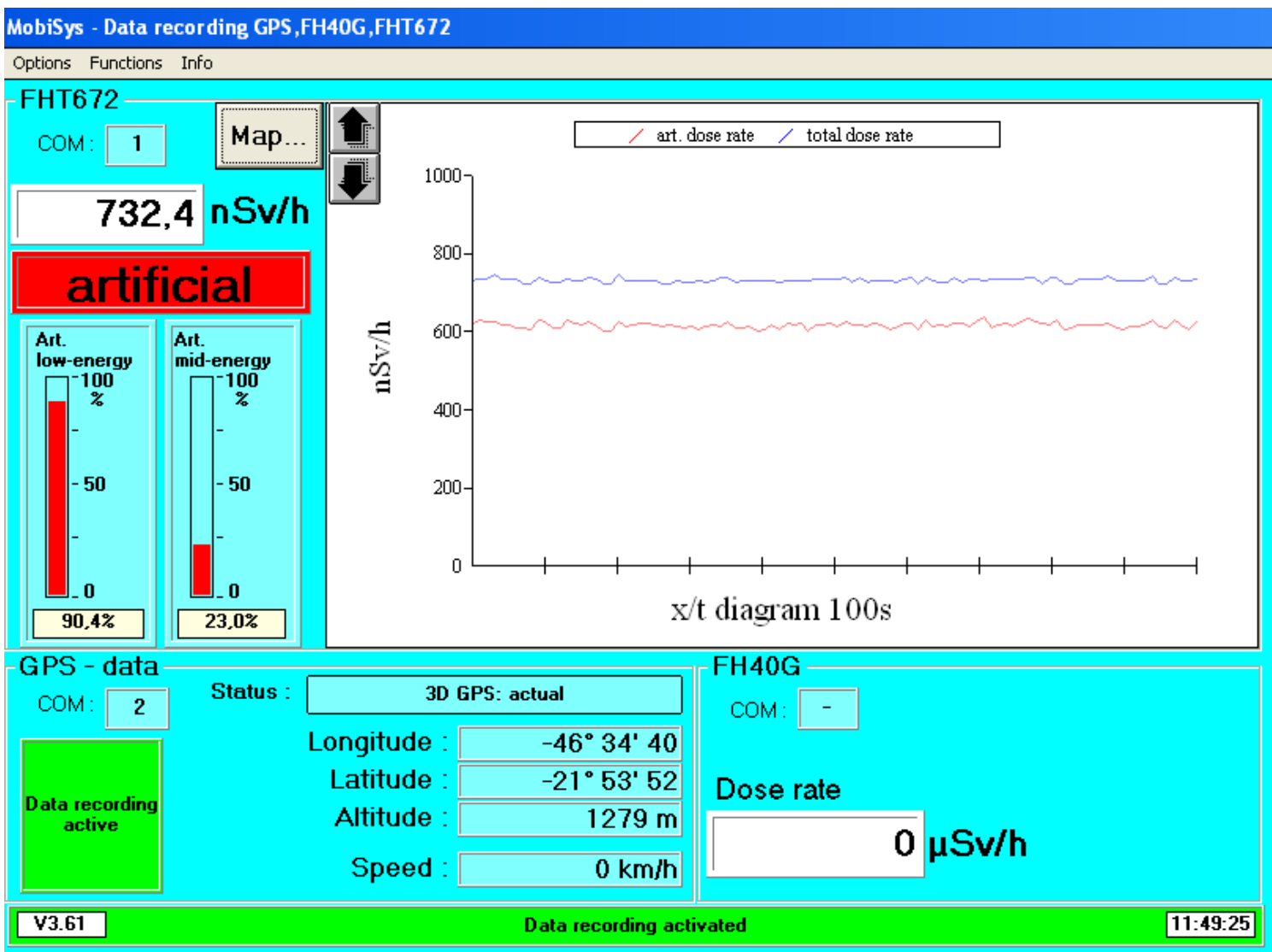

Figura 3.2. Janela do programa MobiLog.

O programa possibilita dois modos de leitura dos dados: "taxa de dose" e "taxa de exposição". No canto superior esquerdo, a natureza da radiação gama é mostrada (natural ou artificial) e duas barras indicam a participação percentual relativa da 
radiação gama artificial de baixa energia $\left(100 \leq \gamma<700 \mathrm{keV}\right.$, como o ${ }^{192}$ Ir e o $\left.{ }^{137} C s\right)$ e de alta energia (700 $\leq \gamma<1400 \mathrm{keV}$, como o ${ }^{60} \mathrm{Co}$ ) na leitura total, podendo-se inferir que as medidas das energias dos fótons medidos estão no intervalo de 100 a $1400 \mathrm{keV}$ (Tabela 3.1). O diagrama do lado direito mostra os valores de "taxa de dose" (ou "taxa de exposição") total e artificial em função do tempo de medida. Já na parte inferior da tela, tem-se os dados de latitute, longitude, altitude e velocidade coletados pelo GPS e correlacionados às medidas.

\section{MobiView}

Neste programa, os dados de "taxa de dose" (ou "taxa de exposição") no percurso de medidas realizado, são representados de forma gráfica num mapa da região monitorada. Este mapa foi inserido ao programa e calibrado com um GPS antes da tomada dos dados.

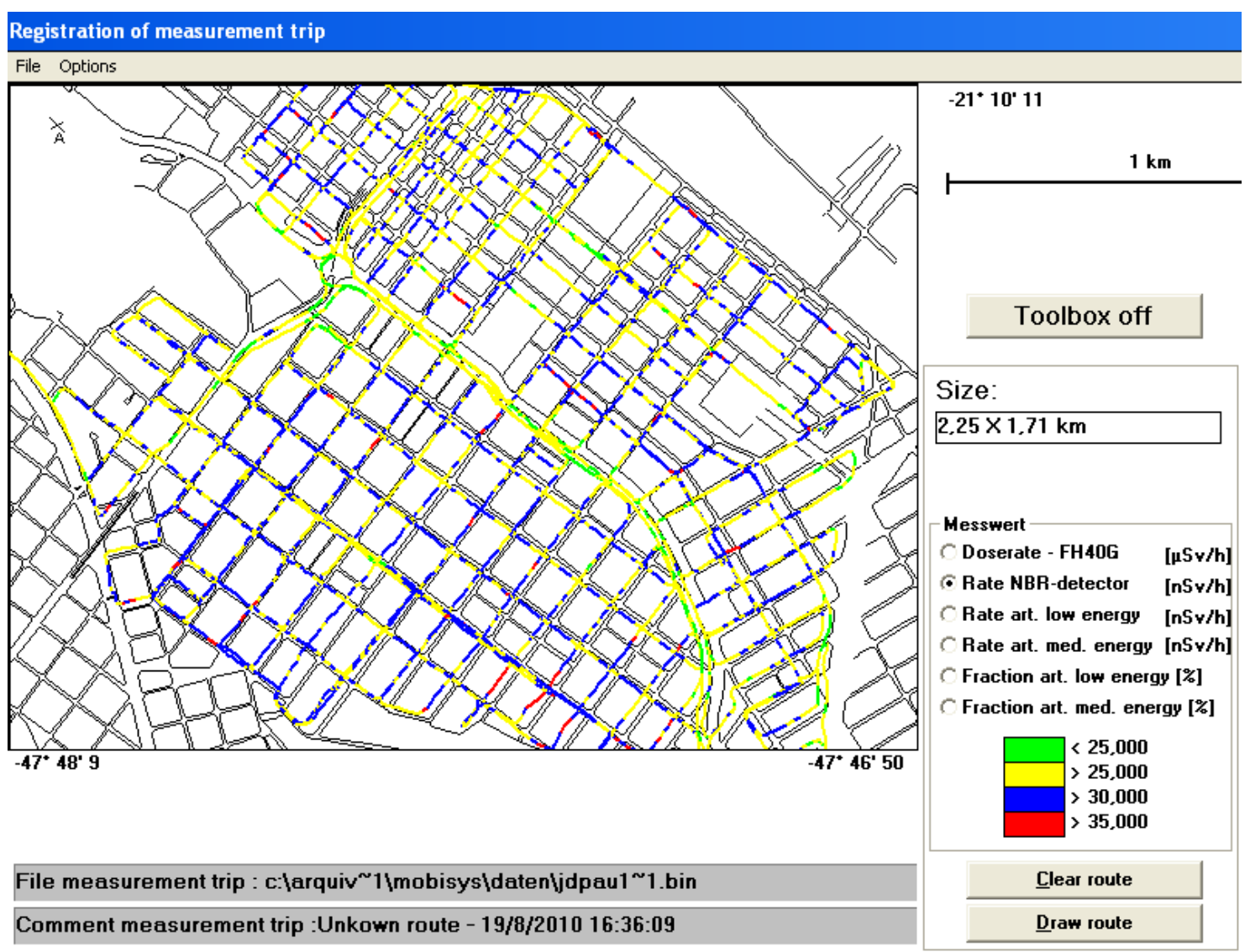

Figura 3.3. Janela do programa MobiView durante monitoração da região Jardim Paulista. 
A Figura 3.3 mostra a monitoração de uma área de interesse, com relação aos dados radiométricos e geográficos da mesma. Cada ponto colorido descreve um valor de "taxa de dose" que representa um ponto de medida nas respectivas coordenadas geográficas.

\section{MobiConv}

Os arquivos gerados no formato (.BIN) passaram por um filtro, onde foi feita uma média aritmética dos pontos de mesma coordenada geográfica, e foram convertidos para formato de texto (.TXT). Este programa também permite unir dados de arquivos diferentes, bastante útil quando uma mesma região não pôde ser monitorada em um único trajeto.

\section{Plataforma ArcGIS}

Os Sistemas de Informações Geográficas (SIG) são plataformas computacionais de geoprocessamento, capazes de integrar informações geográficas com dados de outros formatos (como por exemplo, as medidas radiométricas). No tratamento das medidas realizadas em Ribeirão Preto, utilizou-se a plataforma ArcGIS 9.3, amplamente conhecida da ESRI (Environmental Systems Research Institute), que consiste de três partes: ArcToolbox que é a ferramenta de geoprocessamento; ArcMap que é o aplicativo de visualização e edição dos mapas e ArcCatalog, que é o local do gerenciamento dos arquivos e pastas (criação, edição e organização) $[48,49]$. Esta plataforma foi utilizada para a composição de mapas radiométricos e populacionais, convergindo os dados das coordenadas das taxas de dose e informações censitárias, com as coordenadas do mapa urbano da região de interesse. Foram elaborados oito mapas de taxa de dose efetiva utilizando um ferramenta de interpolação, além de dois mapas gerais da cidade e um mapa populacional.

\subsection{Metodologia}

\section{Caracterização do Sistema}

Verificação dos Modos de Leitura

O sistema FHT 1376 pode operar em dois modos de leitura: "taxa de dose" (dado 
em Sv/h) e "taxa de exposição" (dado em R/h). O método de conversão da medida de radiação para taxa de dose e de exposição não é descrito pelo fabricante, e o processamento dos sinais é feito dividindo-se o espectro de energia em alguns canais discretos de energia, que separam os fótons de baixa, média e alta energia.

Quando se utiliza dosímetros calibrados em outros laboratórios, normalmente se tem fatores de calibração associados aos modos de leitura que se utilizará com esses dosímetros. Os instrumentos voltados a proteção radiológica são normalmente calibrados em termos de exposição, kerma no ar ou equivalente de dose, dependendo do tipo da aplicação do detector [50]. Muitas vezes, no entanto, esses dosímetros têm modos de leitura em grandezas de proteção radiológica (dose efetiva, dose equivalente), sem fornecer os fatores de conversão associados.

O sistema FHT 1376 embora tenha sido fabricado com fins radiométricos, não tem o objetivo de medir doses e por esse motivo os fatores de calibração e de conversão de unidades não são fornecidos pelo fabricante. Tem-se, por exemplo, leituras em "taxa de dose" do tipo $\mathrm{Sv} / \mathrm{h}$, porém não se sabe o fator de conversão da medida da radiação para esta unidade, nem tampouco a qual grandeza (taxa de dose efetiva, taxa de dose equivalente) esta unidade está correlacionada. Dessa forma, a verificação dos modos de leitura, bem como da conversão entre unidades foi feita, utilizando-se uma fonte de ${ }^{137} \mathrm{Cs}$, calibrada no LAPOC, cujas características são descritas na Tabela 3.2 .

Tabela 3.2. Características da fonte de teste ${ }^{137}$ Cs utilizada neste trabalho.

\begin{tabular}{ccccc}
\hline \hline $\begin{array}{c}\text { Atividade } \\
(\mathrm{kBq})\end{array}$ & $\begin{array}{c}\text { Data de } \\
\text { referência }\end{array}$ & $\begin{array}{c}\text { Energia de } \\
\text { emissão }(\mathrm{keV})\end{array}$ & $\begin{array}{c}\text { Meia-vida } \\
(\text { anos })\end{array}$ & $\begin{array}{c}\Gamma[18] \\
\text { R.m }{ }^{2} \cdot(\mathrm{Ci} \cdot \mathrm{h})^{-1} / \\
\mathrm{C} / \mathrm{kg} \cdot \mathrm{m}^{2} \cdot(\mathrm{Bq} \cdot \mathrm{h})^{-1}\end{array}$ \\
\hline 147,5 & $19 / 10 / 2011$ & 661,7 & 30 & $0,33 / 2,30 \cdot 10^{-15}$ \\
\hline \hline
\end{tabular}

Utilizando os dois modos de leitura, a fonte de césio foi posicionada sobre o centro do volume sensível do cintilador e tomou-se medidas variando a distância fonte-detector. Os valores de taxa de exposição encontrados pelo sistema foram então comparados com aqueles calculados utilizando a Equação 2.5, para as mesmas distâncias fonte-detector. 
Avaliação da Radiação Cósmica

O sistema FHT 1376 não tem precisão significativa da taxa de dose devido a radiação cósmica, dada sua limitação para medidas de fótons de altas energias. Este fato foi confirmado através da avaliação dessa radiação pelo sistema FHT 1376 feita pelo LAPOC [51], nas codições descritas pela IAEA (sobre uma superfície de água de, pelo menos, 3 metros de profundidade e a algumas centenas de metros das margens) $[20,52,53]$. Dessas medidas, foi encontrado um valor 5,7 vezes menor do que o esperado para o mesmo ponto, utilizando a Equação 3.1 de Bouville e Lowder [54], sugerida pela UNSCEAR.

$$
\dot{E}(z)=\dot{E}(0) \cdot\left[0,21 \cdot e^{-1,649 z}+0,79 \cdot e^{0,4528 z}\right]
$$

Sendo $\dot{E}(\mathrm{z})$ a taxa de dose efetiva em uma altitude z (em quilômetros); $\dot{E}(0)$ a taxa de dose efetiva a nível do mar.

Considerando que o referido sistema não tem resolução adequada para medidas da radiação cósmica e que o valor encontrado na avaliação prévia difere em $82 \%$ do esperado, foi decidido que não seriam consideradas as contribuições da radiação cósmica nas medidas.

\section{Teste com Fontes Extensas Padrão}

Instrumentos destinados a monitoração radiológica podem ser calibrados pelo fabricante e/ou por laboratórios especializados. O sistema FHT 1376 foi calibrado somente pelo fabricante, no entanto, assim como o mesmo foi calibrado para a fonte de ${ }^{137} \mathrm{Cs}$, é possível também fazer uma verificação dos modos de leitura para outros campos de radiação ionizante.

Em uma tentativa de padronização de métodos de medida em campos de radiação ambiental, a IAEA publicou um guia de recomendações para calibração de detectores portáteis a partir de blocos (pads) enriquecidos com radioelementos de interesse (normalmente ${ }^{40} \mathrm{~K},{ }^{238} \mathrm{U}$ e ${ }^{232} \mathrm{Th}$ ), que podem ser transportáveis ou fixos em instalações definidas [55]. Esses blocos devem simular fontes de radiação encontradas na natureza ou meio ambiente e são construídos a partir de concreto homogeneizado 
com concentração conhecida de um ou mais radionuclídeos. Nos últimos trinta anos, mais de 40 instalações de calibração foram construídas em diversos países, inclusive o Brasil [52]. Um conjunto de fontes que simulam os campos de radiação no meio ambiente, foi construído por Barreto et al em 1986 [56] no Instituto de Radioproteção e Dosimetria (IRD/CNEN), localizado no Rio de Janeiro. Este é constituído por oito blocos cilíndricos de 3 metros de diâmetro e 0,5 metro de espessura, dispostos em uma circunferência de 10 metros de raio. Além dos blocos, existe ainda uma piscina de 4 metros de diâmetro e 0,7 metro de espessura, como ilustrado na Figura 3.4, para avaliação da contribuição da radiação cósmica local.

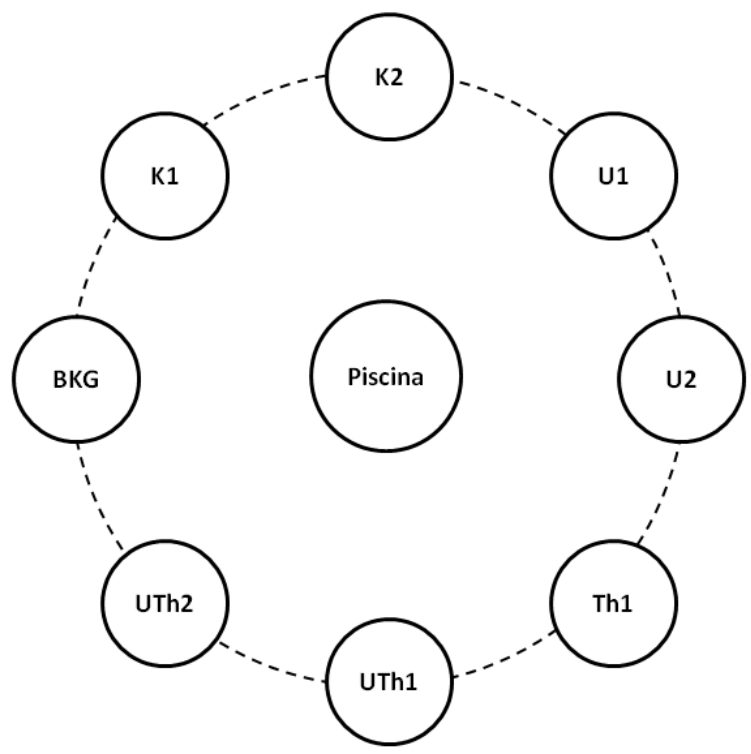

Figura 3.4. Distribuição geométrica das fontes de concreto pertencentes ao IRD/CNEN.

Cada bloco foi construído a partir de concreto comum e diferentes concentrações de minérios de potássio, urânio e tório, que foram homogeneizados ao concreto e se apresentam em equilíbrio secular. A composição de cada fonte foi verificada na época da sua construção, a partir de amostras analisadas por 8 laboratórios diferentes (através de análises químicas e ativação por nêutrons). Durante a construção das fontes, as concentrações de materiais radioativos também foram verificadas através de medidas in situ com espectrômetros, cujos valores e espectros estão descritos respectivamente na Tabela 3.3 e nas Figuras A.5 e A.6 do Anexo 2, e são referências para calibração e verificação de instrumentos para medidas de radiação gama ambiental. A fonte de background (BKG) foi construída de concreto "puro", 
sem misturas radioativas, para avaliar a contribuição dos materiais de construções básicos das fontes nas medidas radiométricas.

Tabela 3.3. Composição e concentração dos minérios radioativos das fontes extensas padrão localizadas no IRD/CNEN [56].

\begin{tabular}{cccc}
\hline \hline Fonte & Potássio (\%) & Urânio (ppm) & Tório (ppm) \\
\hline BKG & $0,08 \pm 0,01$ & $0,82 \pm 0,01$ & $1,75 \pm 0,12$ \\
K1 & $6,71 \pm 0,06$ & $2,00 \pm 0,07$ & $20,90 \pm 0,81$ \\
K2 & $4,43 \pm 0,08$ & $2,97 \pm 0,06$ & $29,72 \pm 1,39$ \\
U1 & $3,47 \pm 0,04$ & $69,92 \pm 0,67$ & $50,13 \pm 0,99$ \\
U2 & $3,54 \pm 0,07$ & $19,45 \pm 0,14$ & $53,06 \pm 1,68$ \\
Th1 & $3,54 \pm 0,07$ & $11,63 \pm 0,15$ & $255,97 \pm 5,25$ \\
UTh1 & $3,64 \pm 0,03$ & $12,10 \pm 0,24$ & $71,59 \pm 1,76$ \\
UTh2 & $3,65 \pm 0,03$ & $44,47 \pm 0,63$ & $152,39 \pm 4,76$ \\
\hline \hline
\end{tabular}

Em medidas de calibração de detectores portáteis utilizando as fontes citadas, deve-se posicionar o instrumento a ser calibrado na superfície das mesmas, já que neste caso a geometria da fonte pode ser comparada à de uma fonte plana infinita (como é na natureza). Essa suposição de plano infinito é descrita pela IAEA [52] como sendo verdadeira para um conjunto de quatro fontes (com mesmas dimensões daquelas no IRD), que produziriam cerca de 96\% da radiação gama observada em fontes infinitas.

As medidas in situ são normalmente realizadas com o detector posicionado a 1 metro da superfície do solo, onde a interferência das outras fontes se torna significativa e a suposição de plano infinito não é mais verdadeira. Para que outros detectores portáteis pudessem ser calibrados ou verificados nesta condição, existe um conjunto de medidas de referência disponíveis no IRD [28], feitas com um espectrômetro de HPGe (EG\&G Ortec/GEM-20190-P) a 1 metro da superfície de cada fonte.

Uma vez que o sistema FHT 1376 realizou medidas de "taxa de dose" a 1 metro da superfície do solo, a validação das medidas nas fontes de concreto foi feita posicionando o instrumento a 1 metro da superfície de cada fonte e os valores 
foram comparados com aquelas de referência em tal geometria. Para cada fonte, as medidas de "taxa de dose" pelo sistema foram coletadas em um intervalo de 300 segundos.

\section{Metodologia de Medidas}

\section{Definição das Regiões e Coleta Radiométrica}

Valores das medidas de "taxa de dose" foram coletados em oito regiões urbanas da cidade de Ribeirão Preto, com alta densidade populacional (exceto pela região do Campus universitário) e distantes o suficientes para que fossem representativas da cidade. Na Figura 3.5, as regiões selecionadas estão destacadas no mapa geral urbano da cidade que representam cerca de $10,4 \%$ da área total de $329,7 \mathrm{~km}^{2}$. As divisões no mapa descrevem os setores censitários demarcados pelo IBGE no censo de 2000 [57], dos quais 211 setores foram estudados, abrangendo aproximadamente 31, 3\% da população total de Ribeirão Preto de 501.728 habitantes.

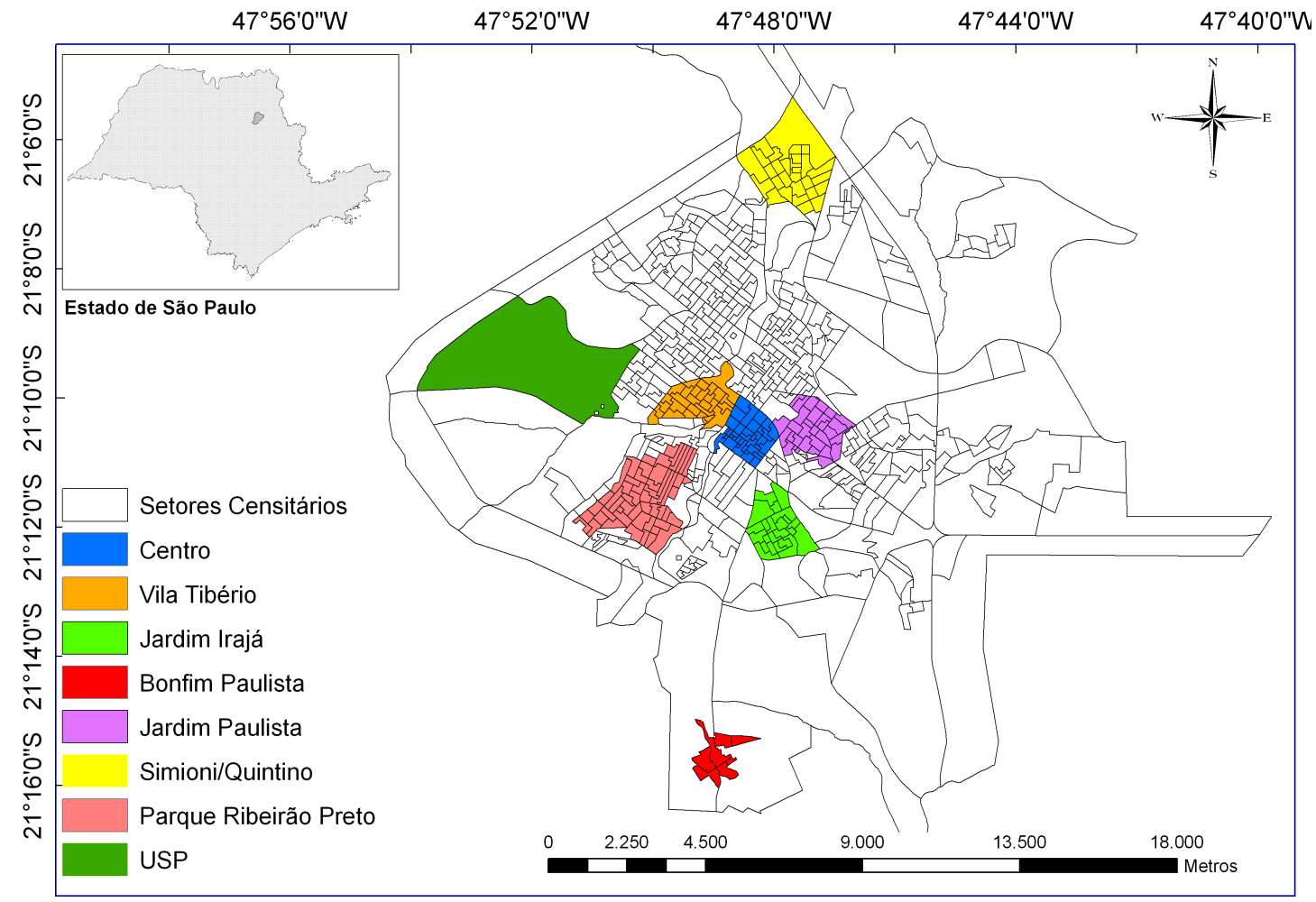

Figura 3.5. Regiões da cidade de Ribeirão Preto selecionadas para monitoração da taxa de dose gama ambiental. 
Foram utilizadas neste trabalho, as informações do censo de 2000 já que as informações do censo de 2010 eram, até a conclusão deste trabalho, insuficientes para serem utilizadas. Dos dados fornecidos pelo IBGE, a densidade demográfica de cada setor censitário é mostrada na Figura 3.6.

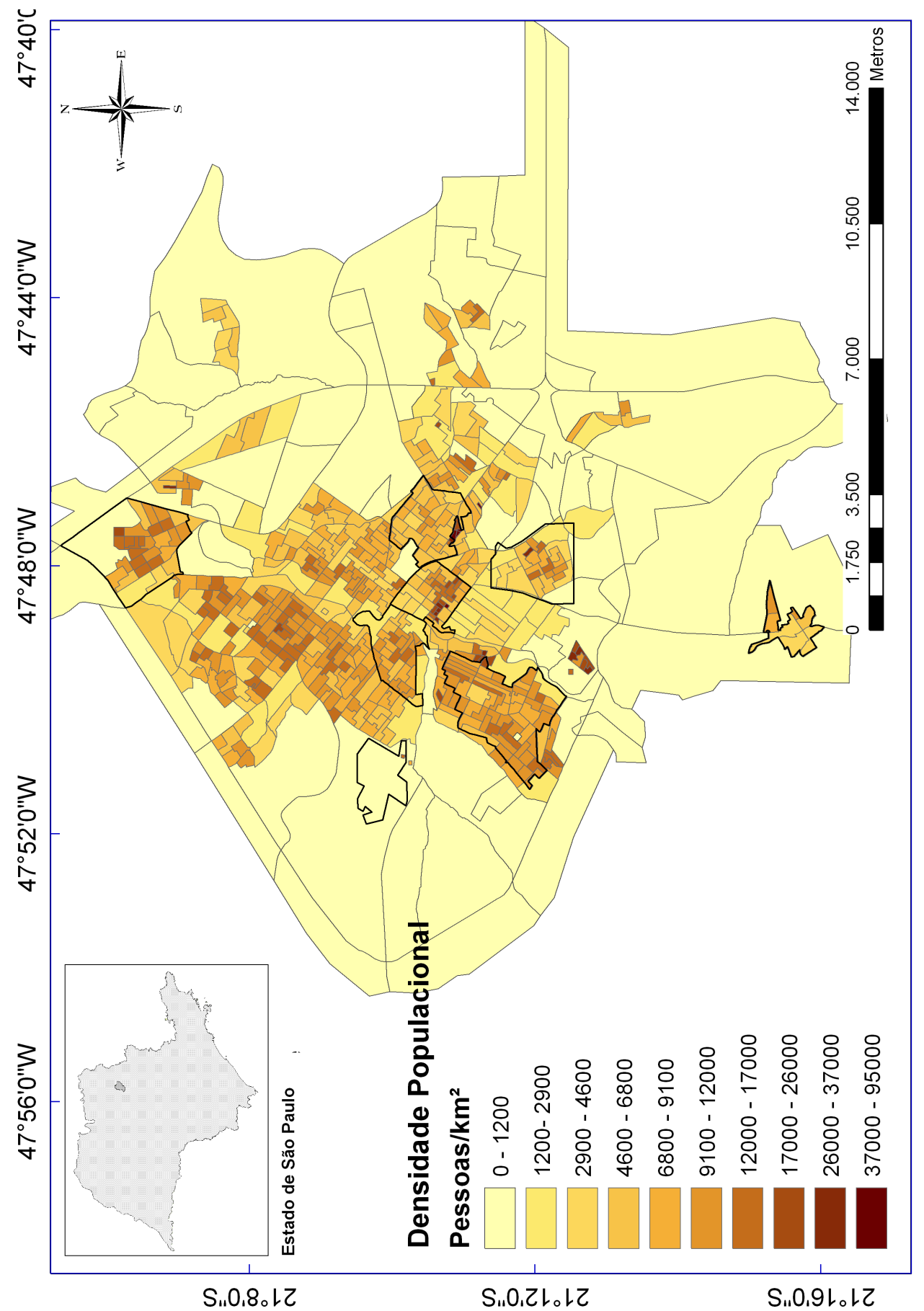

Figura 3.6. Densidade Populacional, segundo IBGE 2000. 
Para o levantamento radiométrico das regiões, o sistema FHT 1376 foi posicionado no porta-malas de um veículo a uma distância de 1 metro da superfície do solo e com a antena do GPS posicionada no teto do carro. Também, um computador foi conectado à caixa do detector e o conjunto foi ligado à fonte de tensão do veículo (12 volts), como mostrado na Figura 3.7.

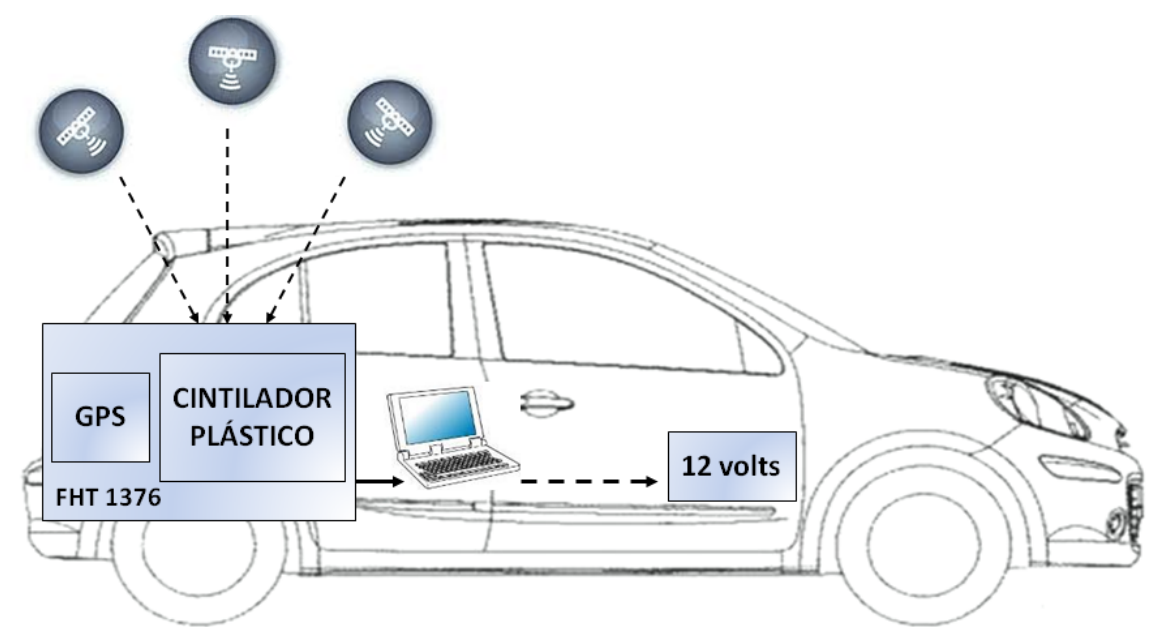

Figura 3.7. Diagrama de blocos representando a instalação do sistema, computador e detector dentro de um veículo de monitoração.

Após ligar o carro e dar início ao programa Mobisys, a antena do GPS recebe o sinal de três satélites (tempo médio de 15 segundos) e, com o recebimento dos sinais, o programa passa a armazenar as informações de "taxa de dose" (ou "taxa de exposição") e as coordenadas geográficas correspondentes a cada segundo. Para que se tenha uma coleta eficiente dos valores de medida ao longo do trajeto, o veículo deve manter uma velocidade no intervalo de 20 a $40 \mathrm{~km} / \mathrm{h}$, o que foi feito com uma média de $30 \mathrm{~km} / \mathrm{h}$. Durante um determinado percurso alguns pontos serão inevitavelmente monitorados mais de uma vez (por exemplo, quando o veículo para em um semáforo, ou quando deve fazer um retorno obrigatório) e por isso, os dados coletados passaram por um primeiro filtro, onde as leituras radiométricas dos pontos de mesmas coordenadas geográficas passaram por uma média aritmética.

Cálculo das Doses Efetivas e Efetivas Coletivas em Ambientes ao Ar Livre

A grandeza dosimétrica de referência para medidas de radiação terrestre, tanto adotada pela IAEA quanto pela UNSCEAR é a taxa de dose absorvida no ar (Gy/h) 
$[2,52]$. Para se trabalhar com grandezas de proteção radiológica, como dose efetiva e dose efetiva coletiva, é necessário utilizar coeficientes de conversão de taxa de dose absorvida no ar para essas grandezas. Esses coeficientes foram calculados por Saito et al [58] a partir de modelos antropomórficos e cálculos em Monte Carlo, em condições de exposição à radiação ambiental, e são apresentados na Tabela 3.4 para as fontes de ${ }^{238} \mathrm{U},{ }^{232} \mathrm{Th}$ e ${ }^{40} \mathrm{~K}$.

Tabela 3.4. Fatores de conversão entre dose absorvida no ar e dose efetiva para potássio, urânio e tório presentes no solo, feito por Saito et al [58].

\begin{tabular}{cc}
\hline \hline Radionuclídeo & $\begin{array}{c}\text { Fator de conversão } \\
\text { Sv/Gy }\end{array}$ \\
\hline${ }^{238} \mathrm{U}$ & 0,672 \\
${ }^{232} \mathrm{Th}$ & 0,695 \\
${ }^{40} \mathrm{~K}$ & 0,709 \\
\hline \hline
\end{tabular}

Segundo a dosimetria ambiental, para o cálculo da dose efetiva anual deve-se levar em conta, além do fator de conversão entre a dose absorvida no ar e a dose efetiva, também o fator de ocupação em um ambiente particular, ou seja, a fração de tempo que se passa em ambientes fechados ou ao ar livre. Este fator pode variar dependendo da idade da população estudada, tipo de clima da região de interesse e a UNSCEAR utiliza como fator de ocupação 0,2 para ambientes ao ar livre e fator de conversão entre dose absorvida no ar a 1 metro e dose efetiva, para indivíduos adultos, como sendo 0, $7 \mathrm{~Sv} / \mathrm{Gy}[2]$.

Assim, dose efetiva anual em ambientes ao ar livre $\left(E_{\text {aal }}\right)$ para cada ponto de monitoração foi calculada utilizando-se a Equação 3.2,

$$
E_{\text {aal }}=\dot{D}_{\text {ar }} \times 8760 \times 0,2 \times 0,7 \quad[\text { Sv/ano }]
$$

Sendo $E_{\text {aal }}$ a dose efetiva anual, $\dot{D}_{\text {ar }}$ a taxa de dose absorvida no ar por hora para cada ponto de medida, e o valor 8760 o número de horas em 1 ano. As medidas de $E_{a a l}$ nas coodenadas permitem encontrar um valor de dose efetiva média anual, $\bar{E}_{i}$, para cada setor censitário $i$.

A dose efetiva coletiva anual $(S)$ e a dose efetiva média anual $(\bar{E})$ de todos os 
setores censitários são relacionadas ao número de residentes de cada setor $p_{i}$ e a população total estudada $p_{T}$, segundo as Equações 3.3 e 3.4.

$$
\begin{array}{cc}
S=\sum_{i} \bar{E}_{i} \times p_{i} & \text { [homem.Sv/ano }] \\
\bar{E}=\frac{\sum_{i} \bar{E}_{i} \times p_{i}}{p_{T}} & {[\text { Sv/ano }]}
\end{array}
$$

Com esta metodologia, embora este aparelho não tenha sido feito para fornecer valores de dose efetiva ou dose efetiva coletiva, a partir da calibração do mesmo com o a fonte de ${ }^{137} \mathrm{Cs}$ do LAPOC e com o sistema de fontes do IRD/CNEN, foi possível inferir essas grandezas numa região de interesse correlacionando-as com as coordenadas geográficas dessa região. 


\section{Capítulo}

\section{Resultados E Discussões}

\subsection{Caracterização do Sistema FHT 1376}

\section{Relação entre os Modos de Leitura}

Para melhor compreender as formas de leitura do sistema FHT 1376, verificou-se primeiramente o fator de conversão entre os dois modos de leitura disponíveis, "taxa de dose" e "taxa de exposição". Isso foi feito considerando a mesma fonte descrita na Tabela 3.2, variando a distância fonte-detector. Para os dois modos de leitura, da Figura 4.1, pode-se inferir que a intensidade de sinal diminui com o inverso do quadrado da distância e um fator entre essas leituras foi encontrado, como $1 \mathrm{~Sv} / \mathrm{h}$ de "taxa de dose" $=99,68 \pm 0,95 \mathrm{R} / \mathrm{h}$ de "taxa de exposição".

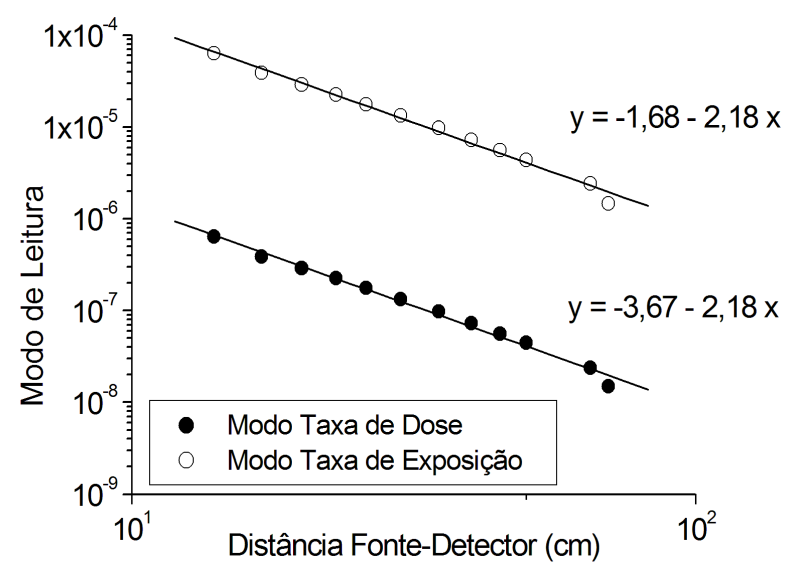

Figura 4.1. Comportamentos dos modos de leitura em função da distancia fonte-detector, com diminuição da intensidade do sinal com $d^{-2}$ e fator $=100$ entre os dois modos. 
Os resultados obtidos mostram que as leituras de um detector nem sempre fazem referência às grandezas dosimétricas adequadas, mas é apenas uma conversão entre unidades [29]. Por esse motivo, a calibração dos modos de leitura deve ser feita para uma fonte conhecida.

\section{Calibração dos Modos de Leitura}

Uma vez que o sistema radiométrico FHT 1376 tem unidades nele registradas que podem não corresponder com as mesmas esperadas foi feito uma verificação com uma fonte conhecida. Uma fonte de ${ }^{137}$ Cs foi utilizada, cujas características são apresentadas na Tabela 3.2, juntamente com sua constante $\Gamma\left[\mathrm{C} / \mathrm{kg} \cdot \mathrm{m}^{2} .(\mathrm{Bq} \cdot \mathrm{h})^{-1}\right]$ (equação 2.5), que permitiram a obtenção dos valores de taxa de exposição para diferentes distâncias fonte-detector. Considerando que o volume sensível do detector é grande o suficiente para que se tenha o equilíbrio das partículas carregadas (equilíbrio eletrônico), a taxa de dose absorvida no ar (dada em Gy/h) pode ser inferida através da taxa de exposição (dada em $\mathrm{R} / \mathrm{h}$ ) [18] como:

$$
\dot{D}_{a r}=\dot{X}\left(\frac{\bar{w}}{e}\right)_{a r}=0,00876 \dot{X} \quad[G y / h]
$$

Sendo que $\frac{\bar{w}}{e}$ é a energia necessária para a formação de um par de íons no ar, igual a $33,97 \mathrm{~J} / \mathrm{C}[18]$.

Os valores de taxa de exposição e taxa de dose absorvida no ar encontrados nos cálculos, foram utilizados como referência para correlacionar a dependência dos dois modos de leitura do sistema FHT 1376.

Os dois gráficos da Figura $\mathbf{4 . 2}$ apresentaram coeficientes angulares muito próximos da unidade portanto, a partir desta consideração, os valores medidos pelo sistema FHT 1376 nos modos "taxa de exposição" e "taxa de dose", foram avalidados como leituras de taxa de exposição em $\mathrm{R} / \mathrm{h}\left(2,58 \cdot 10^{-4} \mathrm{C} / \mathrm{kg} \cdot \mathrm{h}^{-1}\right)$ e taxa de dose absorvida no ar em Gy/h. Esses resultados são importantes para o cálculo da dose efetiva, que leva em conta valores de taxa de dose absorvida no ar.

Das medidas realizadas entre os modos de leitura, pôde-se inferir que o detector FHT 1376 faz a conversão de $1 \mathrm{~Gy} / \mathrm{h} \approx 100 \mathrm{R}$. 


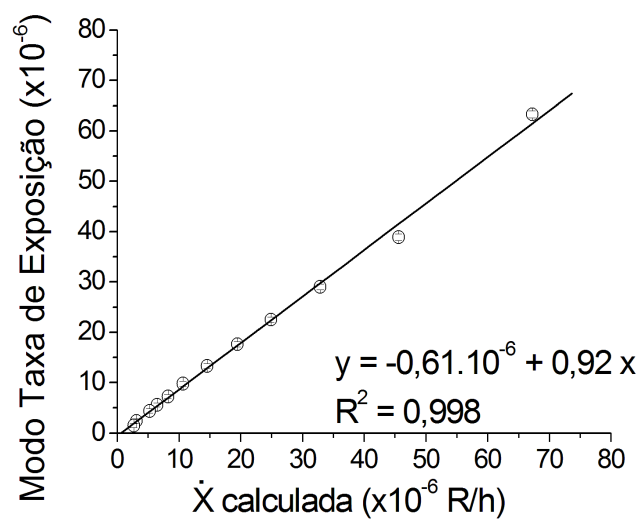

(a)

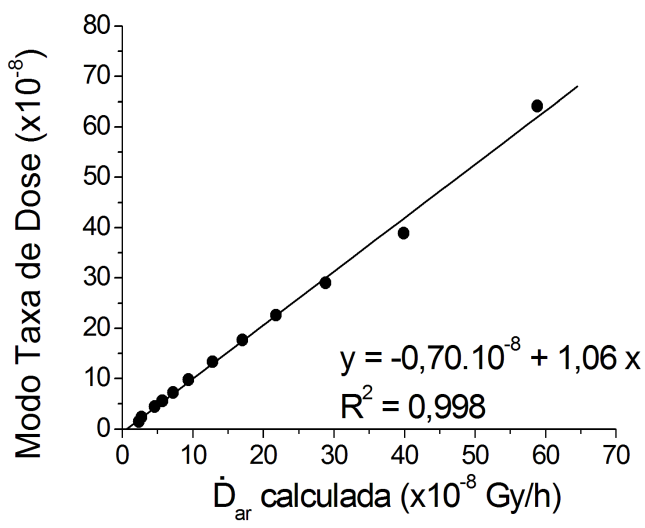

(b)

Figura 4.2. Correlação dos dois modos de leitura do sistema FHT 1376 em função dos valores de taxa de exposição e taxa de dose absorvida no ar, respectivamente (a) e (b).

Comparação de $\dot{D}_{\text {ar }}$ através do Sistema FHT 1376 com $\dot{D}_{\text {ar }}$ de Referência, para Fontes Extensas Padrão

A comparação das leituras do sistema FHT 1376 com relação aquelas de referência, feitas com um espectrômetro gama do HPGe por Conti et al [28], foi feita no conjunto de fontes extensas de concreto do IRD/CNEN. Esses valores, são apresentados na Tabela 4.1 e as curvas que correlacionam ambos os dados são mostradas na Figura 4.3.

Tabela 4.1. Taxa de dose absorvida de cada fonte medida pelo sistema FHT 1376, junto com sua comparação aos os valores de referência a 1 metro do solo.

\begin{tabular}{ccccc}
\hline \hline Fonte & FHT 1376 & Referência & Razão & Diferença \\
& $(\mathrm{nGy} / \mathrm{h})$ & $\begin{array}{c}\text { (Conti } \text { et al }) \\
(\mathrm{nGy} / \mathrm{h})\end{array}$ & $($ FHT $/$ Referência $)$ & $(\%)$ \\
\hline $\mathrm{U} 1$ & $173,42 \pm 4,71$ & 191,0 & 0,91 & 9,2 \\
$\mathrm{U} 2$ & $120,05 \pm 3,30$ & 131,0 & 0,92 & 8,4 \\
Th1 & $262.43 \pm 5,28$ & 282,0 & 0,93 & 6,9 \\
UTh1 & $121,70 \pm 3,75$ & 136,0 & 0,89 & 10,5 \\
UTh2 & $236,77 \pm 4,81$ & 239,0 & 0,99 & 1,0 \\
K1 & $76,58 \pm 3,03$ & 85,0 & 0,90 & 9,9 \\
K2 & $78,53 \pm 2,61$ & 92,4 & 0,85 & 15,0 \\
\hline \hline
\end{tabular}




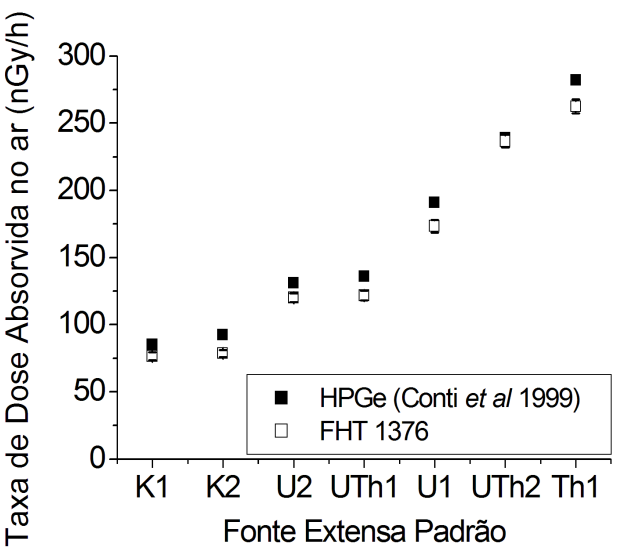

(a)

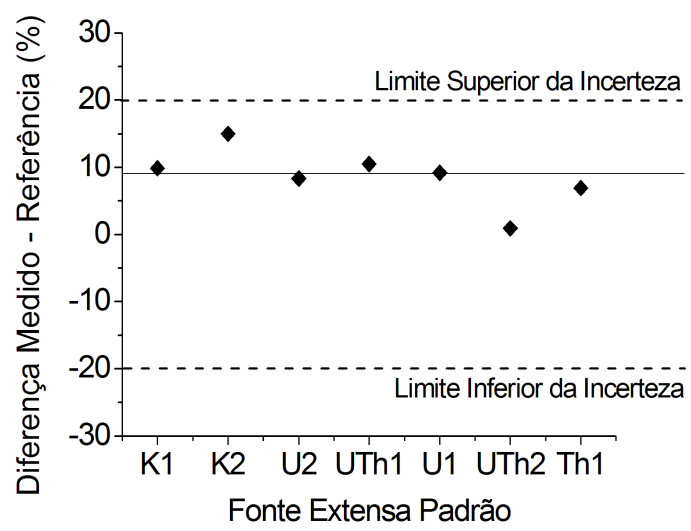

(b)

Figura 4.3. Comparação entre os comportamentos dos dois sistemas em (a) e incerteza entre os valores medidos pelo sistema FHT 1376 e aqueles de referência descritos por Conti et al em (b). A figura também apresenta os limites inferior e superior a serem considerados pela radioproteção.

Dos dados obtidos e da Figura 4.3 (a), pode-se inferir, a partir das curvas, que as leituras feitas tanto para o sistema FHT 1376 quanto para o HPGe [28] seguem o mesmo comportamento.

Segundo a norma da CNEN 6.04 [59], sobre instalações radiativas, os medidores portáteis de radiação devem obedecer aos ensaios descritos pela norma ABNT 10011 [60]. Nesta norma, os instrumentos de radioproteção são divididos em diferentes classes, cujos requisitos são especificados de acordo com dependência energética, direcional e outras que, segundo a CNEN, devem ter resultados com uma incerteza máxima de $\pm 20 \%$ da taxa de exposição real. A diferença média percentual encontrada neste trabalho, entre os valores obtidos com o sistema FHT 1376 em relação aqueles de referência, foi de 8,7\%; com uma diferença máxima de $15 \%$, mostrando que este sistema possui leituras dentro dos limites permitidos, Figura 4.3 (b).

\subsection{Obtenção da $\dot{D}_{a r}$}

De acordo com o último relatório da UNSCEAR de 2008, a dose efetiva mundial relativa à radiação natural, varia de $1 \mathrm{mSv}$ /ano a $13 \mathrm{mSv} /$ ano com uma média igual a 2, $4 \mathrm{mSv} /$ ano. Desta, tem-se os valores médios anuais de dose efetiva como sendo 
0,39 $\mathrm{mSv} /$ ano; $0,48 \mathrm{mSv} / \mathrm{ano} ; 1,26 \mathrm{mSv} /$ ano e $0,29 \mathrm{mSv} /$ ano respectivamente para radiação cósmica, terrestrial externa (ar livre e ambientes fechados) inalação e ingestão. Do valor médio de 0,48 mSv/ano tem-se que, 0,07 mSv/ano é a média relativa às exposições ao ar livre [2]. Segundo recomendações internacionais da IAEA [61], que são seguidas pela ICRP [12] e pela CNEN [27], o limite da dose efetiva anual (para os indivíduos do público) é de $1 \mathrm{mSv}$ acima daqueles valores de dose efetiva anual recebidos por exposição à radiação natural.

Neste trabalho, cerca de 45.400 medidas georreferenciadas da taxa de dose absorvida no ar foram coletadas pelo sistema FHT 1376, nas oito regiões monitoradas da cidade de Ribeirão Preto/SP. Os valores dessas medidas variaram de 17, 7 nGy/h até 85,2 nGy/h, com uma média de 27,38 $\pm 2,41 \mathrm{nGy} / \mathrm{h}$ e desses valores, através da Equação 3.2, pôde-se inferir aqueles de taxa de dose efetiva. Os valores obtidos de taxa de dose efetiva variaram de $12,2 \mathrm{nSv} / \mathrm{h}$ até $59,8 \mathrm{nSv} / \mathrm{h}$ e são mostrados no histograma de frequências versus taxa de dose efetiva na Figura 4.4.

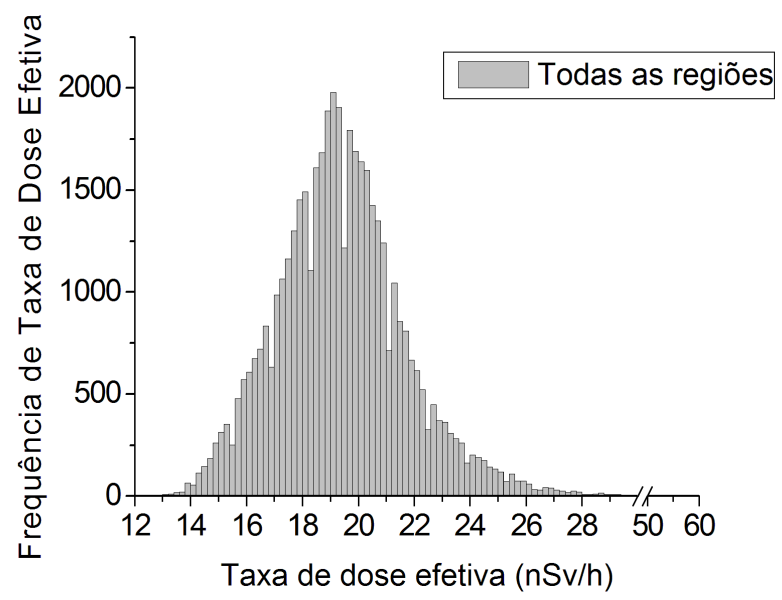

Figura 4.4. Histograma de frequência dos valores de taxa de dose efetiva considerando o grupo das oito regiões monitoradas.

Os valores da taxa de dose efetiva puderam ser classificados para cada setor censitário estudado, possibilitanto a determinação dos valores anuais de dose efetiva coletiva e a dose efetiva média de toda população, segundo o programa de georreferenciamento, os dados do IBGE e as Equações 3.3 e 3.4. Correlacionando todas as informações pertinentes, os resultados obtidos para cada região são apresentados na Tabela $\mathbf{4 . 2}$. 
Tabela 4.2. Doses efetivas e efetivas coletivas obtidas em cada área monitorada. Os valores máximos, mínimos e médios são relativos aos setores censitários.

\begin{tabular}{|c|c|c|c|c|c|c|c|}
\hline $\begin{array}{c}\text { Região } \\
\text { Selecionada }\end{array}$ & $\begin{array}{c}\mathrm{N}^{o} \text { População } \\
\text { segundo }\end{array}$ & $\begin{array}{l}\text { Quantidade } \\
\text { de setores }\end{array}$ & $\begin{array}{l}\text { Taxa de dose } \\
\text { efetiva média }\end{array}$ & \multicolumn{3}{|c|}{$\begin{array}{l}\text { Dose efetiva } \\
\text { anual (mSv) }\end{array}$} & $\begin{array}{l}\text { Dose efetiva } \\
\text { coletiva anual }\end{array}$ \\
\hline & & & & Mín & Máx & Média & Média \\
\hline Centro & 16.687 & 38 & 22,847 & 0,036 & 0,045 & $0,040 \pm 0,002$ & $17,12 \pm 5,24$ \\
\hline VL Tibério & 18.430 & 28 & 20,269 & 0,032 & 0,038 & $0,035 \pm 0,001$ & $23,25 \pm 6,94$ \\
\hline USP & 546 & 1 & 16,004 & 0,028 & 0,028 & 0,028 & 15,29 \\
\hline PQ Ribeirão & 49.929 & 54 & 18,909 & 0,030 & 0,036 & $0,033 \pm 0,001$ & $29,44 \pm 7,56$ \\
\hline Simioni & 31.802 & 29 & 18,657 & 0,030 & 0,034 & $0,032 \pm 0,001$ & $35,69 \pm 7,23$ \\
\hline JD Iraja & 15.261 & 23 & 20,023 & 0,032 & 0,038 & $0,035 \pm 0,001$ & $22,43 \pm 6,49$ \\
\hline Bonfim Pta & 6.444 & 7 & 18,768 & 0,032 & 0,034 & $0,033 \pm 0,001$ & $27,71 \pm 11,68$ \\
\hline Jardim Pta & 17.959 & 31 & 20,073 & 0,033 & 0,037 & $0,035 \pm 0,001$ & $19,55 \pm 6,18$ \\
\hline TOTAL & 157.058 & 211 & 20,038 & 0,028 & 0,045 & $0,034 \pm 0,004$ & $25,62 \pm 9,25$ \\
\hline
\end{tabular}

* Censo populacional de 2000 [57]

Uma vez que o concreto e o asfalto levam em suas composições concentrações, ainda que baixas, de ${ }^{40} \mathrm{~K}$ e filhos da série do ${ }^{238} \mathrm{U}$ e ${ }^{232} \mathrm{Th}$, esperava-se que a região do centro da cidade, por ter uma concentração maior desses materiais e ainda por apresentar também um maior aglomerado de pessoas nas ruas (contribuindo com emissões de radiação gama de seus organismos), apresentasse maiores taxas de dose absorvida no ar, enquanto as áreas mais distantes apresentariam valores menores. Isto foi de fato observado, com as regiões do centro e perto do centro de valores maiores do que o valor apresentado pela região do Campus universitário da USP, que tem a maior parte de sua área sem asfalto e concreto e coberta por vegetação. Na Figura 4.5 as doses efetivas médias anuais dos setores censitários nas regiões de interesse foram avaliadas de acordo com a distância média à região central; em (a) tem-se as coroas circulares que compreendem os setores censitários das regiões e em (b) tem-se as doses efetivas anuais médias para as coroas circulares correspondentes às regiões mostradas. Nota-se que o valor da dose efetiva anual média diminiu a medida que se afasta do centro, com os valores de 0, $0400 \mathrm{mSv} / \mathrm{ano}, 0,0356 \mathrm{mSv} / \mathrm{ano}$, $0,0347 \mathrm{mSv} /$ ano, respectivamente para as três primeiras coroas circulares. A partir 
da quarta coroa, os valores são próximos com média de 0,0320 $\pm 0,0019 \mathrm{mSv} /$ ano e uma diferença máxima de 6,5\%. Considerando a média do quarto valor em diante, tem-se diferenças de 19,8\%,10\% e 7,6\% respectivamente para as coroas circulares 1 2 e 3. Esses resultados confirmam o que se esperava das regiões mais centrais terem níveis maiores de radiação gama natural ao ar livre, devido às maiores quantidades de materiais com concentrações de radionuclídeos naturais.

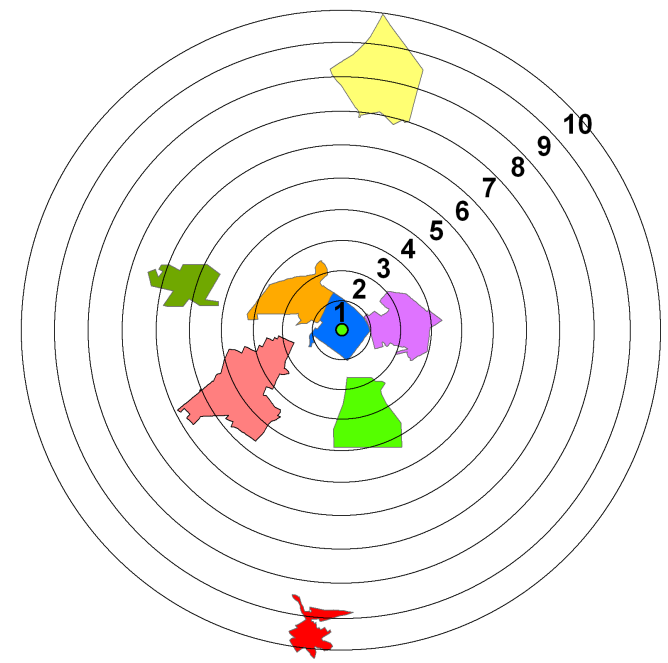

(a)

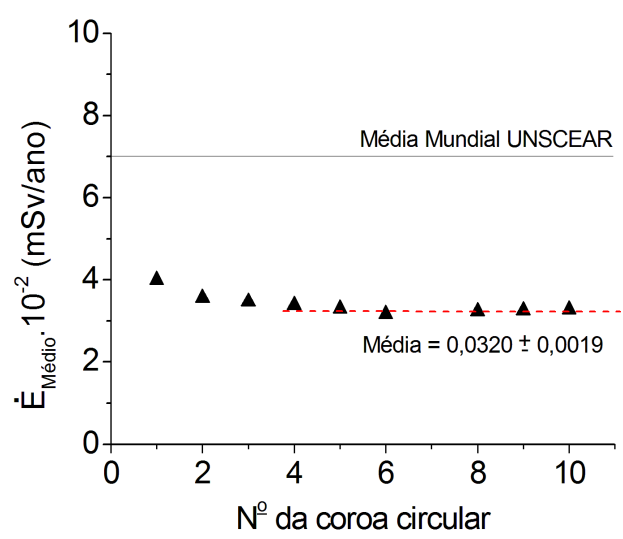

(b)

Figura 4.5. (a) Esquema ilustrativo das regiões avaliadas, relativas à coroas circulares referenciadas ao centro da cidade; (b) valores de E் média anual de cada coroa.

Embora as áreas do centro tenham um valor de dose efetiva maior, as doses efetivas coletivas para essas regiões são relativamente baixas quando comparadas às regiões mais populosas (como as regiões do Simioni/Quintino e Parque Ribeirão), uma vez que leva-se em conta o número de pessoas que moram nessas regiões.

A média anual da dose efetiva e dose efetiva coletiva terrestrial para ambientes ao ar livre puderam ser inferidas respectivamente como 0,034 $\pm 0,004 \mathrm{mSv} /$ ano e 25, $62 \pm 9,25$ homem.mSv. A primeira é cerca de metade do valor médio mundial da dose efetiva média anual publicada pela UNSCEAR. Esta média também é baixa quando comparada a valores encontrados $[8-11,36]$ em outros estudos sobre dose de radiação gama ao ar livre no território brasileiro. A maioria desses estudos foram realizados em áreas de alta radioatividade natural, cujos valores $\dot{D}_{a} r$, em comparação ao valor médio obtido neste trabalho, são apresentados na Tabela 4.3. 
Tabela 4.3. Comparação dos valores de taxa de dose absorvida deste trabalho com outros da literatura, feitos em regiões urbanas.

\begin{tabular}{|c|c|c|c|}
\hline Região Estudada & $\dot{D}_{a r}$ média $(\mathrm{nGy} / \mathrm{h})$ & Detector utilizado & Referência \\
\hline Ribeirão Preto (SP) & 27,38 & FHT 1376 & Este trabalho \\
\hline Poços de Caldas $(\mathrm{MG})^{1}$ & 154,92 & FHT 1376 & Silva et al $[36]$ \\
\hline Rio de Janeiro $(\mathrm{RJ})^{2}$ & 106,19 & Espectrômetro gama $[\mathrm{NaI}(\mathrm{Tl})]$ & Sachett [8] \\
\hline Águas da Prata $(\mathrm{SP})^{2}$ & 105,60 & Espectrômetro gama $[\mathrm{NaI}(\mathrm{Tl})]$ & Sachett [8] \\
\hline Poços de Caldas $(\mathrm{MG})^{2}$ & 144,46 & Espectrômetro gama $[\mathrm{NaI}(\mathrm{Tl})]$ & Sachett [8] \\
\hline Andradas $(\mathrm{MG})^{2}$ & 98,50 & Espectrômetro gama $[\mathrm{NaI}(\mathrm{Tl})]$ & Sachett [8] \\
\hline Caldas $(\mathrm{MG})^{2}$ & 128,20 & Espectrômetro gama $[\mathrm{NaI}(\mathrm{Tl})]$ & Sachett [8] \\
\hline Guarapari $(\mathrm{ES})^{2}$ & 88,90 & Espectrômetro gama $[\mathrm{NaI}(\mathrm{Tl})]$ & Sachett [8] \\
\hline São Paulo (SP) & 88,00 & Espectrômetro gama $[\mathrm{NaI}(\mathrm{Tl})]$ & Yoshimura et al [9] \\
\hline São Paulo $(\mathrm{SP})^{1}$ & 200,59 & $\mathrm{TLD} \mathrm{CaSO}_{4}: \mathrm{Dy}$ & Carneiro et al [11] \\
\hline CTMSP - Aramar (SP) & 46,23 & TLD $\mathrm{CaF}_{2}: \mathrm{Dy}$ & Moraes et al [10] \\
\hline
\end{tabular}

(1) Dado em taxa de dose efetiva anual e aqui calculado em termos de $\dot{D}_{a r}$ média utilizando o fator de conversão de $0,7 \mathrm{~Sv} / \mathrm{Gy}$;

(2) Dado em taxa de kerma no ar e aqui inferido como $\dot{D}_{a r}$ média supondo a condição de $E P C$.

\subsection{Dose Efetiva Média Anual na Cidade de Ribeirão Preto}

Utilizando a plataforma ArcGIS, os dados de população e taxa de dose efetiva média anual foram organizados na forma de mapas de Ribeirão Preto. Para cada região do município, os pontos das medidas de dose efetiva anual foram interpolados, obtendo-se os mapas das Figuras 4.6, 4.7, 4.8, 4.9, 4.10, 4.11, 4.12 e 4.13.

Os mapas finais das médias anuais de dose efetiva e dose efetiva coletiva são mostrados nas Figuras 4.14 e $\mathbf{4 . 1 5}$, cujas divisões nos mapas são referentes aos diversos setores censitários demarcados pelo IBGE.

Dos resultados obtidos, as distribuições de dose efetiva média anual e dose efetiva média coletiva puderam ser encontradas para as regiões de Ribeirão Preto. 


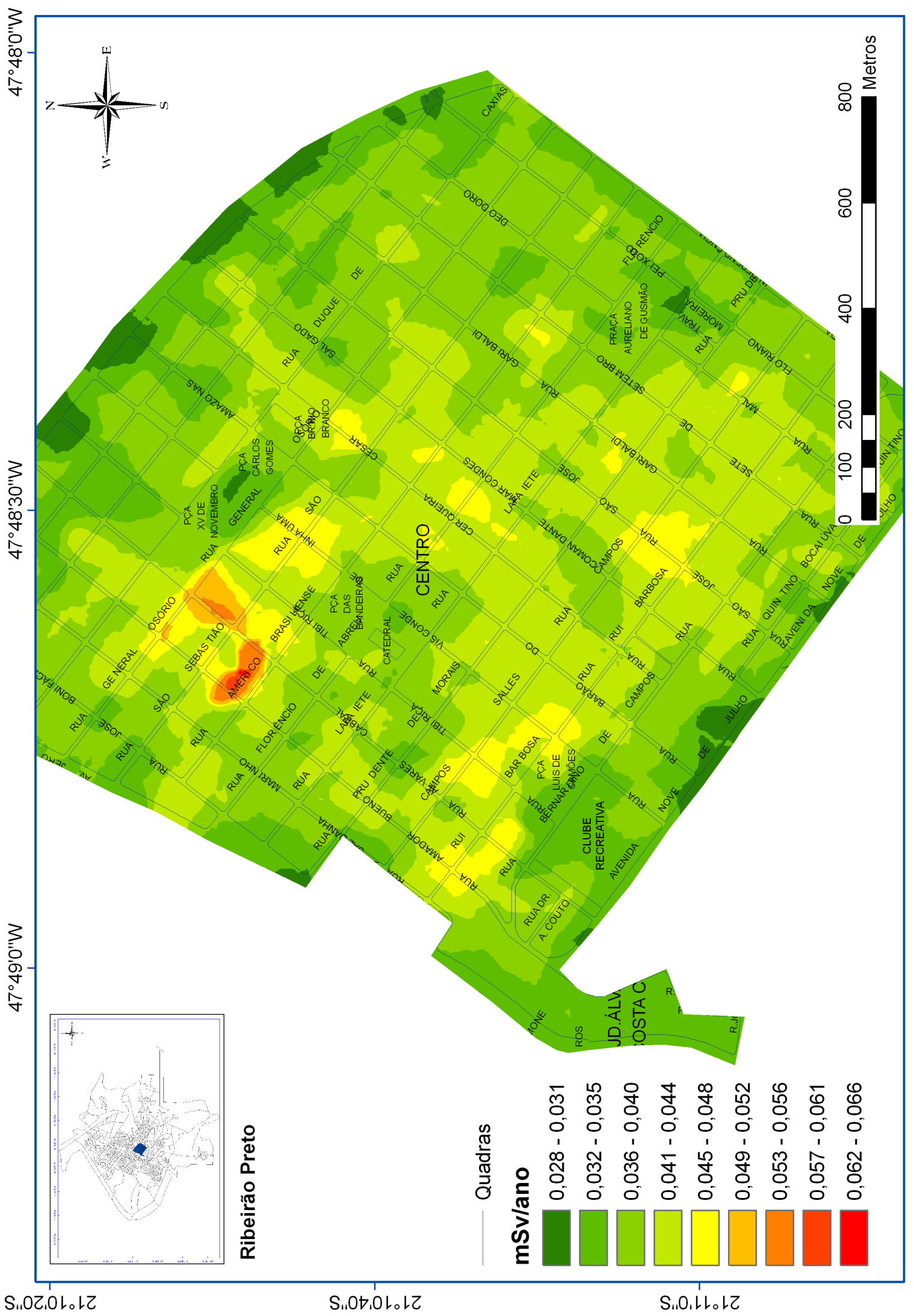

Figura 4.6. Distribuição espacial das doses efetivas anuais para a região do Centro. 


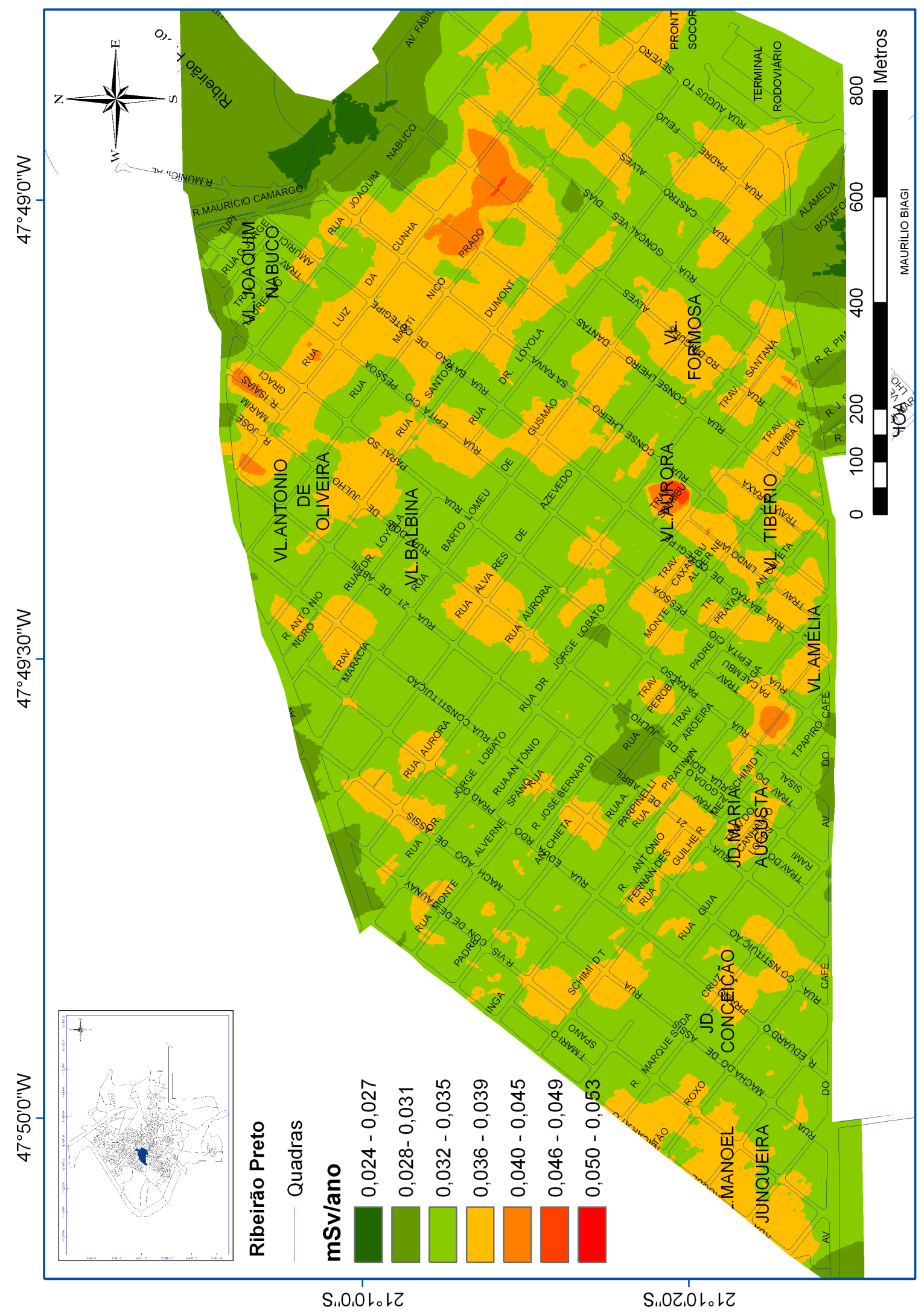

Figura 4.7. Distribuição espacial das doses efetivas anuais para a região da Vila Tibério. 


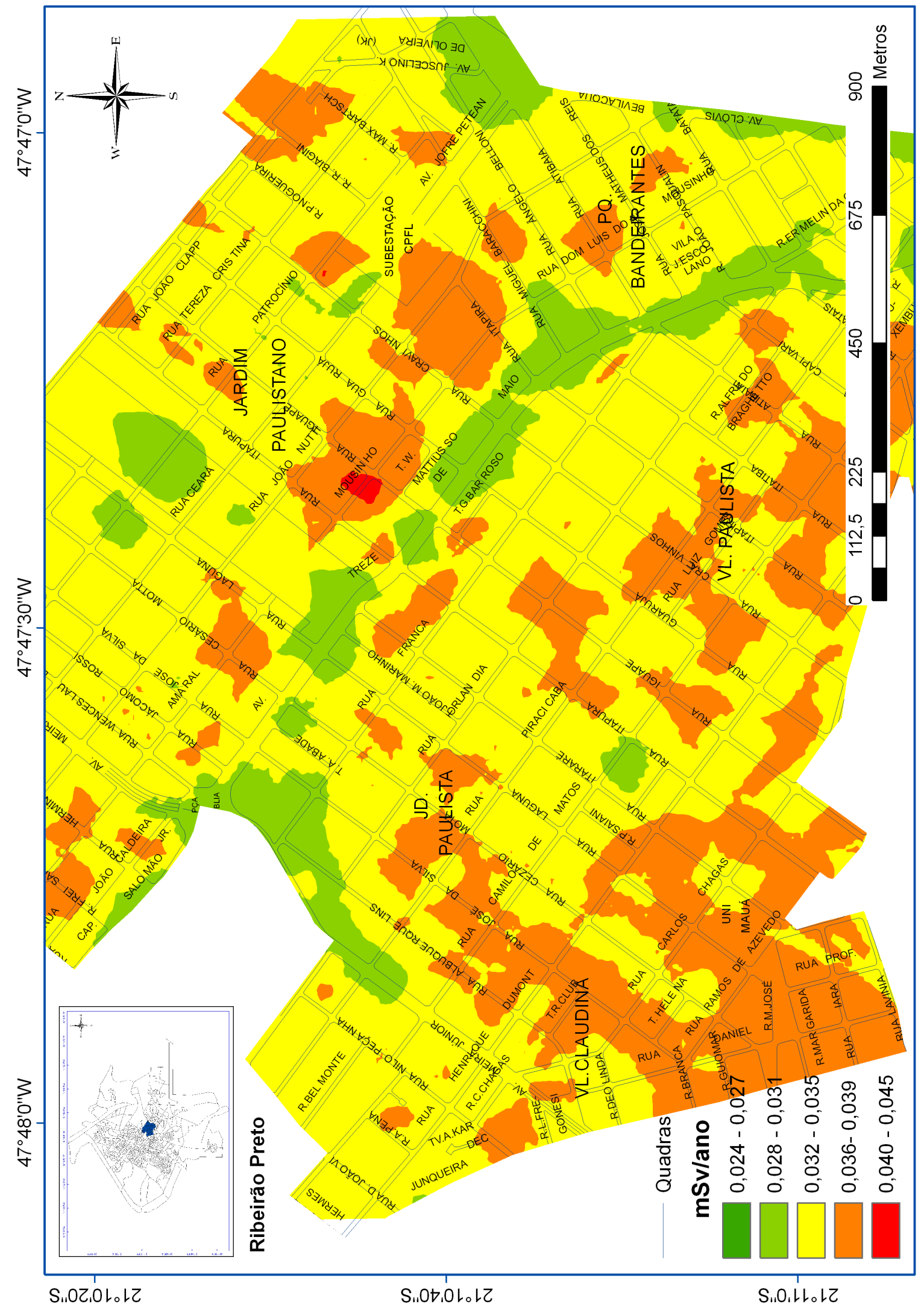

Figura 4.8. Distribuição espacial das doses efetivas anuais para a região do Jardim Paulista. 


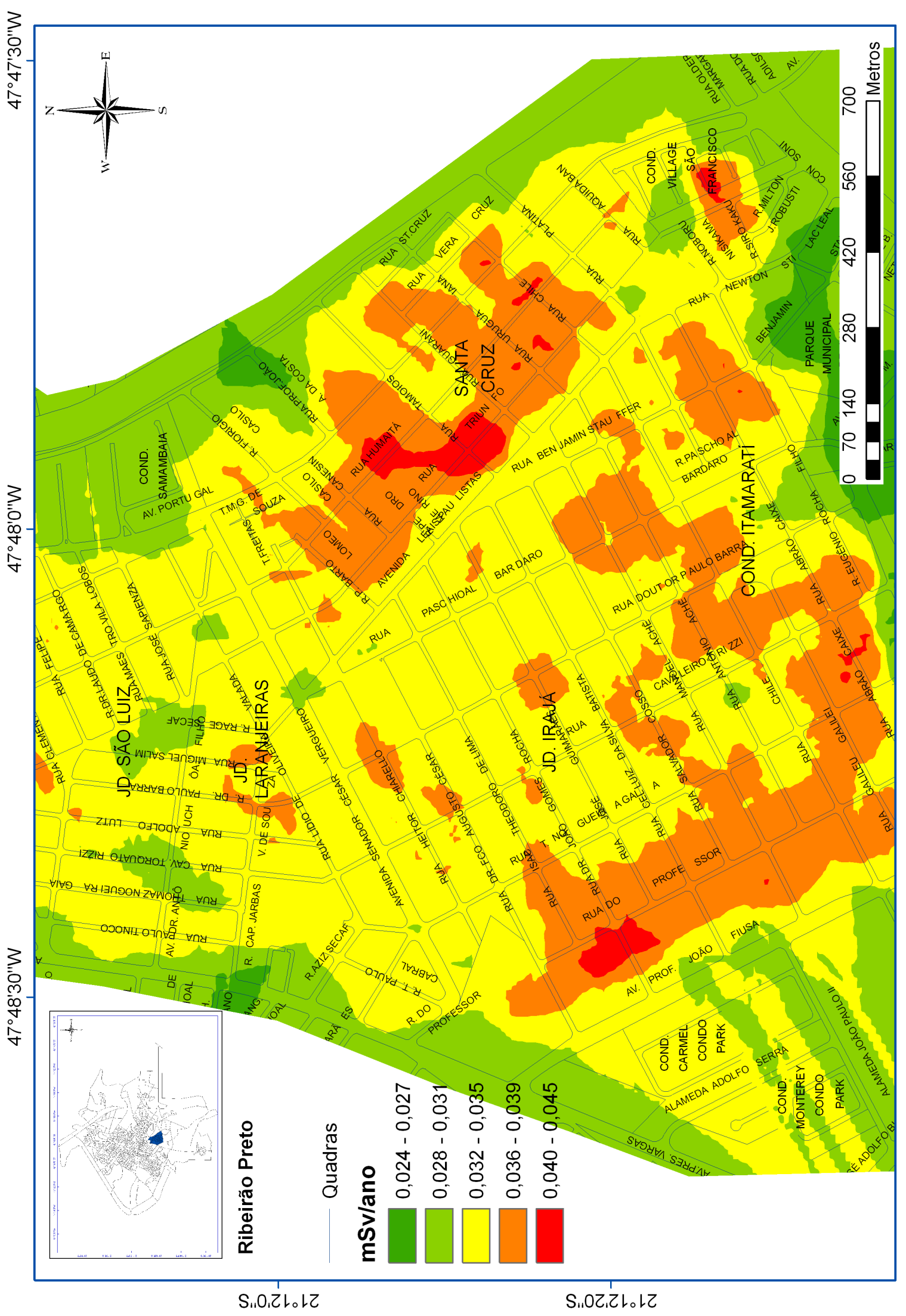

Figura 4.9. Distribuição espacial das doses efetivas anuais para a região do Jardim Irajá. 


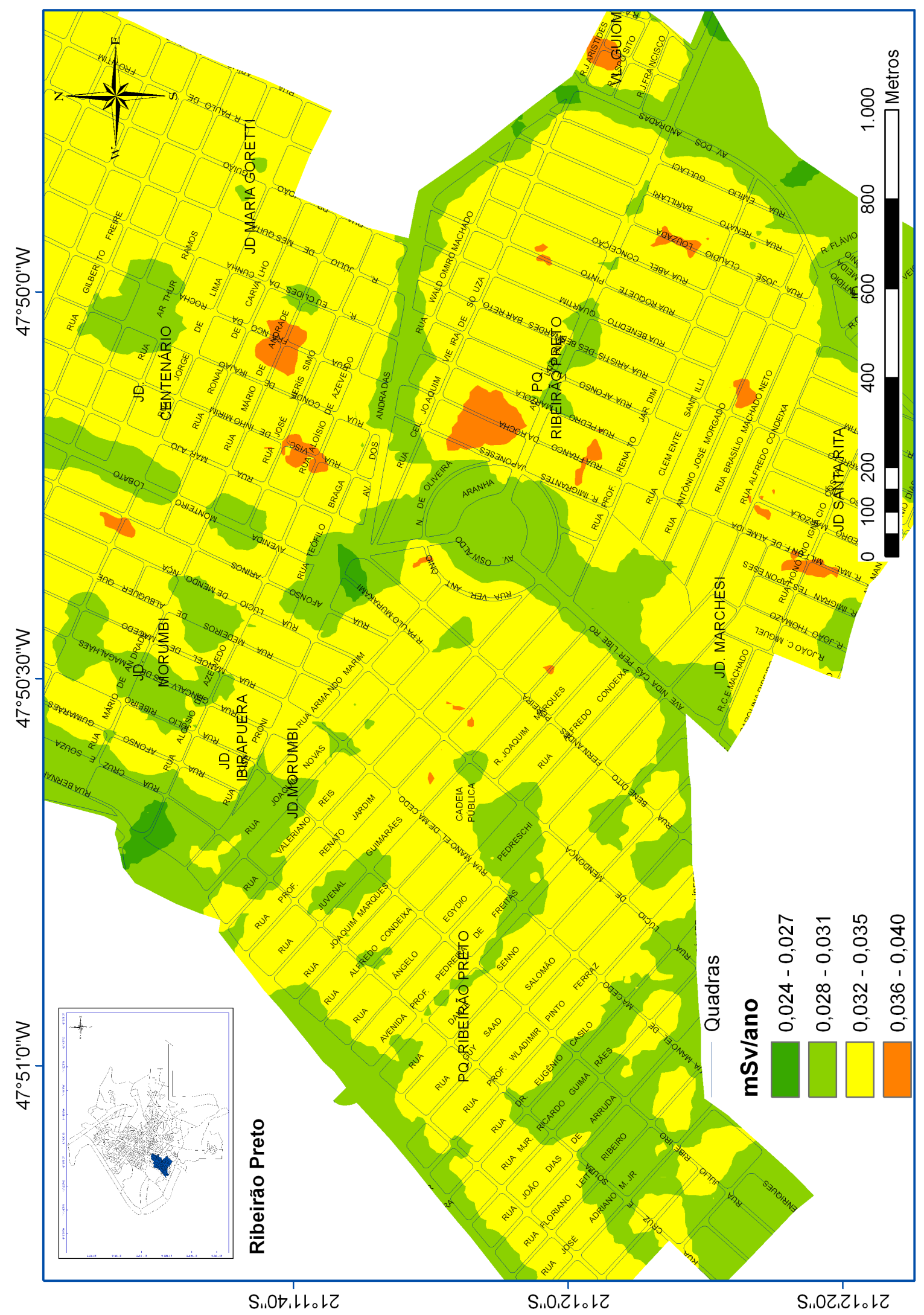

Figura 4.10. Distribuição espacial das doses efetivas anuais para a região do Parque Ribeirão Preto. 


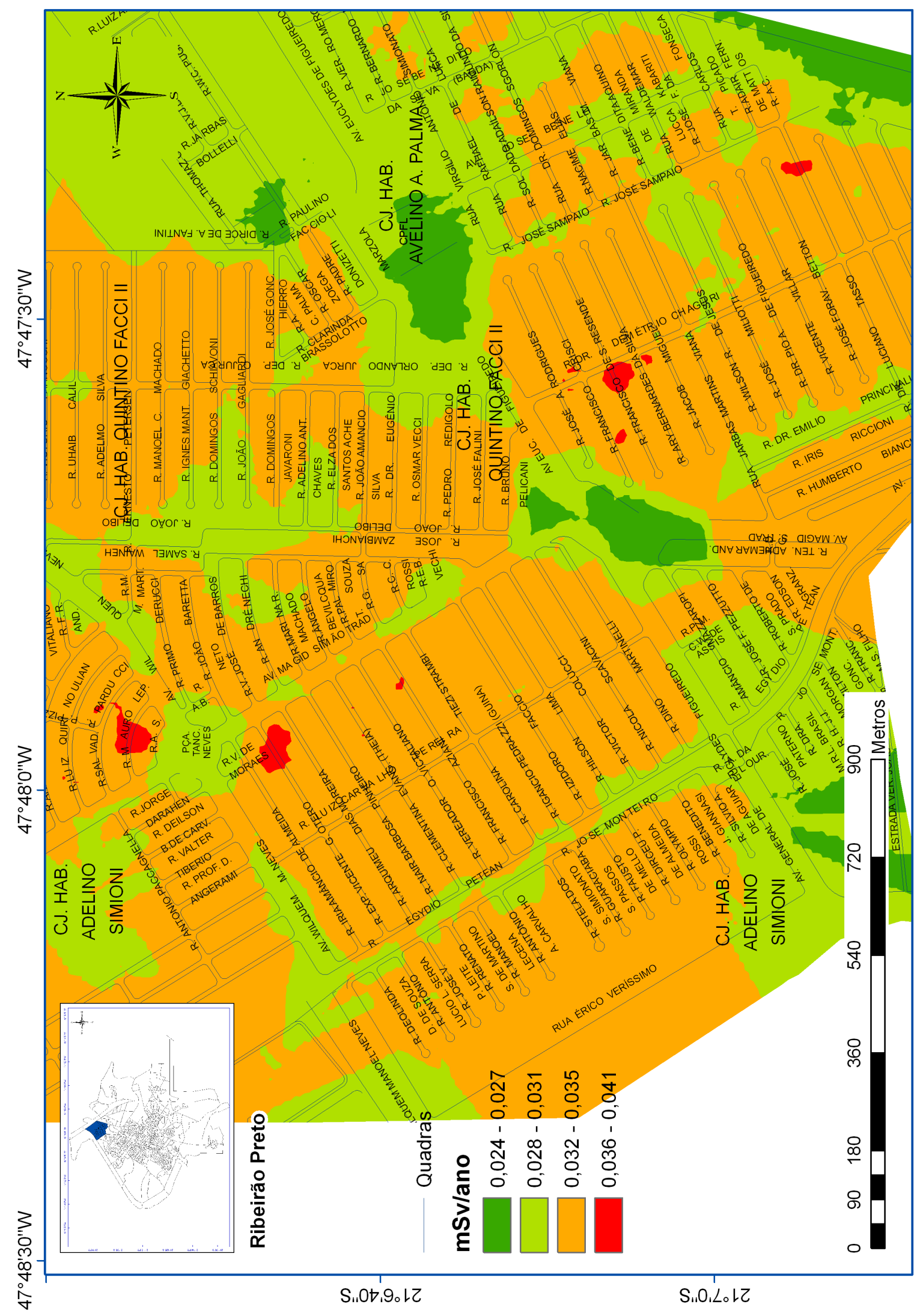

Figura 4.11. Distribuição espacial das doses efetivas anuais para a região do conjunto Quintino/Simioni. 


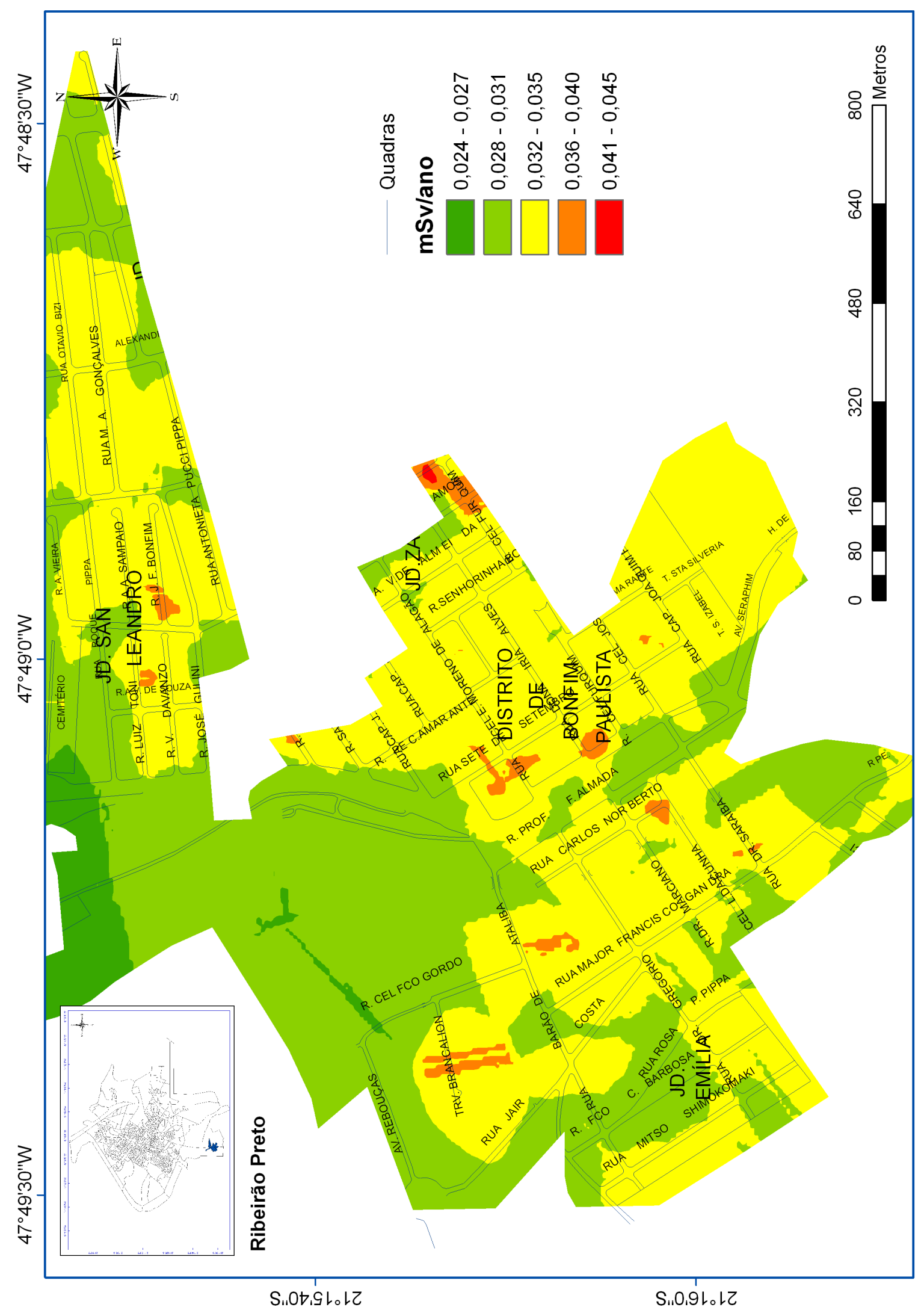

Figura 4.12. Distribuição espacial das doses efetivas anuais para a região de Bonfim Paulista. 


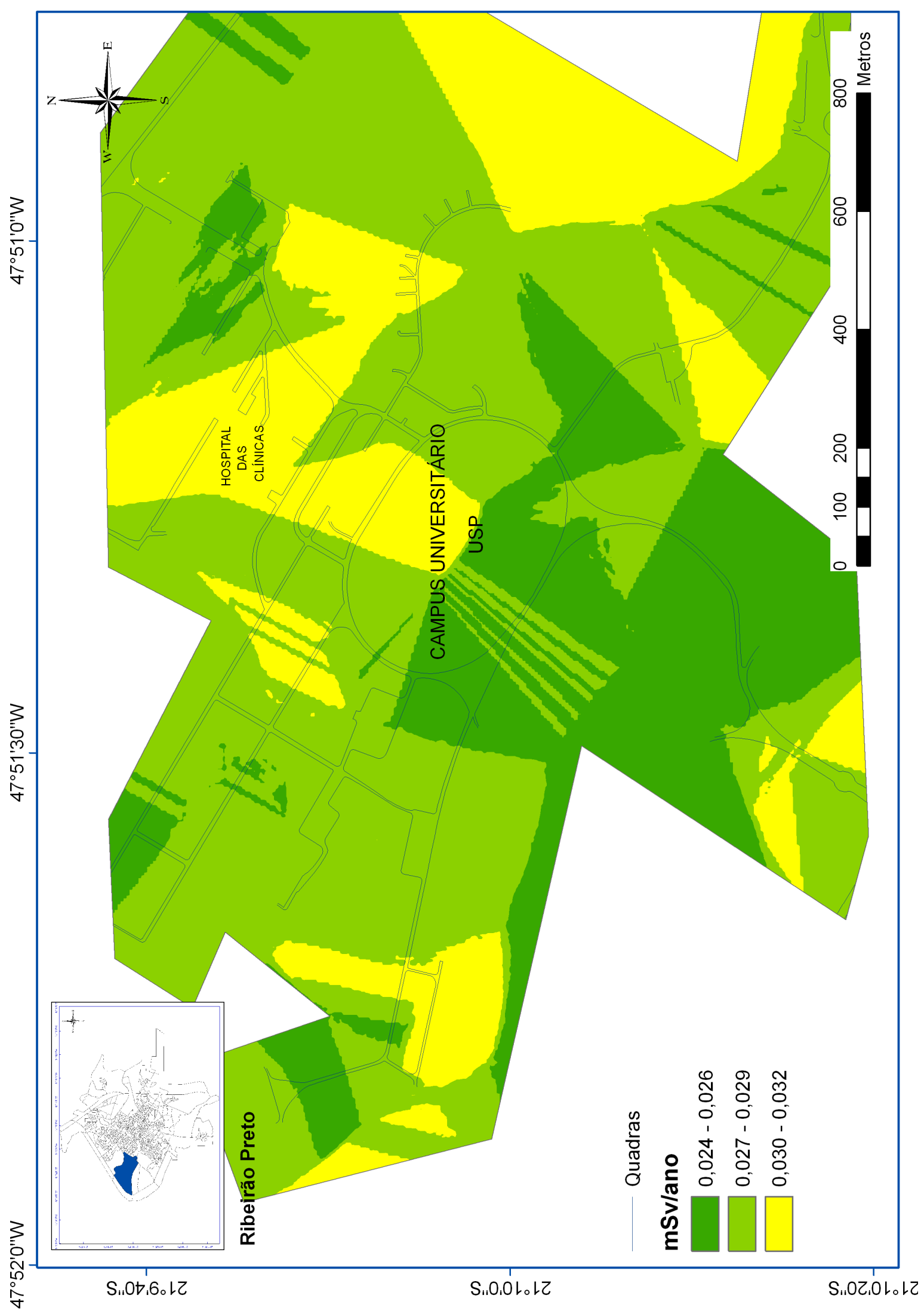

Figura 4.13. Distribuição espacial das doses efetivas anuais para a região do Campus da USP. 


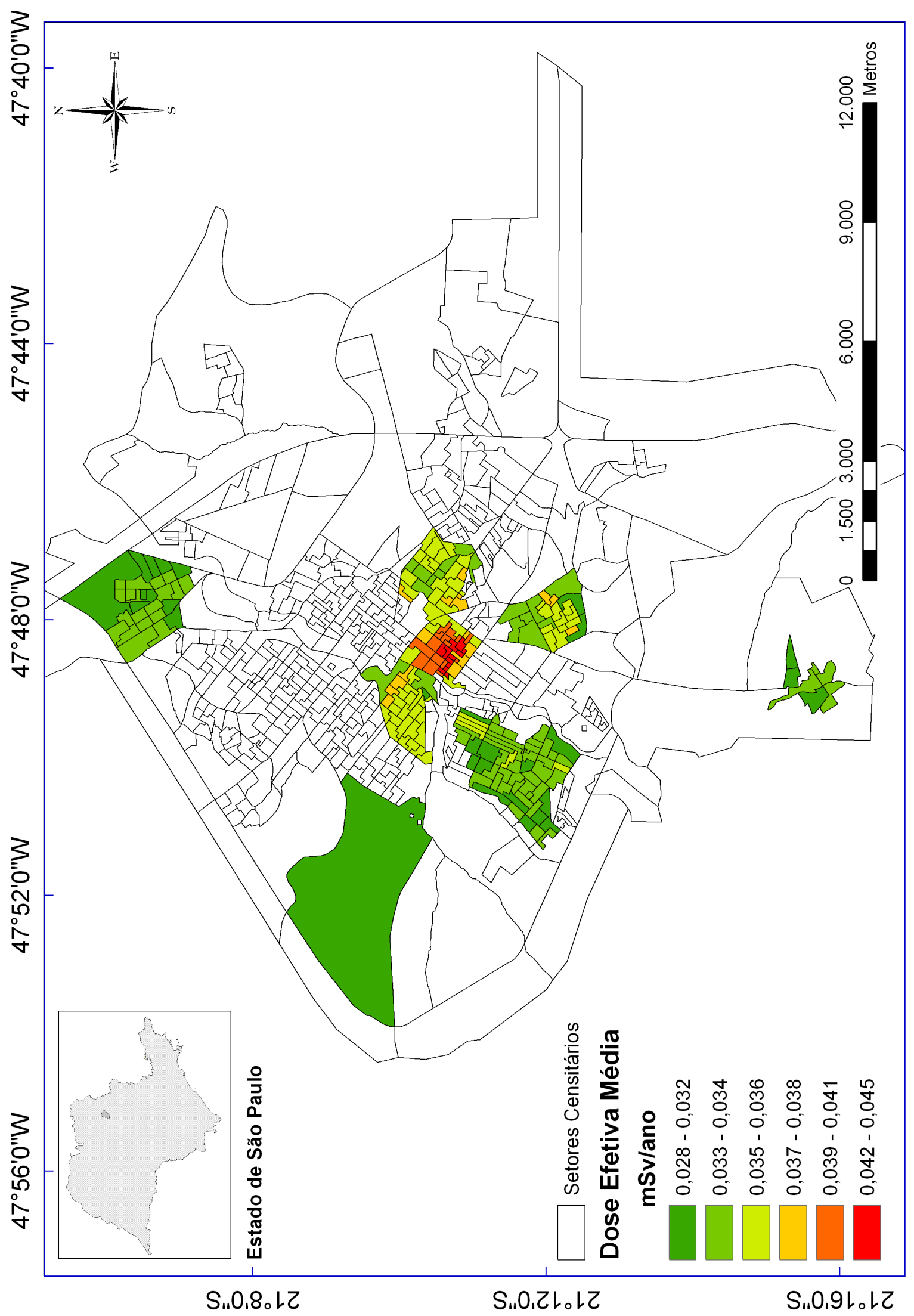

Figura 4.14. Dose efetiva anual média para cada setor censitário, sendo a média geral de $0,034 \pm 0,004 \mathrm{mSv} /$ ano. 


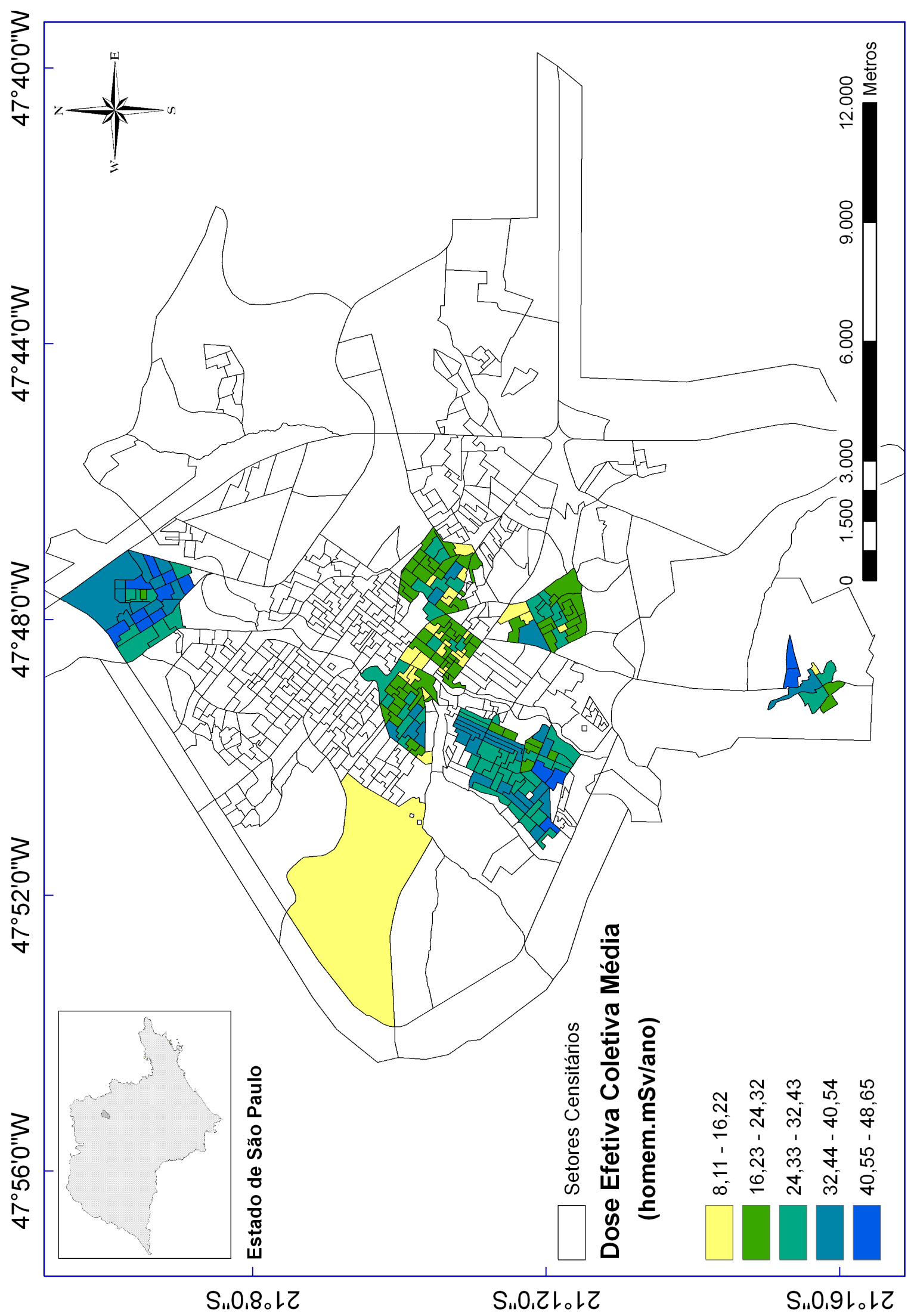

Figura 4.15. Dose efetiva coletiva anual média para cada setor censitário, sendo a média geral de 25,62 \pm 9, 26 homem mSv/ano. 


\section{Capítulo}

\section{CONCLUSÕES}

Medidas de taxa de dose absorvida no ar, segundo a radiação gama ambiental, foram realizadas na cidade de Ribeirão Preto para avaliar os níveis de dose efetiva e dose efetiva coletiva que a população está submetida. Estes valores foram comparados a outros de trabalhos realizados em outras cidades brasileiras e também aos descritos pela UNSCEAR. Para tal, foi utilizado um sistema de detecção baseado em cintilador orgânico plástico FHT 1376, calibrado inicialmente com ${ }^{137} \mathrm{Cs}$.

Das medidas utilizando a fonte de ${ }^{137} \mathrm{Cs}$, foi verificado que o modo de leitura "taxa de dose" em Sv/h não faz referência exatamente às grandezas de proteção (dose efetiva, dose equivalente). A calibração das duas escalas de leitura, utilizando a fonte de ${ }^{137} \mathrm{Cs}$ e a sua constante $\left.\Gamma\left[\mathrm{C} / \mathrm{kg} \cdot \mathrm{m}^{2} \text {.(Bq.h }\right)^{-1}\right]$ para obter a taxa de exposição por hora $\left[\mathrm{R} / \mathrm{h}\left(2,58 \cdot 10^{-4} \mathrm{C} / \mathrm{kg} \cdot \mathrm{h}^{-1}\right)\right]$, permitiu a utilização do referido sistema para obtenção das leituras de taxa de dose absorvida no ar. Foi verificado que "taxa de exposição" corresponde diretamente a uma escala de taxa de exposição no ar $[\mathrm{R} / \mathrm{h}$ $\left.\left(2,58 \cdot 10^{-4} \mathrm{C} / \mathrm{kg} \cdot \mathrm{h}^{-1}\right)\right]$ e a escala de "taxa de dose" corresponde a escala de taxa de dose absorvida no ar [Gy/h], com um fator entre as duas de $\approx 100$ (1 Gy $\approx 100 \mathrm{R}$ ).

Uma comparação das respostas do sistema FHT 1376 foi feita com resultados publicados obtidos com fontes extensas no IRD, para as mesmas fontes e condições de geometria. Os resutados obtidos mostraram incertezas de $1 \%$ até $15 \%$ com uma média de 8,7\% que se encontram dentro do limite recomendado pela CNEN [59], para detectores portáteis de radiação gama, que é de $\pm 20 \%$.

Para o cálculo das doses efetivas coletivas e o cálculo do valor médio da dose efetiva anual da cidade, foi necessário coletar as informações sobre a população de cada setor censitário, disponíveis pelo IBGE. Até a conclusão deste trabalho, 
as tabelas disponíveis eram relativas somente ao censo de 2000, enquanto que as informações do censo realizado em 2010 ainda não tinham sido finalizadas (dados insuficientes) para o cálculo das doses e para a composição dos mapas.

Cerca de 45.400 medidas georreferenciadas de taxa de dose absorvida no ar foram realizadas nas oito regiões urbanas selecionadas, que variaram de 17, $7 \mathrm{nGy} / \mathrm{h}$ até 85, $2 \mathrm{nGy/h,} \mathrm{com} \mathrm{uma} \mathrm{média} \mathrm{de} \mathrm{27,38 \pm 2,} 41 \mathrm{nGy/h}$, levando às taxas de dose efetiva de $12,2 \mathrm{nSv} / \mathrm{h}$ até $59,8 \mathrm{nSv} / \mathrm{h}$. As maiores taxas de dose absorvida se encontram nas regiões centrais da cidade, como esperado, uma vez que nessas regiões se encontra a maior concentração de concreto, asfalto e pessoas, ou seja maior concentração de radionuclídeos, e portanto maiores taxas de dose absorvida devido a radiação gama natural ao ar livre. O menor nível de taxa de dose absorvida foi encontrado na região do Campus universitário da USP, cuja área, em sua maior parte é coberta por vegetação. Desses resultados, pôde-se entender como a composição dos solos das diferentes regiões contribui diretamente aos níveis de radiação terrestre natural ao ar livre. Ainda, uma vez que dentre as regiões urbanas mais afastadas do centro (coroa circular 4 até 10) a diferença entre as médias de taxa de dose efetiva não foi maior que $6,5 \%$, é possível inferir que a composição dos solos desses locais deve ser semelhante.

As médias anuais da dose efetiva e dose efetiva coletiva para ambientes ao ar livre foram encontradas respectivamente com os valores $0,034 \pm 0,004 \mathrm{mSv} /$ ano e 25, $62 \pm 9,25$ homem.mSv. A primeira é cerca de metade da média mundial da dose efetiva publicada pela UNSCEAR $(0,07 \mathrm{mSv} / \mathrm{ano})$, que também é baixa quando comparada às encontradas em outros estudos sobre dose de radiação gama ao ar livre no território brasileiro, como: Poços de Caldas/MG, Guarapari/ES, Andradas/MG, Caldas/MG, regiões de alta radioatividade natural, onde as médias de taxas de dose absorvida no ar podem chegar a $144,5 \mathrm{nGy} / \mathrm{h}[8,36]$ (cerca de 5,3 vezes maiores que o valor médio de Ribeirão Preto). As taxas de dose absorvida no ar obtidas em Ribeirão Preto comparadas aquelas de outras cidades, como no centro CTMSP de Aramar, Iperó/SP e São Paulo/SP [9] são 1,7 e 3 vezes menores respectivamente.

Finalmente, através dos valores médios anuais da dose efetiva e dose efetiva coletiva devido a radiação gama natural ao ar livre das diversas regiões, foram feitos mapas de Ribeirão Preto, permitindo a visualização deste trabalho de forma mais 
detalhada, já que cada rua de cada região avaliada tem sua identidade radiométrica apresentada. Sendo que os valores encontrados são mais baixos que aqueles descritos na literatura, pode-se dizer que a região de Ribeirão Preto é uma área de baixa radioatividade natural, por geologicamente ter em sua composição rochas com baixa atividade de emissão, de 0,034 $\pm 0,004 \mathrm{mSv} /$ ano da dose efetiva média anual da radiação gama natural ao ar livre. Este valor pode ser utilizado para ser comparado com os níveis de radioatividade em outras áreas de interesse no país, o que possibilitaria identificar anomalias, caso existentes, e permitir planejamentos e políticas de proteção. 


\section{REFERÊNCIAS BIBLIOGRÁFICAS}

1 UNSCEAR. Sources, effects and risks of ionizing radiation, report to the general assembly with scientific annexes. United Nations Scientific Committee on Effects of Atomic Radiation, 2000. 1, 2

2 UNSCEAR. Sources and effects of ionizing radiation, report to the general assembly with scientific annexes. United Nations Scientific Committee on Effects of Atomic Radiation, 2008. 1, 2, 7, 8, 29, 35, 59, 60, 61

3 FERREIRA, A. O.; PECEQUILO, B. R. S. Natural radioactivity assessment by gamma spectrometry in some commercially-used granites from paraná state, brazil: Preliminary results. Radioprotection, v. 46, p. S43-S47, 2011. 1

4 BRINDHA, J. T.; RAJARAM, S.; KANNAN, V. A comparative study of body potassium content in males and females at kalpakkam (india). Radiation Protection Dosimetry, v. 123, n. 1, p. 36-40, 2007. 2, 8

5 AMARAL, E.; ROCHEO, E.; PARETZKE, H. The radiological impact of agricultural activities in an area of high natural radioactivity. Radiation Protection Dosimetry, v. 45, p. $289-292,1992.2$

6 PFEIFFER, W. C.; PENNA-FRANCA, E.; RIBEIRO, C. C. Measurements of environmental radiation exposure dose rates at selected sites in brazil. Academia Brasileira de Ciências, v. 53, p. 683 - 691, 1981. 2

7 VEIGA, L.; AMARAL, E.; MAGALHãES, M. Brazilian areas of elevated levels of natural radiation: a critical review and relevant future studies. Second Symposium on Technologically Enhanced Natural Radiation, Rio de Janeiro, 1999. 2

8 SACHETT, I. A. Caracterização da Radiação Gama Ambiental em Áreas Urbanas utilizando uma Unidade Móvel de Rastreamento. Tese (Doutorado) Universidade do Estado do Rio de Janeiro, 2002. 3, 12, 37, 38, 50

9 YOshimurA, E. M.; OTSUBO, S. M.; OliveiRA, R. E. R. Gamma ray contribution to the ambient dose rate in the city of sao paulo, brazil. Radiation 
Measurements, Pergamon-elsevier Science Ltd, v. 38, n. 1, p. 51-57, fev. 2004. 3, $12,37,38,50$

10 MORAES, M. A. P. V. de; DALTRO, T. F. L. Environmental gamma radiation and natural radioactivity in soils in centro experimental aramar (ctmsp-brazil) and region. Radiation Protection Dosimetry, Nuclear Technology Publ, v. 87, p. 207-211, 2000. 3, 12, 37, 38

11 CARneiro, J. C. G.; BETTi, F.; SAnChES, M. P.; SORDI, G. M. A. A.; PECEQUILO, B. R. S. Assessment of the environmental outdoor gamma radiation levels in são paulo city. International Journal of Low Radiation, v. 7, p. 359 - 365, 2010. $3,12,37,38$

12 ICRP. Publication 60 - recommendations of the international commission on radiological protection. International Commission on Radiological Protection, Pergamon Press, Oxford, n. v. 21-23, 1991. 3, 11, 15, 16, 35, 66

13 PNUD. Programa das Nações Unidas para o Desenvolvimento Acesso em Fevereiro/2012. Disponínel em www.pnud.org.br. 3

14 IPRS. Índice Paulista de Responsabilidade Social Acesso em Fevereiro/2012. Disponível em www.saopaulo.sp.gov.br. 3

15 BASTOS, G. Estruturação de Banco de Dados a Partir do Mapeamento Geotécnico Aplicado à Região de Ribeirão Preto (SP). Tese (Doutorado) Universidade de São Paulo, Escola de Engenharia de São Carlos, 2005. 3

16 MENEZES, D. P. Introdução à física nuclear e de partículas elementares. Editora da UFSC, p. 186, 2002. 5

17 PODGORSAK, E. B. Radiation physics for medical physicists. Springer Berlin Heidelberg, 2010. 6, 7, 9, 62

18 ATTIX, F. H. Introduction to radiological physics and radiation dosimetry. John Wiley \& Sons, John Wiley \& Sons, 1986. 6, 9, 10, 15, 22, 32

19 EISBERG, R.; RESNICK, R. Física quântica de Átomos, moléculas, sólidos, núcleos e partículas. Editora Campus, 1974. 7 
20 IAEA. Tecdoc 1363 - guidelines for radioelement mapping using gamma ray spectrometry data,. International Atomic Energy Agency, International Atomic Energy Agency, Vienna, 2003. 8, 10, 17, 23

21 SABOL, J.; WENG, P. Introduction to radiation protection dosimetry. World Scientific, 1995. 8, 61

22 ICRP. Publication 23 - reference man: Anatomical, physiological, and metabolic characteristics. International Commission on Radiological Protection, $\mathrm{n}$. Publication 23, 1976. 8, 61

23 AFFOnSECA, M. de; AlveS, R.; JúNIOR, J.; ALMEIDA, C. de. The influence of urbanization on natural radiation levels in anomalous areas. Journal of Environmental Radioactivity, v. 63, p. $65-75,2002.8$

24 Anjos, R.; AYUB, J.; CID, A.; CARDOSO, R.; LACERDA, T. External gamma-ray dose rate and radon concentration in indoor environments covered with brazilian granites. Journal of Environmental Radioactivity, v. 102, p. 1055 - 1061, 2011. 8

25 KUCUKOMEROGLU, B.; KURNAZ, A.; DAMLA, N.; CEVIK, U.; CELEBI, N.; ATAKSOR, B.; TASKIN, H. Environmental radioactivity assessment for bayburt, turkey. Journal of Radiological Protection, v. 29, p. $417-428,2009.8$

26 HALL, E.; GIACCIA, A. Radiobiology for the radiologist. Lippincott Williams \& Wilkins, 2006. 11

27 CNEN. Nn 3.01 - diretrizes básicas de proteção radiológica. Comissão Nacional de Energia Nuclear, Rio de Janeiro, 2005. 11, 35, 66

28 CONTI, C. de C. Medida de Kerma no Ar e Determinação de Coeficientes de Conversão para Dose devido à Radiação Gama Ambiental. Tese (Doutorado) Universidade Federal do Rio de Janeiro, 1999. 12, 25, 33, 34, 67

29 YOSHIMURA, E. M.; UMISEDO, N. K.; OKUNO, E. Assessment of ambient dose equivalent rate: performance of an automatic survey meter as an instrument to quantify the presence of radiation in soils. Nuclear Instruments $\mathscr{G}$ Methods In 
Physics Research Section A-accelerators Spectrometers Detectors and Associated Equipment, v. 487, n. 3, jul. 2002. 12, 32

30 ALENCAR, A. S.; FREITAS, A. C. Reference levels of natural radioactivity for the beach sands in a brazilian southeastern coastal region. Radiation Measurements, v. 40 , p. $76-83,2005.12$

31 GRASTY, R. L.; LAMARRE, J. R. The annual effective dose from natural sources of ionising radiation in canada. Radiation Protection Dosimetry, v. 108, n. 3, p. 215-226, 2004. 12

32 SAGHATCHI, F.; SAlOUTI, M.; ESLAMI, A.; SHARAFI, A. Natural radioactivity levels of (226)ra and (40)k in soil of zanjan province, iran. Radiation Protection Dosimetry, v. 141, n. 1, p. 86-89, set. 2010. 12

33 PAPP, Z. Natural radioactivity in the soils of some eastern counties of hungary. Radiation Protection Dosimetry, v. 141, n. 1, p. 56-63, set. 2010. 12

34 IAEA. Trs 323 - airborne gamma ray spectrometer surveying. International Atomic Energy Agency, Vienna, 1991. 12, 17

35 ICRU. Report 53 - gamma-ray spectrometry in the environment. International Commission on Radiation Units and Measurements, International Commission on Radiation Units and Measurements, 1994. 12, 17

36 SILVA, N. C.; MACACINI, J. F.; ALBERTI, H. L. C. Geoprocessing as a technical tool for radiological assessment in the urban area of poços de caldas, mg. 2009 International Nuclear Atlantic Conference, Rio de Janeiro, 2009. 12, 37, 38, 50

37 TASKIN, H.; KARAVUS, M.; AY, P.; TOPUZOGLU, A.; HIDIROGLU, S.; KARAHAN, G. Radionuclide concentrations in soil and lifetime cancer risk due to gamma radioactivity in kirklareli, turkey. Journal of Environmental Radioactivity, v. 100 , n. 1 , p. $49-53$, jan. 2009. 12

38 KNOLL, G. F. Radiation detection and measurement. John Wiley ES Sons, John Wiley \& Sons, Terceira Edição, 2010. 12, 13 
39 ELY, J. H.; KOUZES, R. T.; GEELHOOD, B. D.; SCHWEPPE, J. E.; WARNER, R. A. Discrimination of naturally occurring radioactive material in plastic scintillator material. Ieee Transactions On Nuclear Science, v. 51, n. 4, p. IEEE, ago. 2004. 12

40 MUKHOPADHYAY, S. Plastic gamma sensors: an application in detection of radioisotopes. Hard X-ray and Gamma-ray Detector Physics V, v. 5198, p. SPIE, 2004. 13

41 KWAK, S.-W.; YOO, H.-S.; JANG, S. S.; KIM, J. S.; YOON, W.-K.; JUN, I. S.; KIM, K. H. Plastic scintillator-based radiation detector for mobile radiation detection system against nuclear/radiological terrorism. Nuclear Instruments $\mathscr{E}$ Methods In Physics Research Section A-accelerators Spectrometers Detectors and Associated Equipment, v. 604, n. 1-2, p. 161-163, jun. 2009. 13

42 ELY, J.; ANDERSON, K.; BATES, D.; KOUZES, R.; PRESTI, C. L.; RUNKLE, R.; SICILIANO, E.; WEIER, D. The use of energy information in plastic scintillator material. Journal of Radioanalytical and Nuclear Chemistry, v. 276, n. 3 , p. $743-748$, jun. 2008. 13

43 Almeida, A. de; MOnteiro, A. J. C.; PACAGnella, E. Z. A. Braquiterapia intracavitária na neoplasia uterina. Revista Gaúcha de Enfermagem, v. 13, p. $42-48,1992.13$

44 ICRU. Report 60 - fundamental quantities and units for ionizing radiation. International Commission on Radiation Units and Measurements, 1998. 13, 14, 15

45 ICRP. Publication 74 - conversion coefficients for use in radiological protection against external radiation. International Commission on Radiological Protection, 1995. 13

46 CNEN. Posição regulatória 3.01/002:2011 - fatores de ponderação para as grandezas de preteção radiológica. Comissão Nacional de Energia Nuclear, 2011. 16

47 ESM, T. E. Mobile radioactivity measurement system fht 1376 (manual do fabricante). 1997. 17, 18 
48 SILVA, T. I.; RODRIGUES, S. C. Tutorial de cartografia geomorfológica arcgis 9.2 e envi 4.0. Revista Geográfica Acadêmica, 2009. 21

49 INPE. Sistema de Processamento de Informações Georeferenciadas. Instituto Nacional de Pesquisas Espaciais Janeiro, 2012. 21

50 NONATO, F. B. C. Estudo da Resposta de Monitores de Radioproteção em Feixes Padronizados de Radiação X, Gama e Beta. Dissertação (Mestrado) Instituto de Pesquisas Energéticas e Nucleares, 2010. 22

51 PROJETO Planalto Poços de Caldas Pesquisa Câncer e Radiação Natural. Minas Gerais - Brasil, 2004 a 2009. 23

52 IAEA. Nuclear energy series nf-t-1.3 - radioelement mapping. International Atomic Energy Agency, International Atomic Energy Agency, Vienna, 2010. 23, 24, 25,29

53 WISSMANN, F. Variations observed in environmental radiation at ground level. Radiation Protection Dosimetry, v. 118, n. 1, p. 3-10, abr. 2006. 23

54 BOUVILLE, A.; LOWDER, W. M. Human-population exposure to cosmic-radiation. Radiation Protection Dosimetry, v. 24, n. 1-4, p. 293-299, 1988. 23

55 IAEA. Technical reports series 309 - construction and use of calibration facilities for radiometric field equipment. International Atomic Energy Agency, International Atomic Energy Agency, Vienna, 1989. 23

56 BARreto, P. M. C.; AUsterlitz, C.; MAlheiros, T.; LOVBORG, L. Radioactive concrete sources at ird/cnen, brazil, for the calibration of uranium exploration and environmental fields instruments. Instituto de Radioproteção e Dosimetria, 1986. 24

57 IBGE. Instituto Brasileiro de Geografia e Estatística Acesso em setembro/2010. Disponínel em www.ibge.gov.br. 26, 36 
58 SAITO, K.; PETOUSSI-HENSS, N.; ZANKL, M. Calculation of the effective dose and its variation from environmental gamma ray sources. Health Physics, v. 74, n. 6 , p. $698-706$, jun. 1998. 29

59 CNEN. Nn 6.04 - funcionamento de serviços de radiografia industrial. Comissão Nacional de Energia Nuclear, 1989. 34, 49

60 ABNT. Nbr 10011 - medidores e monitores portáteis de taxa de exposição de raios-x e gama, para uso em radioproteção. Associação Brasileira de Normas Técnicas, 1987. 34

61 IAEA. Safety series 115 - international basic safety standards for protection against ionizing radiation and for the safety of radiation sources. International Atomic Energy Agency, 1996. 35

62 TAUhATA, L.; SAlATI, I. P. A.; PRInZIO, R. D.; PRINZIO, A. R. D. Radioproteção e dosimetria: Fundamentos. Instituto de Radioproteção e Dosimetria, 2003. 60,61

63 LNHB. Laboratoire National Henri Becquerel Acesso em fevereiro/2012. Disponível em www.nucleide.org. 61 


\section{APÊNDICE}

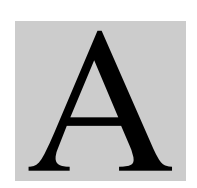

\section{APÊNDICE}

\section{Grandezas Radiológicas}

Tabela A.1. Grandezas radiológicas (antigas e atuais) e suas unidades.

\begin{tabular}{|c|c|c|c|c|c|}
\hline \multirow[t]{2}{*}{ Grandeza } & \multirow[t]{2}{*}{ Símbolo } & \multicolumn{2}{|c|}{ Unidade } & \multicolumn{2}{|l|}{ Valor } \\
\hline & & Antiga & Atual $^{1}$ & Antiga & Atual $^{1}$ \\
\hline Atividade & $\mathrm{A}$ & curie $(\mathrm{Ci})$ & becquerel (Bq) & $3,7.10^{10} s^{-1}$ & $1 s^{-1}$ \\
\hline Exposição & $\mathrm{X}$ & röntgen $(\mathrm{R})$ & $1 C \cdot k^{-1}$ & $2,58.10^{-4} C . \mathrm{kg}^{-1}$ & $1 C \cdot k g^{-1}$ \\
\hline Kerma & $\mathrm{K}$ & kerma $(\mathrm{K})$ & gray (Gy) & $\operatorname{rad}\left(100\right.$ erg. $\left.g^{-1}\right)$ & $1 \mathrm{~J} . \mathrm{kg}^{-1}$ \\
\hline Dose Absorvida & $\mathrm{D}$ & $\mathrm{rad}$ & gray (Gy) & $\operatorname{rad}\left(100 \mathrm{erg} \cdot g^{-1}\right)$ & $1 \mathrm{~J} . \mathrm{kg}^{-1}$ \\
\hline Dose Equivalente & $\mathrm{H}$ & rem & sievert $(\mathrm{Sv})$ & $\operatorname{rem}\left(100 \mathrm{erg} . g^{-1}\right)$ & $1 \mathrm{~J}^{\mathrm{kg}} \mathrm{g}^{-1}$ \\
\hline
\end{tabular}

(1) A partir de 1985.

\section{Radionuclídeos Naturais}

Os radionuclídeos naturais terrestres podem fazer parte de três séries radioativas naturais, a série do urânio, do actínio e do tório, que terminam em isótopos estáveis do chumbo $\left({ }^{206} \mathrm{~Pb},{ }^{207} \mathrm{~Pb}\right.$ e $\left.{ }^{208} \mathrm{~Pb}\right)$. Além dessas séries, existem ainda outros radionuclídeos de ocorrência natural terrestrial, que não fazem parte de nenhuma das séries radioativas como o ${ }^{87} \mathrm{Rb},{ }^{138} \mathrm{La},{ }^{147} \mathrm{Sm},{ }^{176} \mathrm{Lu}$, e ${ }^{40} \mathrm{~K}$ [2]. Este último radioisótopo mais as séries naturais são descritos a seguir. 
Série do Urânio

O Urânio natural é constituído principalmente de quatro isótopos $\left({ }^{230} \mathrm{U},{ }^{234} \mathrm{U}\right.$, ${ }^{235} \mathrm{U} \mathrm{e}^{238} \mathrm{U}$ ), sendo mais abundante o ${ }^{238} \mathrm{U}$ com cerca de 99, 28\% (Figura A.1 [62]). Este radioisótopo tem meia-vida de $4,47.10^{9}$ anos, decaindo inicialmente por emissão alfa dando origem ao núcleo do ${ }^{234} \mathrm{Th}$. Esta série termina no núcleo estável ${ }^{206} \mathrm{~Pb}$, como mostrado na Tabela A.2. O ${ }^{238} \mathrm{U}$ é encontrado na maioria das rochas e solos e sua detecção no meio ambiente se dá pela medida da radiação $\gamma$ de energia $1,765 \mathrm{MeV}$ de seu filho ${ }^{214} \mathrm{Bi}$. O ${ }^{238} \mathrm{U}$ se incorporado no ser humano é depositado principalmente nos ossos, seguido pelos pulmões e rins [2]. Nesta série de decaimento, encontra-se o ${ }^{226} \mathrm{Ra}$, filho do ${ }^{230} \mathrm{Th}$ por emissão alfa, que tem por descendente direto o gás ${ }^{222} \mathrm{Rn}$, responsável pelas maiores exposições internas por inalação.

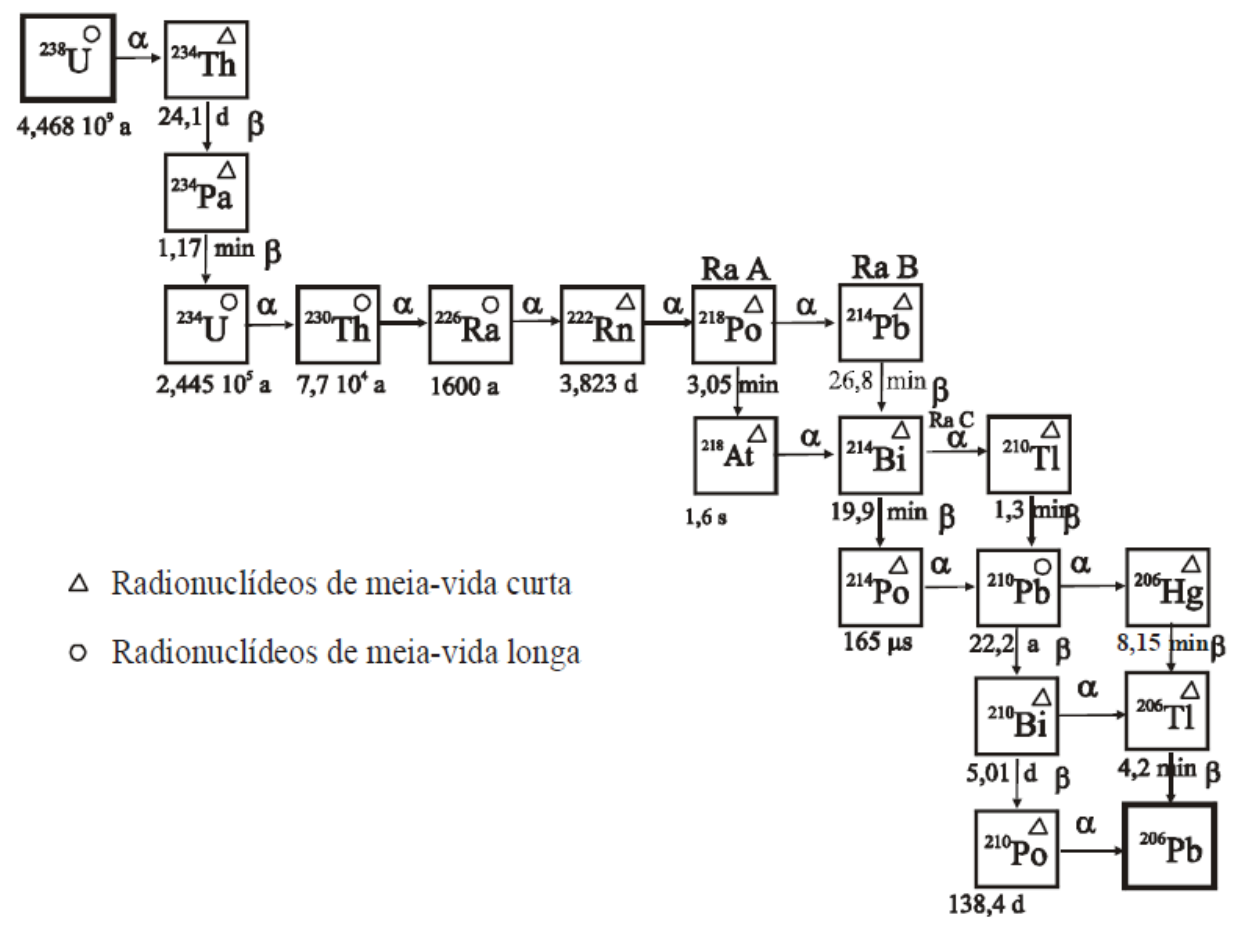

Figura A.1. Série radioativa do ${ }^{238} U$, retirado de [62].

Série do Actínio

A série do ${ }^{235} \mathrm{U}$, cuja meia-vida é de $0,704.10^{9}$ anos, decai inicialmente para ${ }^{231}$ Th, por emissão alfa. Este ${ }^{235} \mathrm{U}$ é encontrado na natureza em baixa proporção, comparada aos outros radionuclídeos do urânio, com cerca de $0,72 \%$. A cadeia deste radioisótopo é mostrada na Tabela A.3, que termina no núcleo estável de ${ }^{207} \mathrm{~Pb}$. 
Série do Tório

A série do ${ }^{232}$ Th (Figura A.2 [62]) se inicia por decaimento alfa gerando o ${ }^{228} \mathrm{Ra}$, e terminando no núcleo estável de ${ }^{208} \mathrm{~Pb}$, mostrado na Tabela A.4. Este radionuclídeo tem meia-vida de $14,05.10^{9}$ anos e sua detecção se dá pela medida do filho ${ }^{208} \mathrm{Tl}$ de energia $\gamma 2,614 \mathrm{MeV}$. De acordo com dados publicados pela UNSCEAR, no corpo humano a deposição dos radionuclídeos dessa série se dá principalmente nos ossos e pulmões. Em média a concentração de ${ }^{232} \mathrm{Th}$ e ${ }^{238} \mathrm{U}$ nos solos, tem valores próximos, respectivamente de $30 \mathrm{~Bq} / \mathrm{kg}$ e $35 \mathrm{~Bq} / \mathrm{kg}$ [2].

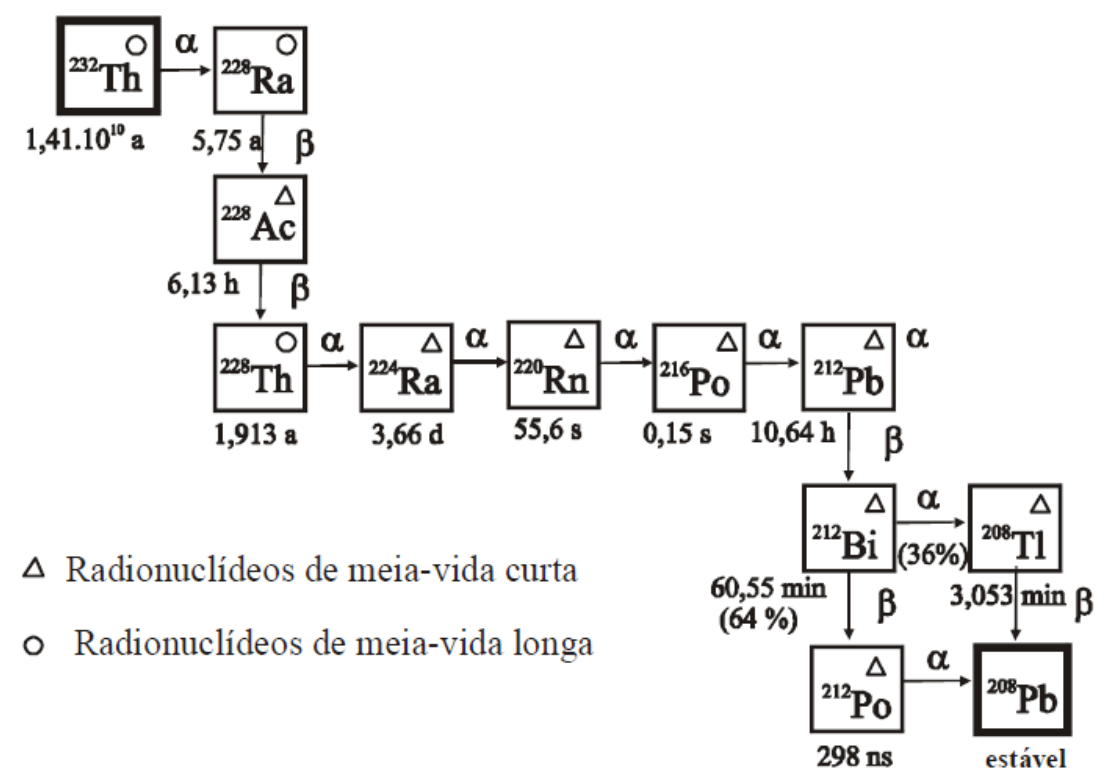

Figura A.2. Série radioativa do ${ }^{232}$ Th, retirado de [62].

${ }^{40} K$

$\mathrm{O}{ }^{40} \mathrm{~K}$ é um radionuclídeo não pertencente a nenhuma das séries de decaimento citadas e está presente no potássio natural, com uma abundância de 0,018\% e meia-vida de $1,277.10^{9}$ anos. Este radionuclídeo decai principalmente por emissão $\beta^{-}$para o ${ }^{40} \mathrm{Ca}(\sim 89 \%)$ e por captura eletrônica para o ${ }^{40} \mathrm{Ar}(\sim 11 \%)$ que se estabilizará liberando um fóton gama de 1,460 MeV, que é detectável (Figura A.3) [21,63]. O ${ }^{40} \mathrm{~K}$ é encontrado na natureza desde solos e rochas, oceanos e em toda matéria viva. Nos seres humanos o potássio é acumulado principalmente nos músculos [22] e por isso sua concentração depende tanto da idade quanto do sexo. 


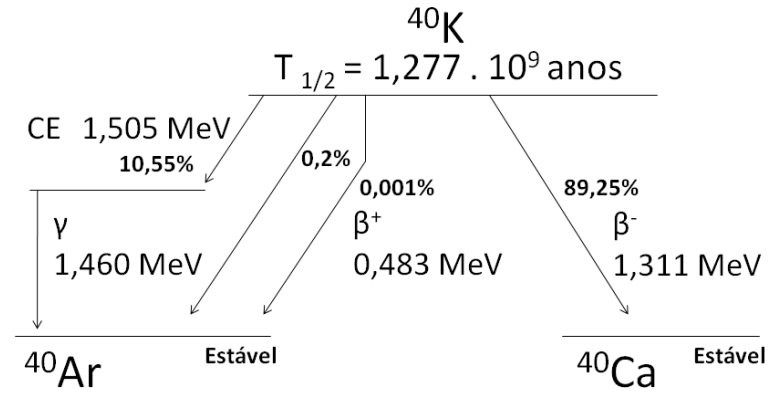

Figura A.3. Esquema de decaimento radioativo do ${ }^{40} \mathrm{~K}$, adaptado de [63].

\section{Radionuclídeo artificiais}

Os radionuclídeos artificias são obtidos pelo bombardeamento de núcleos estáveis por partículas energéticas (nêutrons, prótons, partículas $\alpha$, núcleo de deutério) produzidas em reatores nucleares, síncrotons ou cíclotrons. Desde as primeiras investigações sobre a radioatividade artificial, mais de 3000 radionuclídeos diferentes foram sintetizados [17].

Césio-137

O ${ }^{137}$ Cs é um radionuclídeo produto de fissão nuclear, utilizado principalmente em medidas de calibração de detectores. Este radioisótopo tem meia-vida igual a 30,05 anos, decaindo por emissão $\beta^{-}$para um estado excitado do ${ }^{137} \mathrm{Ba}$, que rapidamente retorna ao estado estável pela emissão de um fóton de $0,662 \mathrm{MeV}$, como mostrado na Figura A.4. Na medicina, o ${ }^{137} \mathrm{Cs}$ foi muito utilizado (em algumas clínicas continua sendo) para produção de feixes de fótons em teleterapia e braquiterapia [17].

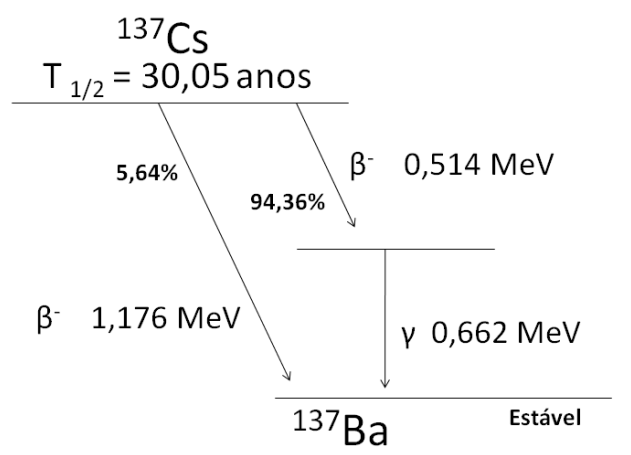

Figura A.4. Esquema de decaimento radioativo do ${ }^{137} \mathrm{Cs}$, adaptado de [63]. 
Tabela A.2. Série de Decaimento Radioativo do ${ }^{238}$ U, adaptado do IAEA, TECDOC 1363 [19].

\begin{tabular}{|c|c|c|c|c|c|}
\hline \multicolumn{2}{|c|}{ Nuclídeo } & \multirow[t]{2}{*}{ Meia-vida } & \multicolumn{3}{|c|}{ Energia e modo de decaimento $(\mathrm{MeV}))$} \\
\hline & & & $\alpha$ & $\beta$ & $\gamma$ \\
\hline \multirow{2}{*}{${ }^{238} U$} & & $4,47 \cdot 10^{9} \mathrm{a}$ & $4,15(23 \%)$ & - & - \\
\hline & & & $4,19(77 \%)$ & & \\
\hline \multirow[t]{2}{*}{${ }^{234} \mathrm{Th}$} & & $24,1 \mathrm{~d}$ & - & $\sim 0,103(19 \%)$ & $0,063(3,5 \%)$ \\
\hline & & & & $0,191(81 \%)$ & $0,093(4 \%)$ \\
\hline \multirow{2}{*}{\multicolumn{2}{|c|}{${ }^{234 m} \mathrm{~Pa}$}} & $1,18 \mathrm{~m}$ & - & $2,29(98 \%)$ & $0,765(0,30 \%)$ \\
\hline & & & & & $1,001(0,60 \%)$ \\
\hline & $(0,14 \%){ }^{234} \mathrm{~Pa}$ & & & & \\
\hline & $(99,86 \%){ }^{234} U$ & & & & \\
\hline \multirow[t]{2}{*}{${ }^{234} U$} & & $2,48 \cdot 10^{5} \mathrm{a}$ & $4,72(28 \%)$ & - & $0,053(0,2 \%)$ \\
\hline & & & $4,77(72 \%)$ & & \\
\hline \multirow[t]{2}{*}{${ }^{230} \mathrm{Th}$} & & $7,52 \cdot 10^{4} \mathrm{a}$ & $4,62(24 \%)$ & - & $0,068(0,6 \%)$ \\
\hline & & & $4,68(76 \%)$ & & $0,142(0,07 \%)$ \\
\hline \multirow[t]{2}{*}{${ }^{226} R a$} & & $1602 \mathrm{a}$ & $4,60(5,5 \%)$ & - & $0,186(4 \%)$ \\
\hline & & & $4,78(94,5 \%)$ & & \\
\hline${ }^{222} R n$ & & $3,825 \mathrm{~d}$ & $5,49(\sim 100 \%)$ & - & $0,510(0,07 \%)$ \\
\hline \multirow[t]{3}{*}{${ }^{218} \mathrm{Po}$} & & $3,05 \mathrm{~m}$ & $6,11(100 \%)$ & $0,33(100 \%)$ & - \\
\hline & $(0,02 \%){ }^{218} A t$ & & & & \\
\hline & $(99,98 \%){ }^{214} \mathrm{~Pb}$ & & & & \\
\hline \multirow[t]{5}{*}{${ }^{214} \mathrm{Bi}$} & & $19,7 \mathrm{~m}$ & $5,61(100 \%)$ & $3,26(100 \%)$ & $0,609(47 \%)$ \\
\hline & & & & & $1,120(17 \%)$ \\
\hline & & & & & $1,765(17 \%)$ \\
\hline & $(0,04 \%){ }^{210} \mathrm{Tl}$ & & & & \\
\hline & $(99,96 \%){ }^{214} \mathrm{Po}$ & & & & \\
\hline \multirow[t]{2}{*}{${ }^{210} \mathrm{~Pb}$} & & $\sim 22 \mathrm{a}$ & $3,7\left(1,8.10^{-8} \%\right)$ & $0,017(85 \%)$ & $0,047(4 \%)$ \\
\hline & & & & $0,064(15 \%)$ & \\
\hline \multirow[t]{4}{*}{${ }^{210} B i$} & & $5,02 \mathrm{~d}$ & $4,93(60 \%)$ & $1,115(100 \%)$ & - \\
\hline & & & & $4,89(34 \%)$ & \\
\hline & $(\sim 0,00001 \%){ }^{206} \mathrm{Tl}$ & & & & \\
\hline & $(\sim 100 \%){ }^{210} \mathrm{Po}$ & & & & \\
\hline${ }^{206} \mathrm{~Pb}$ & & Estável & - & - & - \\
\hline
\end{tabular}


Tabela A.3. Série de Decaimento Radioativo do ${ }^{235}$ U, adaptado do IAEA, TECDOC 1363 [19].

\begin{tabular}{|c|c|c|c|c|c|}
\hline \multirow{2}{*}{\multicolumn{2}{|c|}{ Nuclídeo }} & \multirow[t]{2}{*}{ Meia-vida } & \multicolumn{3}{|c|}{ Energia e modo de decaimento $(\mathrm{MeV}))$} \\
\hline & & & $\alpha$ & $\beta$ & $\gamma$ \\
\hline \multirow[t]{3}{*}{${ }^{235} U$} & & $7,13 \cdot 10^{8} \mathrm{a}$ & $4,36(18 \%)$ & - & $0,143(11 \%)$ \\
\hline & & & $4,39(57 \%)$ & & $0,185(54 \%)$ \\
\hline & & & $4,1(8 \%)$ & & $0,204(5 \%)$ \\
\hline \multirow[t]{2}{*}{${ }^{231} \mathrm{Th}$} & & $25,64 \mathrm{~h}$ & - & $0,3(\sim 100 \%)$ & $0,026(2 \%)$ \\
\hline & & & & & $0,084(10 \%)$ \\
\hline \multirow[t]{3}{*}{${ }^{231} \mathrm{~Pa}$} & & $3,43.10^{4} \mathrm{a}$ & $5,01(<20 \%)$ & - & $0,027(6 \%)$ \\
\hline & & & $4,99(25,4 \%)$ & & $0,29(6 \%)$ \\
\hline & & & $4,94(22,8 \%)$ & & \\
\hline \multirow[t]{5}{*}{${ }^{227} A c$} & & $22 \mathrm{a}$ & $4,95(48,7 \%)$ & $0,046(100 \%)$ & $0,07(0,08 \%)$ \\
\hline & & & $4,94(36,1 \%)$ & & \\
\hline & & & $4,87(6,9 \%)$ & & \\
\hline & $(1,2 \%){ }^{223} \mathrm{Fr}$ & & & & \\
\hline & $(98,86 \%){ }^{227} T h$ & & & & \\
\hline \multirow[t]{3}{*}{${ }^{223} R a$} & & $11,68 \mathrm{~d}$ & $5,61(26 \%)$ & - & $0,149(10 \%)$ \\
\hline & & & $5,71(53,7 \%)$ & - & $0,270(10 \%)$ \\
\hline & & & $5,75(9,1 \%)$ & - & $0,33(6 \%)$ \\
\hline \multirow[t]{3}{*}{${ }^{219} R n$} & & $3,92 \mathrm{~s}$ & $6,42(8 \%)$ & - & $0,272(9 \%)$ \\
\hline & & & $6,55(11 \%)$ & - & $0,401(5 \%)$ \\
\hline & & & $6,82(81 \%)$ & - & \\
\hline${ }^{215} \mathrm{Po}$ & & $1,83 \mathrm{~ms}$ & $7,38(100 \%)$ & - & - \\
\hline \multirow[t]{3}{*}{${ }^{211} \mathrm{~Pb}$} & & $36,1 \mathrm{~m}$ & & $0,95(1,4 \%)$ & $0,405(3,4 \%)$ \\
\hline & & & & $0,53(5,5 \%)$ & $0,427(1,8 \%)$ \\
\hline & & & & $1,36(92,4 \%)$ & $0,832(3,4 \%)$ \\
\hline \multirow[t]{4}{*}{${ }^{211} \mathrm{Bi}$} & & $2,16 \mathrm{~m}$ & $6,28(17 \%)$ & $0,60(0,28 \%)$ & $0,351(14 \%)$ \\
\hline & & & $6,62(83 \%)$ & & \\
\hline & $(98,68 \%){ }^{207} \mathrm{Tl}$ & & & & \\
\hline & $(0,32 \%){ }^{211} \mathrm{Po}$ & & & & \\
\hline${ }^{207} \mathrm{~Pb}$ & & Estável & - & - & - \\
\hline
\end{tabular}


Tabela A.4. Série de Decaimento Radioativo do ${ }^{232}$ Th, adaptado do IAEA, TECDOC 1363 [19].

\begin{tabular}{|c|c|c|c|c|c|}
\hline \multirow{2}{*}{\multicolumn{2}{|c|}{ Nuclídeo }} & \multirow[t]{2}{*}{ Meia-vida } & \multicolumn{3}{|c|}{ Energia e modo de decaimento $(\mathrm{MeV}))$} \\
\hline & & & $\alpha$ & $\beta$ & $\gamma$ \\
\hline \multirow{2}{*}{\multicolumn{2}{|c|}{${ }^{232} \mathrm{Th}$}} & $1,39 \cdot 10^{10} \mathrm{a}$ & $3,95(24 \%)$ & - & - \\
\hline & & & $4,01(76 \%)$ & - & - \\
\hline${ }^{228} R a$ & & $5,75 \mathrm{a}$ & - & $0,055(100 \%)$ & - \\
\hline \multirow{3}{*}{\multicolumn{2}{|c|}{${ }^{228} A c$}} & $6,13 \mathrm{~h}$ & - & $2,11(100 \%)$ & $0,34(15 \%)$ \\
\hline & & & & & $0,908(25 \%)$ \\
\hline & & & & & $0,96(20 \%)$ \\
\hline \multirow{2}{*}{\multicolumn{2}{|c|}{${ }^{228} \mathrm{Th}$}} & 1,913 a & $5,34(28 \%)$ & - & $0,084(1,6 \%)$ \\
\hline & & & $5,42(71 \%)$ & & $0,214(0,3 \%)$ \\
\hline \multirow{2}{*}{\multicolumn{2}{|c|}{${ }^{224} R a$}} & $3,64 \mathrm{~d}$ & $5,45(5,5 \%)$ & - & $0,241(3,7 \%)$ \\
\hline & & & $5,68(94,5 \%)$ & & \\
\hline${ }^{220} R n$ & & $55,6 \mathrm{~s}$ & $6,30(\sim 100 \%)$ & - & $0,55(0,07 \%)$ \\
\hline${ }^{216} P_{O}$ & & $0,145 \mathrm{~s}$ & $6,78(100 \%)$ & - & - \\
\hline \multirow{2}{*}{\multicolumn{2}{|c|}{${ }^{212} \mathrm{~Pb}$}} & $19,64 \mathrm{~h}$ & - & 0,580 & $0,239(47 \%)$ \\
\hline & & & & & $0,3(3,2 \%$ \\
\hline \multirow[t]{8}{*}{${ }^{212} B i$} & & $60,5 \mathrm{~m}$ & $6,05(70 \%)$ & $2,25(100 \%)$ & $0,040(2 \%)$ \\
\hline & & & $6,09(30 \%)$ & & $0,727(7 \%)$ \\
\hline & & & & & $1,620(1,8 \%)$ \\
\hline & $(64 \%){ }^{212} \mathrm{Po}$ & & & & \\
\hline & $(36 \%){ }^{208} \mathrm{Tl}$ & $3,1 \mathrm{~m}$ & - & $1,8(100 \%)$ & $0,511(23 \%)$ \\
\hline & & & & & $0,583(86 \%)$ \\
\hline & & & & & $0,860(12 \%)$ \\
\hline & & & & & $2,614(100 \%)$ \\
\hline${ }^{208} \mathrm{~Pb}$ & & Estável & - & - & - \\
\hline
\end{tabular}




\section{ANEXOS}

\section{A.1 Fatores de Ponderação: Fator peso da radiação ionizante $w_{R}$ e fator peso do tecido irradiado $\boldsymbol{w}_{T}$}

Alguns dos fatores de ponderação para obtenção de $H_{T}$ e $E$ que foram mencionados no Capítulo 2, são apresentados a seguir, como descritos pela ICRP 60 [12] e a Norma 3.01/002 da CNEN [27].

Tabela A.5. Fator peso da radiação ionizante $w_{R}[11]$.

\begin{tabular}{lcc}
\hline \hline Tipo de radiação & Energia & $\mathrm{w}_{R}$ \\
\hline Fótons & todas & 1 \\
Elétrons e múons & todas & 1 \\
Nêutrons & $<10 \mathrm{keV}$ & 5 \\
& $10 \mathrm{keV}$ a $100 \mathrm{keV}$ & 10 \\
& $>100 \mathrm{keV}$ a $2 \mathrm{MeV}$ & 20 \\
& $>2 \mathrm{MeV}$ a $20 \mathrm{MeV}$ & 10 \\
& $>20 \mathrm{MeV}$ & 5 \\
Prótons (exceto os de recuo) & $>2 \mathrm{MeV}$ & 5 \\
Partículas $\alpha$, fragmentos & & 20 \\
de fissão e núcleos pesados & & \\
\hline \hline
\end{tabular}

Os valores apresentados na Tabela A.5 estão relacionados à radiação de fontes internas e também internas.

Para os valores de fator peso do tecido (alguns tecidos), tem-se a Tabela A.6 a seguir. 
Tabela A.6. Fator peso do tecido irradiado $w_{T}[11]$.

\begin{tabular}{lc}
\hline \hline Tecido ou Órgão & $\mathrm{w}_{T}$ \\
\hline Gônadas & 0,20 \\
Medula óssea (vermelha) & 0,12 \\
Cólon & 0,12 \\
Pulmão & 0,12 \\
Estômago & 0,12 \\
Bexiga & 0,05 \\
Mama & 0,05 \\
Fígado & 0,05 \\
Esôfago & 0,05 \\
Tireóide & 0,05 \\
Pele & 0,01 \\
Superfície óssea & 0,01 \\
\hline \hline
\end{tabular}

\section{A.2 Espectros das Fontes Extensas Padrão}

Os espectros de cada fonte extensa padrão (K1, K2, U1, U2, Th1, UTh1 e UTh2) apresentadas a seguir, foram retirados do trabalho de Conti et al [28], que os obteve através de um espectrômetro HPGe a uma distância de 1 metro da superfície de cada fonte. Esta geometria de medidas foi a mesma utilizada para o sistema FHT 1376, e a comparação dos resultados foi apresentada no Capítulo 4. A identificação de alguns picos nos espectros das fontes extensas foi feita neste trabalho, baseado nas emissões das fontes considerando o decaimento dos radionuclídeos das séries utilizadas. 


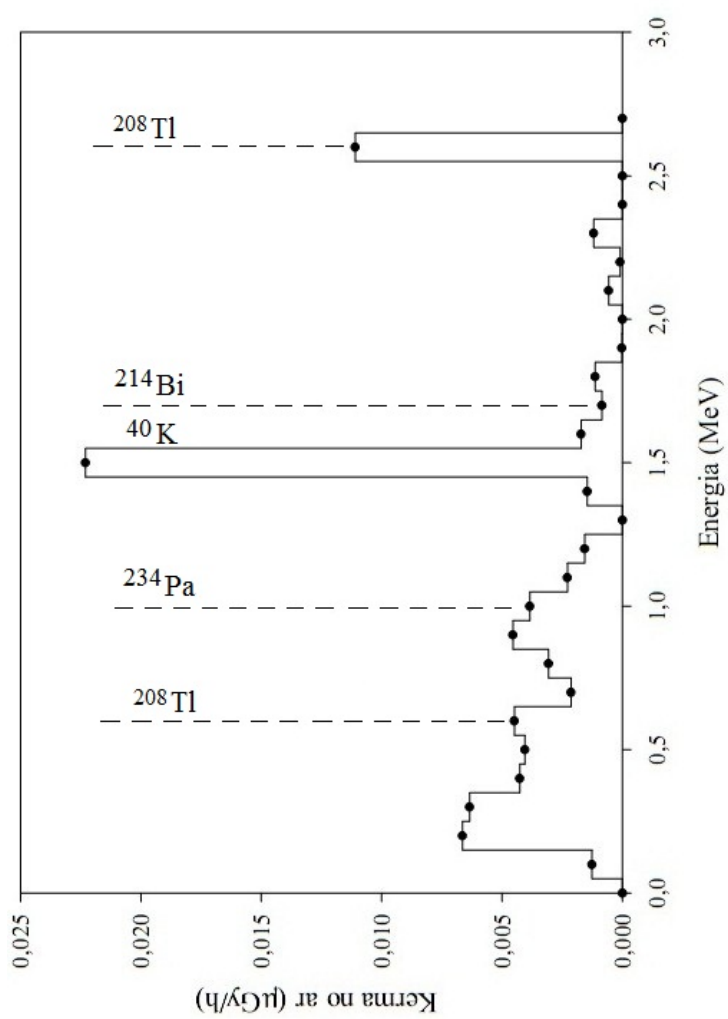

(a) $\mathrm{K} 1$

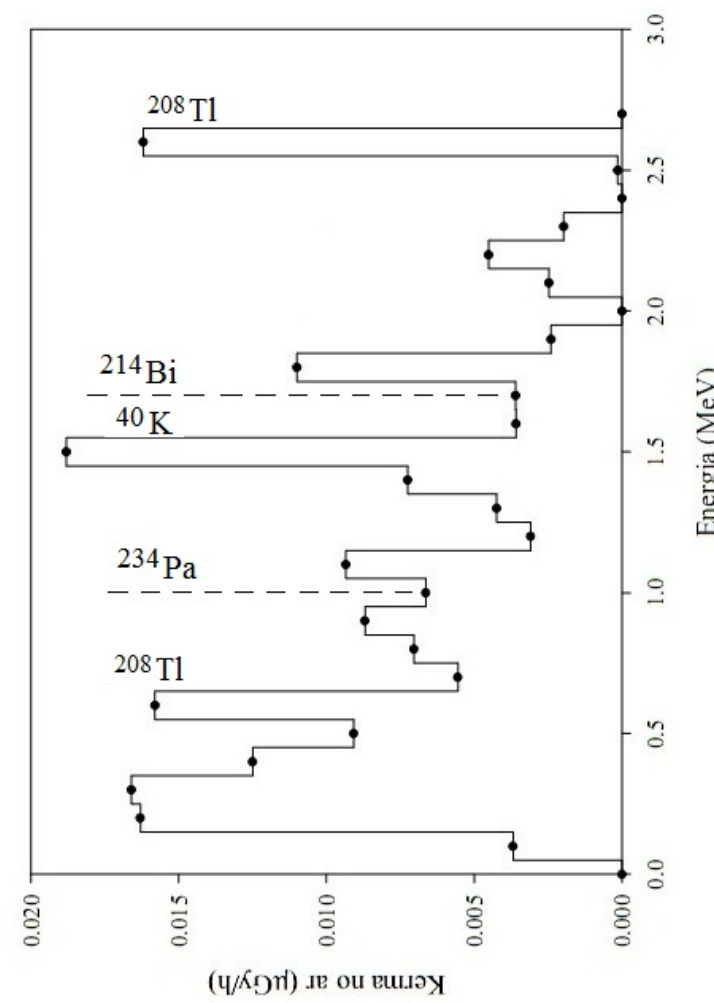

(c) U1

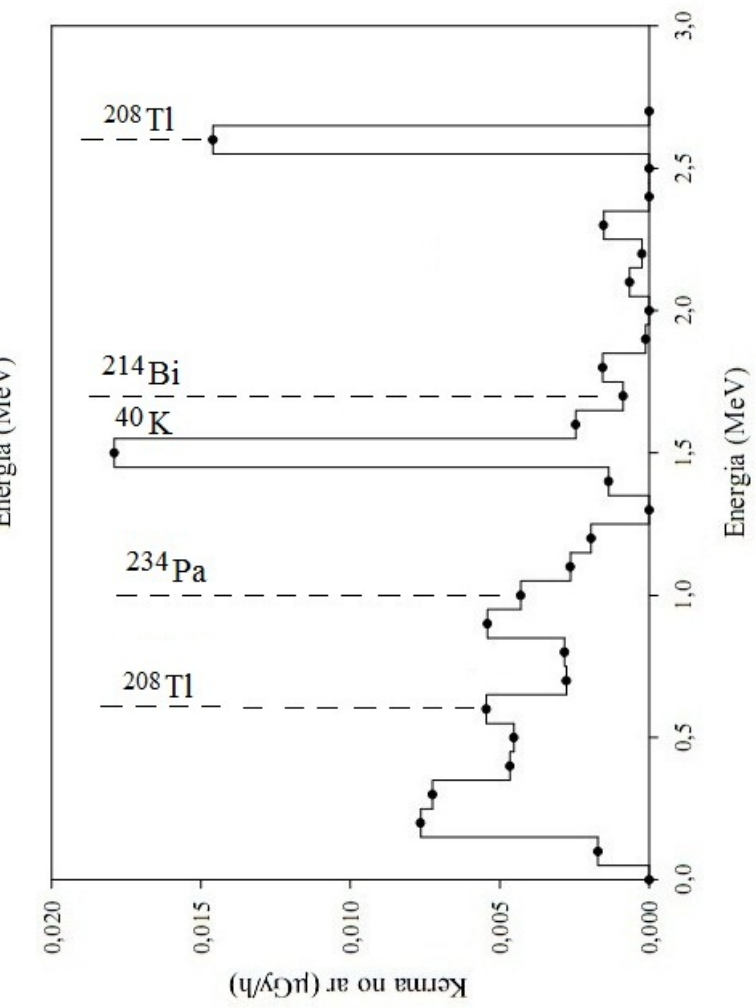

(b) $\mathrm{K} 2$

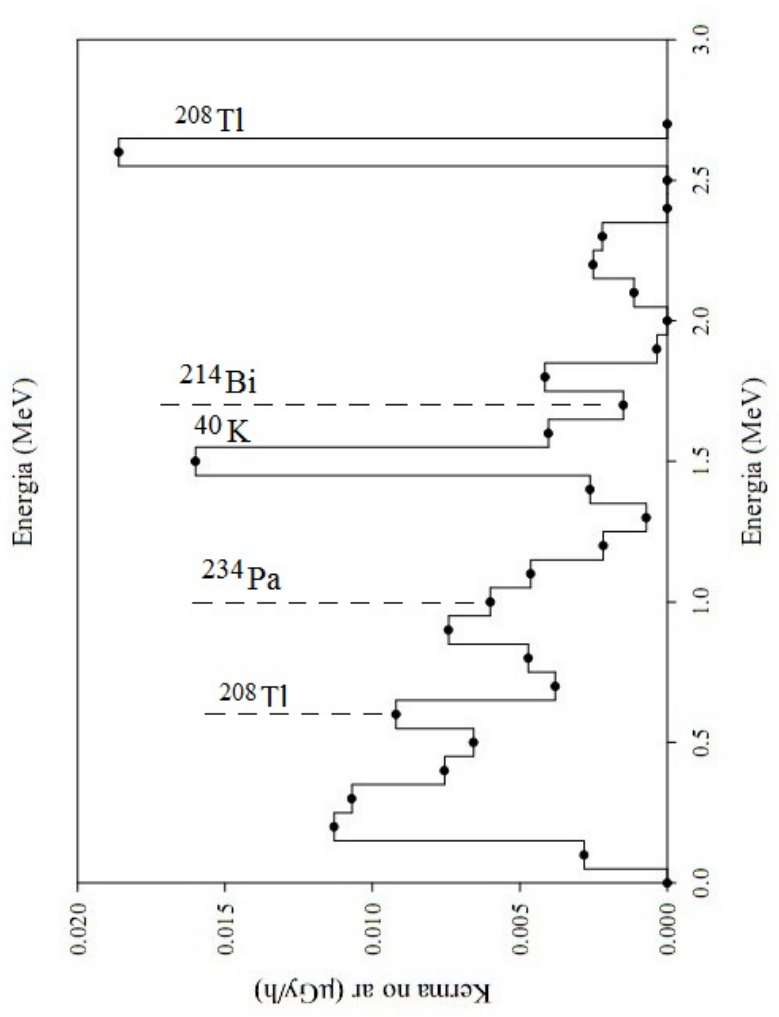

(d) $\mathrm{U} 2$

Figura A.5. Espectros das fontes extensas padrão, K1, K2, U1 e U2, obtidos por Conti et al com um detector de HPGe a 1 metro da superfície de cada fonte. A identificação dos picos foi feita neste trabalho, baseado nas emissões das fontes considerando o decaimento dos radionuclídeos das séries utilizadas. 


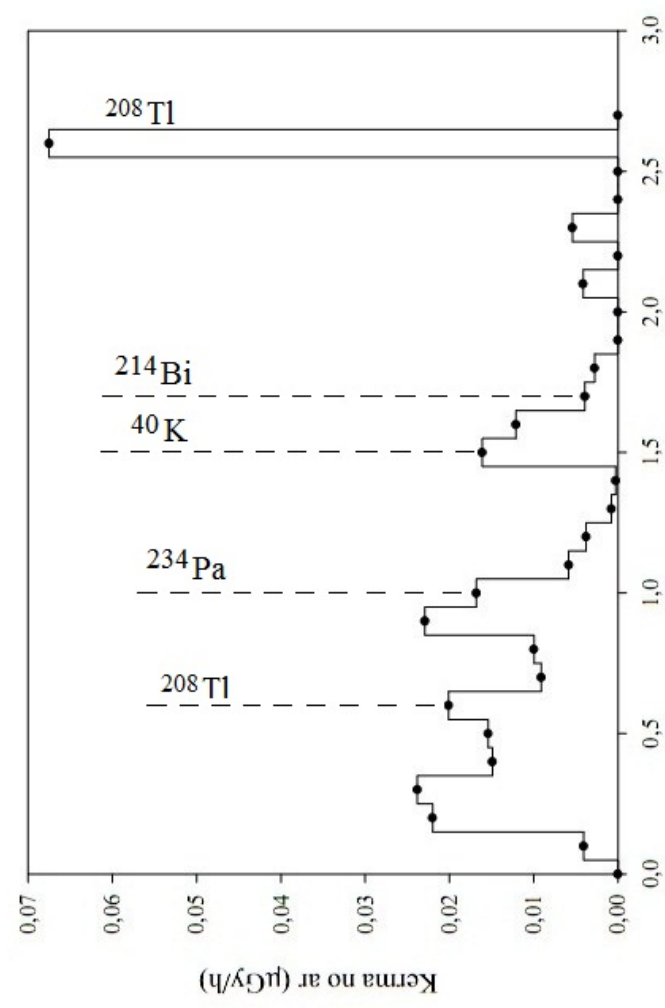

(a) Th1

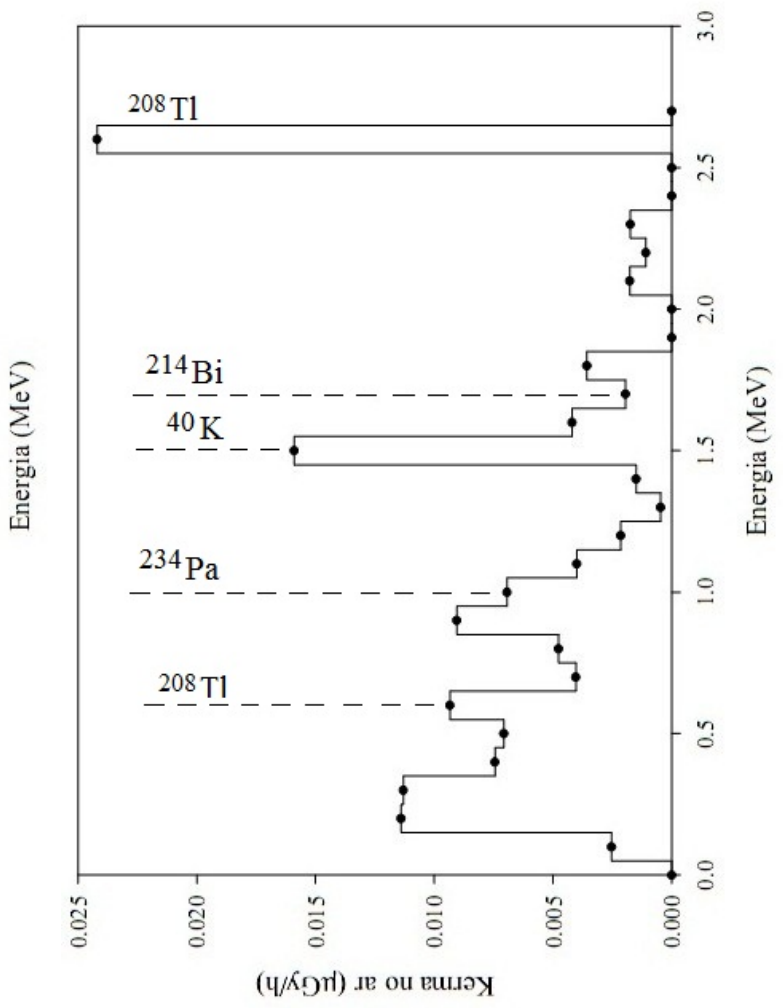

(b) UTh1

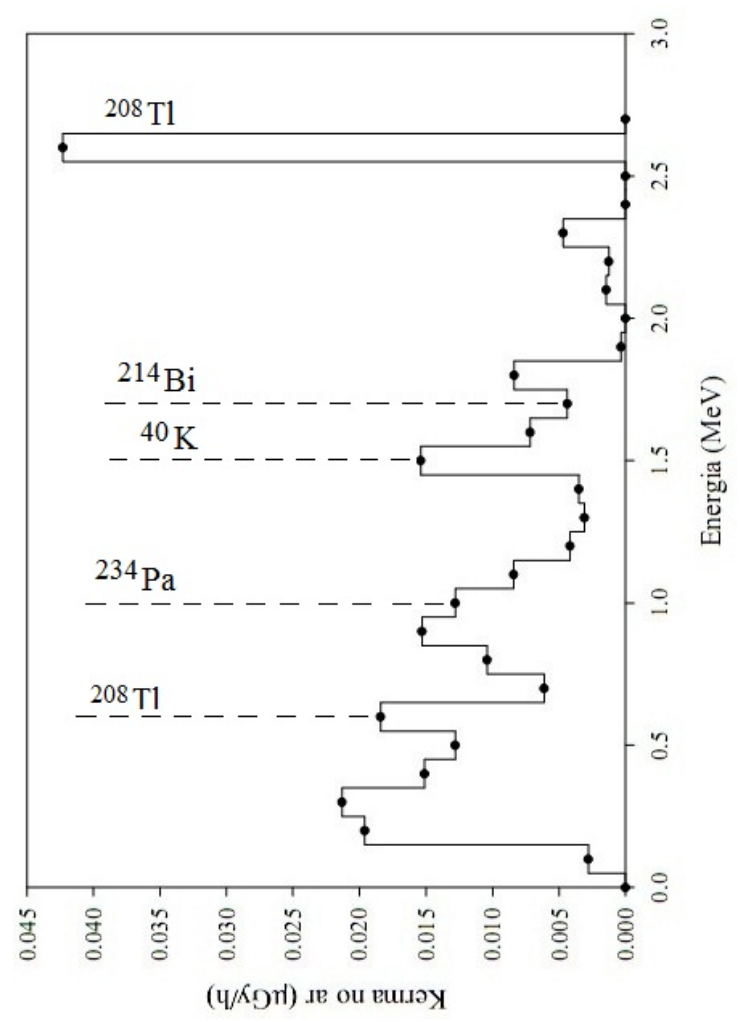

(c) UTh2

Figura A.6. Espectros das fontes extensas padrão, Th1, UTh1 e UTh2, obtidos por Conti et al com um detector de HPGe a 1 metro da superfície de cada fonte.A identificação dos picos foi feita neste trabalho, baseado nas emissões das fontes considerando o decaimento dos radionuclídeos das séries utilizadas. 